\title{
PARKING POLICY ACCEPTABILITY IN WELLINGTON CBD
}

\section{Kate Coles}

Environmental Studies 593

A 90 point thesis submitted to Victoria University of Wellington in partial fulfilment of requirements for the degree of Master of Environmental Studies

School of Geography, Environment and Earth Sciences

Victoria University of Wellington

March, 2015 



\begin{abstract}
The car has become the dominant mode of transportation in many cities, giving drivers the sense of freedom and convenience to travel at any time between specific locations. However, this increase in car use has created numerous negative outcomes for society including pollution and congestion. Changing individual travel behaviour away from car use is a challenge that many cities now face in an effort to combat car induced issues. Transport pricing policies are often viewed as an effective method in decreasing levels of car use. However, these policies are often not implemented due to a lack of public support. This research uses a quantitative approach to explore potential factors that may be influencing parking policy acceptability among levels of residents in the Greater Wellington Region. Using an online survey, findings indicate that parking policy acceptability levels to the public are influenced by policy differences in fee level and revenue allocation, as well as individuals' level of personal environmental understanding and concern. The GreedEfficiency-Fairness (GEF) hypothesis is presented as a theory to explain the changes seen in acceptability levels between different policies and personal characteristics of individuals. It is concluded that, for the study sample, parking policy acceptability levels would most increase when revenue was allocated to improving the quality of active transportation and public transportation. Acceptability levels would further be enhanced by highlighting the beneficial outcomes that the policy would have at both an individual and societal level.
\end{abstract}

Key words: acceptability, parking policy, on-street parking, Greed-EfficiencyFairness Hypothesis. 


\section{Acknowledgements}

Many people have assisted me by providing guidance, participating in and supporting me throughout this thesis, all of whom I am incredibly grateful to.

Firstly, I would like to thank my fantastic supervisor Wokje Abrahamse for her valuable advice, vigilant editing and feedback and time spent guiding me through this research.

I would like to acknowledge and thank the Victoria University Scholarship Committee for awarding me the Tu Horomata Scholarship.

To Susan Hutchinson-Daniel and the rest of the Sustainable Transport Team at the Greater Wellington Regional Council thank you for a fantastic placement during this research. You all gave me inspiration, encouragement and a renewed enthusiasm for this topic.

To my office mates at Waiteata Road, thank you for the many coffee breaks, imposed silent times and helpful discussions.

A huge amount of gratitude needs to go to my friends and family for their unconditional support and unwavering encouragement. In particular, Mum for your constant support in every way possible, my sister Alex for your careful proofreading and numerous research discussions, and my partner Matthew for keeping life balanced.

And finally, I would like to acknowledge all the people who took the time to participate in my research survey and especially those who passed it on. I appreciate the time you took to give your opinions and the essential contribution it had for this work. 


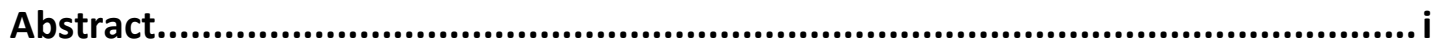

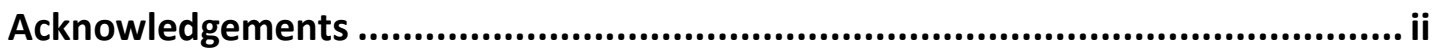

Table of Contents ..................................................................................... ii

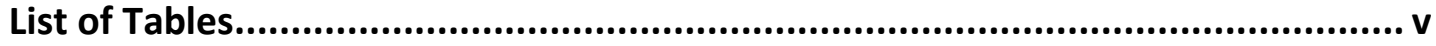

List of Figures .................................................................................................... vi

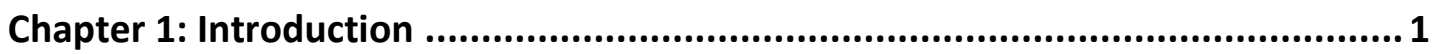

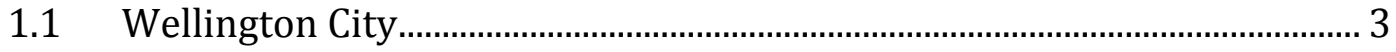

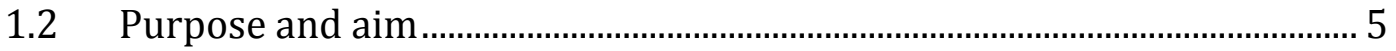

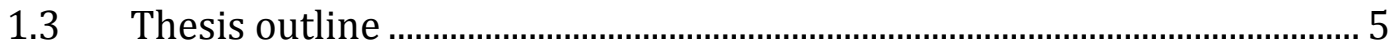

Chapter 2: Literature Review ................................................................ 7

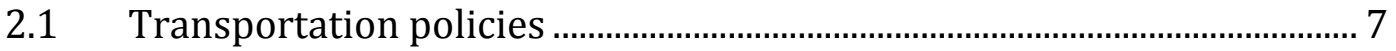

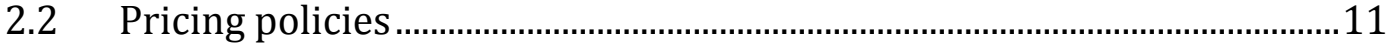

2.3 Examples of transport pricing policies ............................................................12

2.3.1 London congestion charge ......................................................................12

2.3.2 Stockholm congestion charge ...................................................................

2.3.3 Singapore area license scheme …….........................................................13

2.3.4 Norway (Trondheim, Bergen, Oslo) toll rings ........................................13

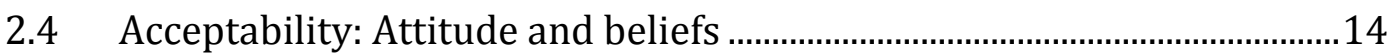

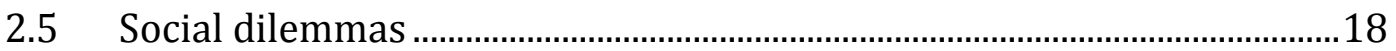

2.6 Motives in social dilemmas: Greed-Efficiency-Fairness (GEF)

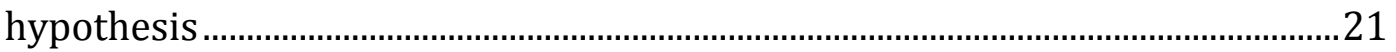

2.6.1 Greed and individual policy outcomes..................................................22

2.6.2 Efficiency and collective policy outcomes ..............................................23

2.6.3 Fair distribution of policy outcomes ............................................................24

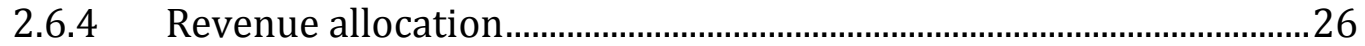

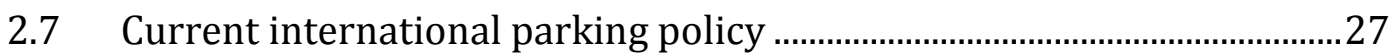

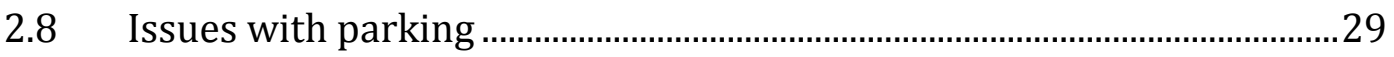

2.9 Parking policy in New Zealand ……............................................................

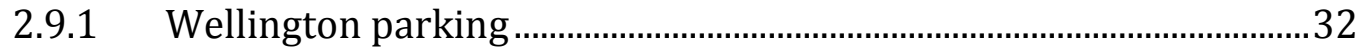

2.9.2 WCC transport strategy and parking policy..........................................33

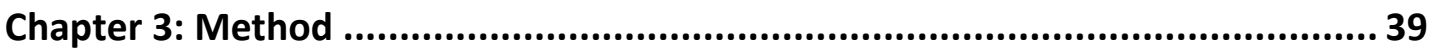




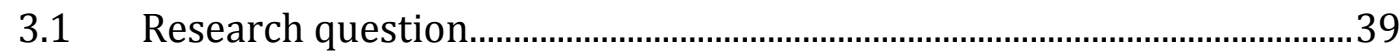

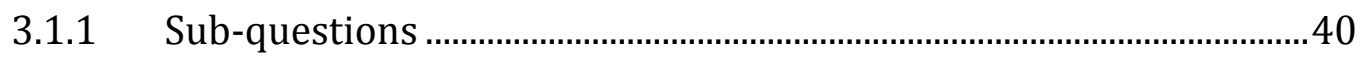

3.2 Rationale

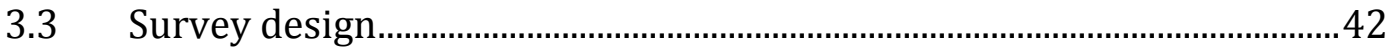

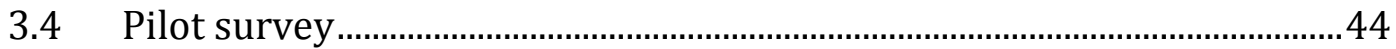

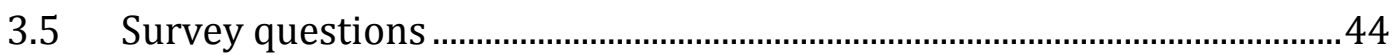

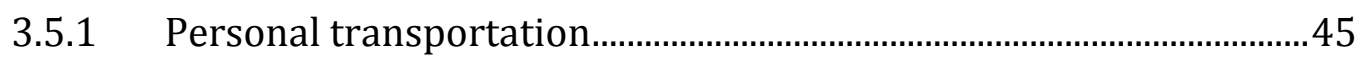

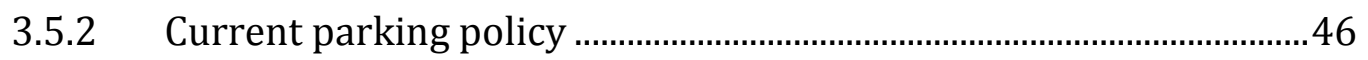

3.5.3 Opinion about parking policies ...................................................................46

3.5.4 Revenue use in pricing policies................................................................ 48

3.5.5 Environmental awareness and concern .............................................49

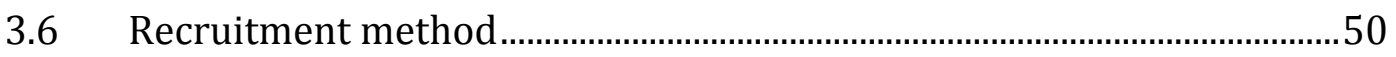

$3.7 \quad$ Responses and sample characteristics ….........................................................50

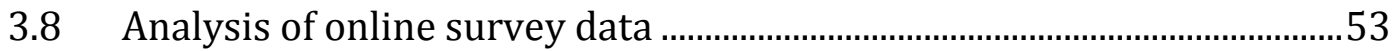

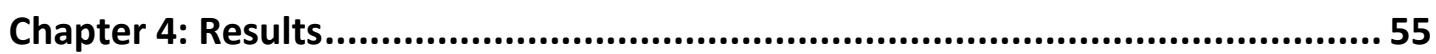

4.1 Current parking mechanisms and policy in the CBD .................................55

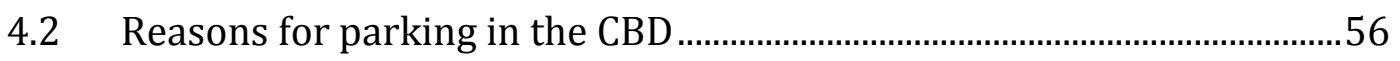

4.3 Correlational analyses of acceptability and other variables ....................57

4.3.1 Acceptability and perceived effects........................................................58

4.3.2 Acceptability and policy measures ........................................................59

4.3.3 Acceptability and environmental concern............................................59

4.4 Acceptability levels to the public of a range of parking policies...............60

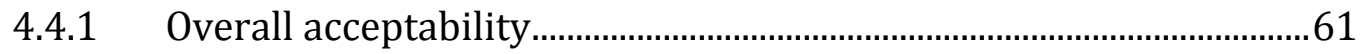

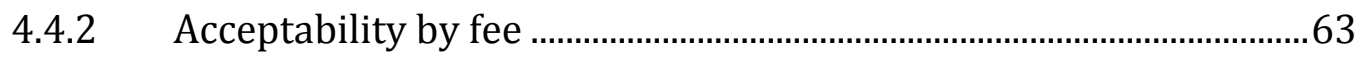

4.4.3 Acceptability by revenue use .............................................................64

4.5 Perceived perception of parking policies to the public in terms of

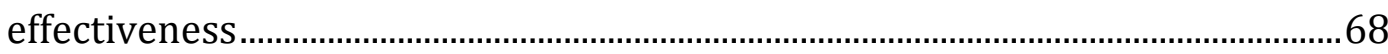

4.5.1 Overall perceived effectiveness ...........................................................68

4.5.2 Perceived effectiveness by policy ………..............................................68

4.5.3 Perceived effectiveness by fee..............................................................69

4.5.4 Perceived effectiveness by revenue use ...............................................70

4.6 Perceived consequences of the public to a range of parking policies....71

4.6.1 Overall perceived consequences .......................................................... 71 
4.6.2 Perceived consequences by fee............................................................... 73

4.6.3 Perceived consequences by revenue use ...............................................74

4.7 Environmental concern and acceptability levels of parking policies ....76

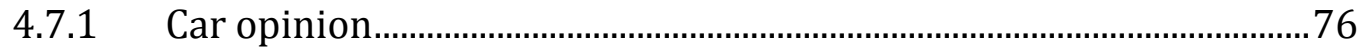

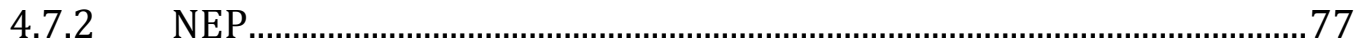

4.7.3 Environmental consequences of car use ..............................................77

4.7.4 Overall environmental awareness ..........................................................78

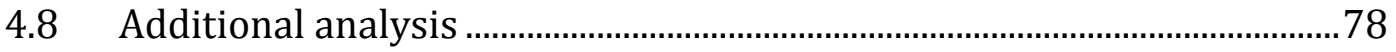

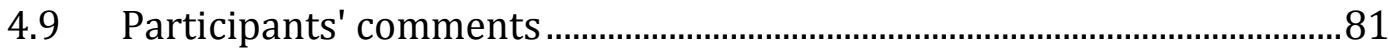

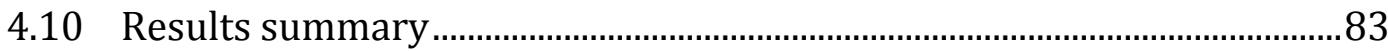

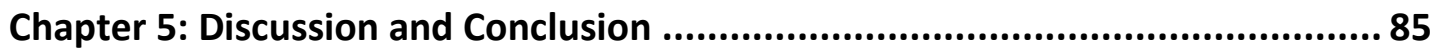

$5.1 \quad$ Car parking behavior and context ………............................................................ 85

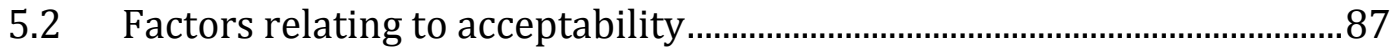

5.2.1 Policy acceptability and greed................................................................ 87

5.2.2 Policy effectiveness and efficiency …….................................................91

5.2.3 Policy outcomes and fairness .....................................................................

5.2.4 GEF hypothesis and parking policies........................................................95

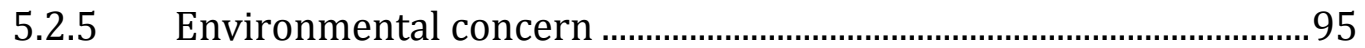

5.3 Current Wellington CBD car parking policy …..............................................97

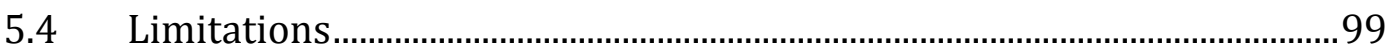

$5.5 \quad$ Recommendations and conclusion................................................................ 100

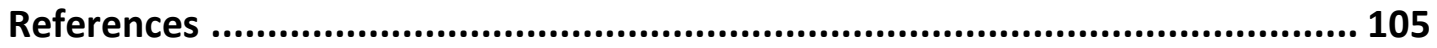

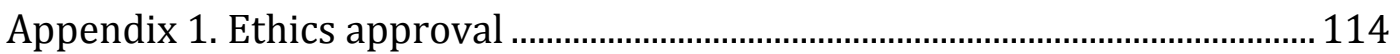

Appendix A3. Consent to participate in research ................................................... 116

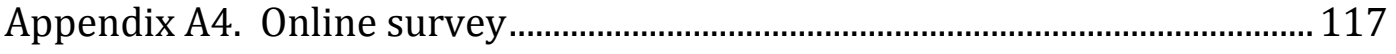

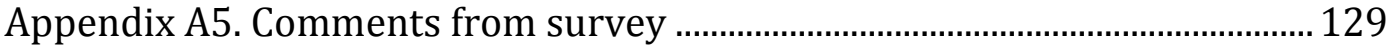

\section{List of Tables}

Table 3.13 by 3 between-subject policy design.

Table 3. 2 Comparison of age groups between survey respondents and the 2013 Census data for the Wellington Region.

Table 3. 3 Comparison of ethnicity between survey respondents and the 2013 Census data for the Wellington Region. 
Table 3. 4 Comparison of employment and income between survey respondents and the 2013 Census data for the Wellington Region...........................................53

Table 4. 1 Correlational statistics between eight variables. .....................................58

Table 4. 2 Policy description of fee and revenue use. ............................................60

Table 4. 3 Mean acceptability of policy by policy number. .......................................61

Table 4. 4 Mean acceptability of policy by fee. .....................................................63

Table 4. 5 Mean acceptability of policy by revenue use.........................................64

Table 4. 6 Mean perceived effectiveness of policy by policy number.......................68

Table 4. 7 Mean perceived effectiveness of policy by fee.......................................69

Table 4. 8 Mean perceived effectiveness of policy by revenue use. .........................70

Table 4. 9 Mean perceived consequences of policy by policy number.....................72

Table 4. 10 Mean perceived consequences of policy by fee. ...................................73

Table 4. 11 Mean perceived consequences of policy by revenue use. ......................75

Table 4. 12 Descriptive statistics of environmental variables. ...................................76

Table 4. 13 Correlation statistics between five variables......................................79

\section{List of Figures}

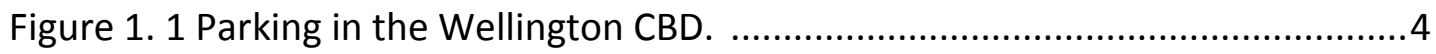

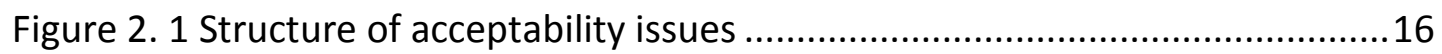

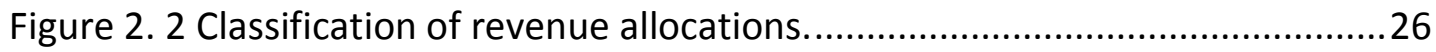

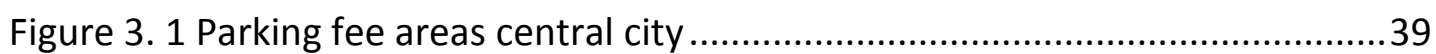

Figure 4. 1 Mean acceptability of policy by policy number. ...................................62

Figure 4. 2 Mean acceptability of policy by fee .....................................................64

Figure 4. 3 Mean acceptability of policy by revenue use ......................................65

Figure 4. 4 Mean acceptability of general pricing policies by revenue use...............67

Figure 4. 5 Mean perceived effectiveness of policy by policy number. ....................69

Figure 4. 6 Mean perceived effectiveness of policy by fee......................................70

Figure 4. 7 Mean perceived effectiveness of policy by revenue use .........................71

Figure 4. 8 Mean perceived consequences of policy by policy number....................73

Figure 4. 9 Mean perceived consequences of policy by fee. ....................................74

Figure 4. 10 Mean perceived consequences of policy by revenue use. ....................75 


\section{Chapter 1: Introduction}

Humans across the globe are becoming more reliant on cars as they become increasingly affordable (Chapman, 2007). Car ownership holds the promise to free people from the constraints of time and space, giving people flexibility to travel wherever they want and whenever they want (Hagman, 2006). However, the individual advantages of car use are now overshadowed by the problems of rising greenhouse gas (GHG) emissions, air and noise pollution, urban sprawl (Chapman, 2007), traffic congestion, energy consumption, low-density urban form (Willson, 1995), and increased accident risk (Litman, 2009). These environmental and societal costs of private car use in urban areas need to be addressed.

Globally across many urban areas, the last four decades of transport policy have encouraged car-oriented development and supported suburban growth (Ewing, Bartholomew, Winkelman, Walters, \& Chen, 2007; Willson, 1995). This has seen the subsequent expansion of roading infrastructure, parking capacity, and traffic services (Litman, 2009). Consequently, people in many cities are reliant on cars as their main mode of transportation. This creates a large quantity of road transport that generates a number of negetive consequences, in the forms of intrasectoral costs that road users impose on each other such as congestion, and the environmental costs that are inflicted on society and the enironment (Verhoef, Nijkamp, \& Rietveld, 1997). Externalities are the costs or benefits felt by a third party who did not choose to incur these from another party and so no monetary payments are exchanged (Pearce, 2002). Negative externalities are the costs that the third party has inflicted on somebody or something with no form of compensation and can be observed in a car use context. Societal and environmental costs such as air and noise polluton are often transferred to the rest of society from road users. However the price of these costs inflicted on others is not reflected in the costs of running a car, 
such as fuel. These environmental and societal costs can therefore be viewed as negative externalities.

An important GHG in terms of quantity produced by humans is carbon dioxide $\left(\mathrm{CO}_{2}\right)$. This $\mathrm{GHG}$ is formed in many human driven processes and becomes a negative externality on the wider society. The total $\mathrm{CO}_{2}$ emissions from operating an average car are calculated to be attributed at 76 percent from fuel usage, 9 percent from manufacturing and 15 percent from the fuel supply system (Potter, 2003). The amount a car is driven thus impacts to a large degree how much $\mathrm{CO}_{2}$ is released. One way to decrease the percentage of GHGs attributed to transport is by introducing transportation policies aimed at reducing car use. One study in Perth found that an estimated 40 percent of current car journeys had viable mode alternatives such as public transport. With modest infrastructure improvements, the study found that a further 40 percent of car trips could be reduced (Brog \& John, 2001). However, making this shift away from car use to other modes of transportation is a challenge as public acceptability levels for policies that reduce car use are often low (Schuitema, 2010).

The issue in reducing car use can be recognised as a social dilemma that is caused when doing what produces the most favourable outcome for society in the long-term, does not align with what is best for an individual in the short-term (Dawes, 1980). In the context of transportation, it would be best for society if people used active and public forms of transport to diminish the negative externalities caused by car use. However, this can be in conflict with the positive benefits individual car users get from driving which are further enhanced when areas have transport infrastructure built around car use. Accordingly, policies that aim to reduce car use are seen to be creating negative outcomes for individuals so overall there will be low levels of public support and low acceptability for the policy to be implemented. 
Low acceptability levels have hindered implementation of new transport policies in many car dependent countries. In the Netherlands, the Minister of Transport openly acknowledged the importance of high levels of public support before new transport policies could be introduced (Schuitema, 2010). Therefore, understanding what factors influence transport policies' acceptability to the public is vital in creating support for new policies aimed at decreasing car use.

\subsection{Wellington City}

Wellington is the capital city of New Zealand with a population of 491,500 residents in the Greater Wellington Region (Statistics New Zealand, 2014b). The CBD (central business district) of Wellington is the main destination for transport journeys in the region for purposes of business, study, shopping and recreation. A range of travel modes including active transportation, public transportation and private vehicle use are seen as valid options to individuals and used when they travel to and from the CBD. People will make choices regarding their travel journeys based on the individual costs and benefits they perceive each mode to have. 


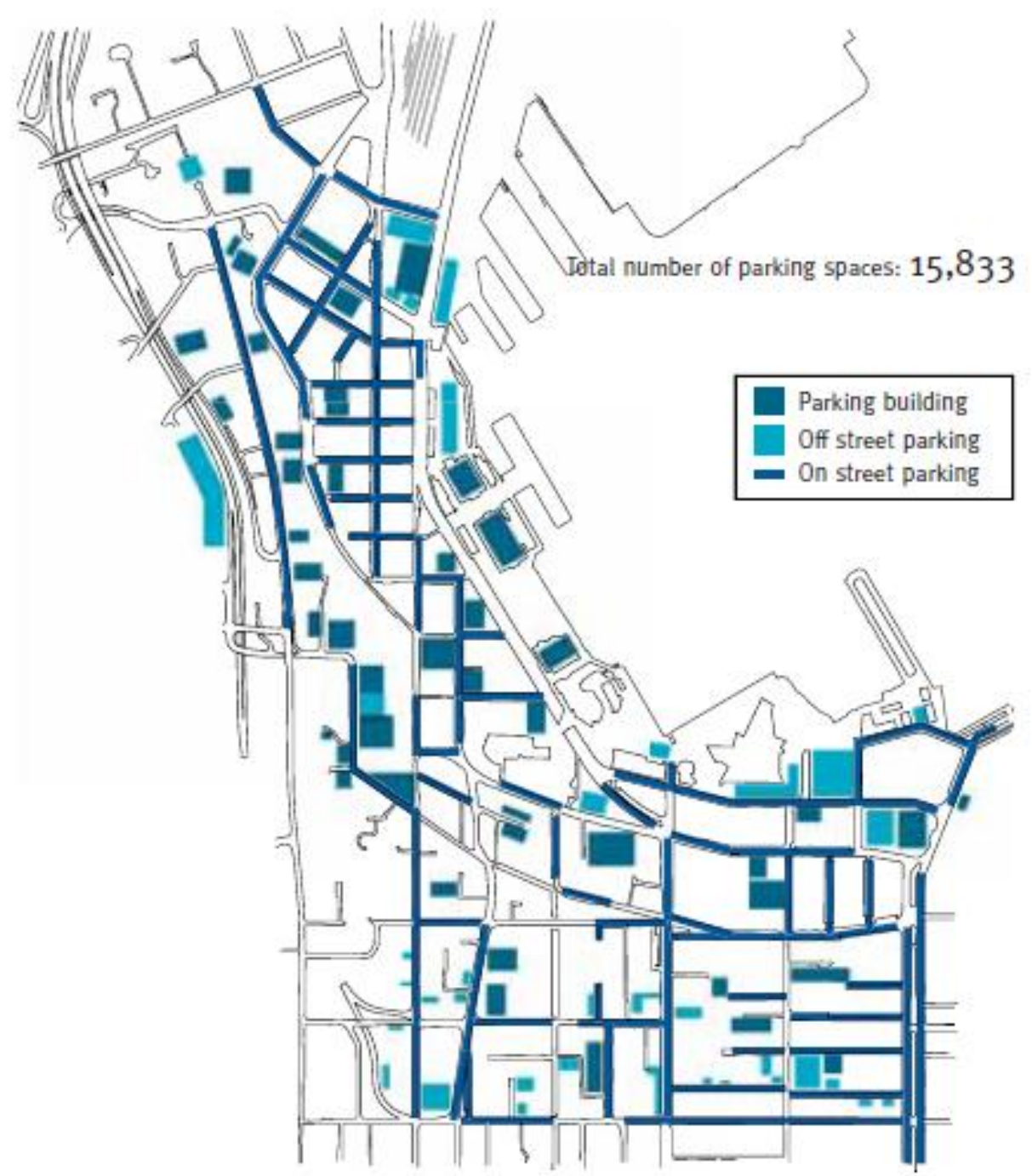

Figure 1. 1 Parking in the Wellington CBD. Source of image: Gehl (2004, p. 12).

The Wellington CBD has an infrastructure that currently promotes car use. Wellington has around 15,833 parking spaces within the CBD (Gehl, 2004). These are made up of parking spaces located off-road, on-road and in specific parking buildings as can be seen in Figure 1.1. This makes the Wellington CBD very parking dominated that can be seen in context when compared to other cities. Copenhagen, Stockholm and Oslo have larger populations than Wellington with around 570,000, 789,000 and 593,000 residents each respectively. However, they all have a less car-dominated transport culture that is highlighted by the $3,100,8,000$ and 4,800 parking spaces respectively that each has within its CBD. This shows how even with larger populations, each of these cities' CBDs functions with significantly 
fewer parking spaces than Wellington. Other car-dominated cities do have larger numbers of parking spaces such as Adelaide with 35,000 (Gehl, 2004). A report by Gehl (2004) for the Wellington City Council (WCC) noted that the high amount of parking available, together with the unlimited levels of vehicle traffic allowed into the $C B D$ has resulted in the deterioration in the quality of both the street and pedestrian landscape. The result has been street layouts that tend to resemble urban motorways and do not allow straightforward access for active and public transportation (Gehl, 2004).

Hence possible changes could be made to Wellington CBD parking policies to reduce car traffic in and around the city. This would allow alleviation of many of the negative externalities that car use creates and could improve the CBD's overall physical environment. Nevertheless with the current highly car-dependent nature of the city, public acceptability levels to support such policy change are likely to be low.

\subsection{Purpose and aim}

The purpose of this research is to explore what factors influence public acceptability levels of parking policies within the Greater Wellington Region. The research aims to find ways that could increase levels of public acceptance of parking polices that are aimed at decreasing car use into and around the CBD.

\subsection{Thesis outline}

Chapter 1 , the introduction outlined the issues surrounding acceptability levels in parking policy. Next, chapter 2, the literature review, explores the existing research of transport pricing policies. This literature review will then focus on research around acceptability and specifically focus on the Greed-Efficiency-Fairness (GEF) hypothesis as a theory that could be used to explain policy acceptability levels. WCC documents are also examined to see if the current transport policies are in line with each other and future 
plans of the WCC in this area. In particular, the current Wellington City parking policy is assessed to give context to the current Wellington situation.

Chapter 3, the method, explains the quantitative method used. Details in this chapter explain how data was gathered using an online survey.

Chapter 4 , the results, reports on the findings from the online survey on public acceptability of parking policies. Lastly chapter 5 , the discussion and conclusion, discusses the results found in relation to findings from other studies in the literature review. Conclusions and recommendations for the WCC are then given as to how parking policy can be made more acceptable among car users in Wellington CBD. 


\section{Chapter 2: Literature Review}

\subsection{Transportation policies}

Transportation policies affect many aspects of life (Litman, 2009). Travel policies facilitate practices that can impact on the environment, in terms of land use and air pollution that can contribute to climate change; economic development in terms of gross domestic product (GDP); and social equity, in terms of how the physical environment impacts health (for example air quality) and accessibility of a community, region or nation, influencing the quality of life of people in that area (Berrittella, Certa, Enea, \& Zito, 2007). Studies of public acceptability of transport policies are important in order to examine which factors are related to overall levels of acceptability. Understanding these factors would assist in gaining public support for the implementation of policies that have positive outcomes for society.

Minimum-parking requirements were the main form of parking policy in urban areas from the 1950s and were particularly popular in New Zealand, Australia and the United States (Ferguson, 2004). This policy allowed local governments to dictate a minimum number of parking spaces that each specific development must supply. Creating numerous parking spaces intended to keep parked vehicles off the road in a bid to increase roading efficiency (Still \& Simmonds, 2000). However, if parking supply exceeds demand it can create additional negative externalities (Willson, 1995). A subsidy is implicitly given to car parking when inefficient minimum standards generate very cheap or free parking from an oversupply of parking spaces. Abundant parks are not viewed as a limited resource and thus people are not willing to pay a high fee to occupy the space, at the same time not valuing the opportunity cost of the land used for parking Low cost parking is a positive for an individual but externalities that driving produces cannot be encompassed and paid for at this low price. The externalities of traffic congestion and air and noise pollution support the spread of urban sprawl and low-density low-value developments. This in 
turn exacerbates the development of a car-oriented city, encouraging further driving and creates more negative externalities (Millard-Ball, 2002; Shoup, 2005; Willson, 1995).

To limit these externalities, policies aim to suppress car demand by reducing the amount of parking available; a shift from minimum to maximum standards (Still \& Simmonds, 2000). Maximum standards put a limit on the number of car parks a development can supply, to try to limit traffic demand, while still keeping the road system efficient (Still \& Simmonds, 2000). Many European countries including the United Kingdom, France and the Netherlands have started to use maximum-parking standards, either in place of, or together with minimum standards in CBDs. In the United States, cities including New York, San Francisco and Portland have introduced maximum-parking standards or relaxed their minimum standards in CBD areas (Li \& Guo, 2014).

In the long term, continuing to improve car technologies and fuel systems to run on cleaner fuels or creating systems that are more energy efficient, may see reductions in some negative externalities like the level of air pollution emitted by cars. Relying purely on these types of technological solutions will not necessarily resolve some of the problems that heavy car traffic creates such as the need to reduce congestions levels and improve the accessibility of destinations (Gärling \& Schuitema, 2007). Alongside technological advancements to create more environmentally friendly cars, to reduce other negative externalities of car use, policies targeting individual behavioural change are needed (Chapman, 2007).

Behaviours can be altered to achieve desired outcomes. For example, changes can be made to technical or organisational systems to alter the availability and quality of products and services (Steg \& Vlek, 2009). These changes may make unwanted behaviour less feasible or impossible (such as banning cars in $\mathrm{CBDs}$ ), or show encouragement by making wanted 
behaviours beneficial in some way (providing quality public transport at a reduced fee).

Policy works to create these changes and influence public behaviour. Travel demand management (TDM) offers a range of common policy measures that can influence car use behaviours (Kitamura, Fujii, \& Pas, 1997). TDM measures aim to change individual behaviour either by making a desired behaviour more attractive (pull measures), or making undesired behaviours less attractive (push measures). In general push measures are considered to be more coercive than pull measures as push measures are harder for people to evade, and accordingly are generally more effective in changing car use and ownership patterns (Schuitema, 2010). Gärling and Schuitema (2007) categorise four types of TDM measures as follows:

- Constructing physical changes with the assumption that people will change their car use behaviours as physical settings changes. This may include increasing the attractiveness of alternative travel modes physically by improving infrastructure of public transport, or decreasing the attractiveness of car use physically by creating speed bumps or removing parking spaces. This type of measure also includes making technical improvements to cars to enhance their energy efficiency.

- Implementing legal measures to enforce certain behaviours with the assumption that people will comply with the law. Over time more people will begin to adopt these enforced behaviours as normal behaviour. If these policies are long-term then they will eventually become the social norm. These measures include reducing speed limits, prohibiting cars in certain areas and forming parking regulations.

- Applying economic measures that either aim to make car use more expensive, or aim to make alternative modes less expensive. This measure relies on the assumption that modal travel choice is made purely from a monetary cost-benefit analysis. Economic measures 
can include parking and congestion pricing, taxation of fuels and cars and reducing the cost of public transport.

- Creating information and education measures that aim to change people's knowledge, awareness and attitudes to car use. These types of measures include feedback on environmental impacts, customised individual marketing, social modelling (e.g. prominent public figures using sustainable transport), and providing information about the positives and negatives of car use.

Common proposals for discouraging car use include push measures that make driving less attractive, pull measures that improve alternative travel modes such as public and active transport, or measures to change the locations of work places, homes, shopping and recreational facilities to reduce driving distances (Gärling et al., 2002). These proposals all aim to reduce car use but differ in terms of efficiency, cost, technical feasibility and political feasibility within and between different contexts (Gärling et al., 2002). Parking price and supply restrictions are among the most widely and readily used methods of limiting car use as they are considered easy to implement, yet have a practical influence on travel decisions (Institution of Highways and Transportation, 2005).

The OECD (2013) states that policies need to provide the right financial incentives to increase the levels of environmentally friendly choices being made. Pricing policies are considered one of the most effective transport policies in decreasing car use, but they are often judged to be unacceptable by the public (Schuitema, 2010). This is an important issue of pricing policies that needs to be addressed, because without sufficient public support these effective policies are rarely implemented. Therefore, this study examines the acceptability of parking policies and the factors that determine acceptability judgements. 


\subsection{Pricing policies}

Economists believe that increasing the costs associated with car travel is an effective way to reduce car use (Ubbels \& Verhoef, 2006). Price based policies provide motivation to alter behaviour by ensuring that prices reflect underlying externalities that previously were not taken in to account (Schade \& Schlag, 2000). Pricing policies can decrease the cost of desirable behaviours and increase the cost of undesirable behaviours (Steg \& Vlek, 2009). The transport sector can reduce negative impacts of car use by using push measures, including pricing instruments, together with pull measures that increase the attractiveness of public and active transport through policy (Hensher, 2008). Current road pricing policies show how the cost of traffic congestion, accidents and pollution can be internalised by imposing charges on car users who create them (Seik, 1997). A similar pricing structure could be used in parking to increase the price of parking to internalise the costs (i.e. externalities) created by car use. Those people who currently drive then have the option of paying to park or could choose different modes of transport to avoid paying the increased fee (Benenson, Martens, \& Birfir, 2008).

People tend to regard public roads as free goods, so they can have a strong emotional response when charges are implemented (Schade \& Schlag, 2000). As such, legal regulations may need to be introduced to make the charges compulsory, with enforcement measures and sanctions for non compliers (Steg \& Vlek, 2009). Common pricing strategies aim to offset the affordability of car ownership through indirect taxation, increasing parking charges and fuel tax levies (Chapman, 2007), expanding paid-parking areas, or introducing congestion charges or road tolls (Trodahl \& Weaver, 2007). The following section gives examples of cities that have established transport pricing policies. These examples outline fee requirements that must be paid to enter a certain area by car, thus imposing a push measure on drivers to incentivise them to reconsider their driving behaviour. 


\subsection{Examples of transport pricing policies}

\subsubsection{London congestion charge}

In 2003, London imposed a daily charge for driving or parking a vehicle on central London roads on weekdays between 7:00am and 6:30pm (Prud'homme \& Bocarejo, 2005). Proposals for a congestion charge had been made since the early 1960 s, but took decades to implement due to political resistance, perceived difficulties in finding an appropriate cordon, lack of decision about the level of the charge and concerns around enforcement costs (Leape, 2006). The eventual implementation of the policy, along with improved bus services, saw traffic congestion decline substantially and the programme became largely supported by the public and seen as a political success (Leape, 2006; Prud'homme \& Bocarejo, 2005). The quantity of cars coming in to central London was reduced by 33 percent and congestion in terms of minutes of delay dropped by 30 percent (Leape, 2006).

\subsubsection{Stockholm congestion charge}

In 2006, the Swedish Government conducted a seven month congestion charge trial in Stockholm. During 6:30am to 6:30pm motorised vehicles were charged every time they passed a point entering the city centre, with the exception of taxis, emergency vehicles and low-emission vehicles (Schuitema \& Jakobsson Berstad, 2012). The primary push measure of the congestion charge was also combined with the implementation of supplementary pull measures. In this case, pull measures included expanding the public transport network and creating additional parking near train stations.

Before the trial, acceptability of the congestion charge was low. There were high levels of scepticism about the positive effects of the charge, with large individual cost increases expected (Schuitema, Steg, \& Forward, 
2010). However, after the trial acceptability for the policy increased. 51.3 percent of the residents of Stockholm voted in favour of the permanent implementation of the congestion charge, which took effect in 2007 (Schuitema \& Jakobsson Berstad, 2012). This was the first instance worldwide where a congestion charge was approved by the majority of a city (Hensher \& Li, 2013; Schuitema, Steg, \& Forward, 2010).

\subsubsection{Singapore area license scheme}

An area license is a scheme whereby a permit must be purchased to take a vehicle into a designated area during peak times (Seik, 1997). Singapore has been a pioneer in this area, having introduced the scheme to the CBD in 1975 (Seik, 1997). The scheme resulted in fewer individuals journeying to the city by cars in morning hours and a corresponding increase in bus and car-pooling commuting (Willoughby, 2001). Little change was made to the system until 1998 when it was replaced by the more modern electric road pricing system (Willoughby, 2001). The new system allowed charges to be varied according to time and place and will soon be updated to enable distance-based congestion charging (Haque, Chin, \& Debnath, 2013).

\subsubsection{Norway (Trondheim, Bergen, Oslo) toll rings}

Tolls have been used in Norway to finance road projects and raise the revenue of the national roading budget (Odeck \& Bråthen, 1997). Road infrastructure in Norway is expensive due to the topography of the land. As such, toll rings had been in place in Norway to supplement government funds for over 100 years, and account for 25 percent of the total annual state budget for road construction (Odeck \& Bråthen, 2002). In 1986 the toll ring in Bergen was opened as the first toll system in a major city, followed by the Oslo ring in 1990 and the Trondheim ring in 1992 (Odeck \& Bråthen, 1997).

The Bergen toll ring was not intended to affect traffic levels and only a small initial drop of 6-7 percent was seen. Once the road infrastructure was 
built from the annual toll revenue (around 70 million Norwegian Krone (12 million New Zealand Dollars)by 2000), traffic levels through the toll began to increase by 3-5 percent a year (leromonachou, Potter, \& Warren, 2006).

The Oslo toll ring was installed as a revenue gathering scheme, but with problems of congestion growing, it may evolve into a congestion pricing scheme (leromonachou et al., 2006). Trondheim became the first city to install a fully automated toll ring on 1991 using the AutoPass system that allowed for fee changes throughout the day to reflect demand (leromonachou et al., 2006). 70 percent of the public first opposed the scheme, but this subsequently dropped to 50 percent after implementation (Odeck \& Bråthen, 2002).

These examples all show how large cities have used pricing policies to charge car users to travel into certain areas. Examples of how smaller cities could use these types of policies however are missing in the literature. Even though the cities in each example had different reasons for collecting a fee, each policy acted as a push measure to change travel behaviour away from driving. In all cases, acceptability levels for each policy were initially low with a lack of public support for policy implementation. Understanding more about initial public acceptability levels and what factors within policy influence these could help to increase levels of support for pricing policies. Therefore this research aims to identify what the acceptability levels are towards a range of parking policy measures.

\subsection{Acceptability: Attitude and beliefs}

Attitudes are an important determinant of behaviour and can influence if a policy is implemented and its level of success (Schuitema \& Jakobsson Berstad, 2012). Acceptability refers to a positive attitude towards a specific object or entity (Schade \& Schlag, 2000). Attitudes, and thus acceptability, are the psychological tendency that is expressed in evaluating a particular entity (such as pricing policies), with some degree of favour or disfavour 
(Eagly \& Chaiken, 1993, 2007). Attitudes in turn are determined by individuals' beliefs about the outcome and consequences of a specific object or entity (Eagly \& Chaiken, 1993; Schuitema, Steg, \& Forward, 2010). Beliefs are defined as the subjective probability that an object has a specific outcome, be it favourable, neutral or unfavourable (Schuitema, Steg, \& Forward, 2010). Beliefs an individual has about the personal and collective outcomes of a policy will influence the acceptability and expectations they have towards that policy (Schuitema, 2010). One may see the outcome of a pricing policy as leading to increased costs which are an unfavourable outcome, but also see the potential for favourable outcomes in that congestion and pollution levels will decrease. Overall how acceptable the individual will find the pricing policy will depend on how they rank these outcomes in terms of their own beliefs.

A small difference can be seen between acceptability and acceptance. Acceptability relates to attitudes before a scheme or policy is implemented, while acceptance refers to the attitude after implementation (Garling, Jakobsson, Loukopoulos, \& Fujji, 2008). Acceptability levels of transport pricing policies are generally low (Schade \& Schlag, 2003). The lack of public and political acceptability is the main obstacle in implementing transport pricing policies, with parking fees, congestion charges and distance based pricing often judged to be least acceptable (Schade \& Schlag, 2000). Acceptability is thus an important precondition to a transport pricing policy being introduced (Schuitema, 2010). In general non-coercive pull TDM measures are more acceptable than coercive push TDM measures (Steg, Dreijerink, \& Abrahamse, 2006). 


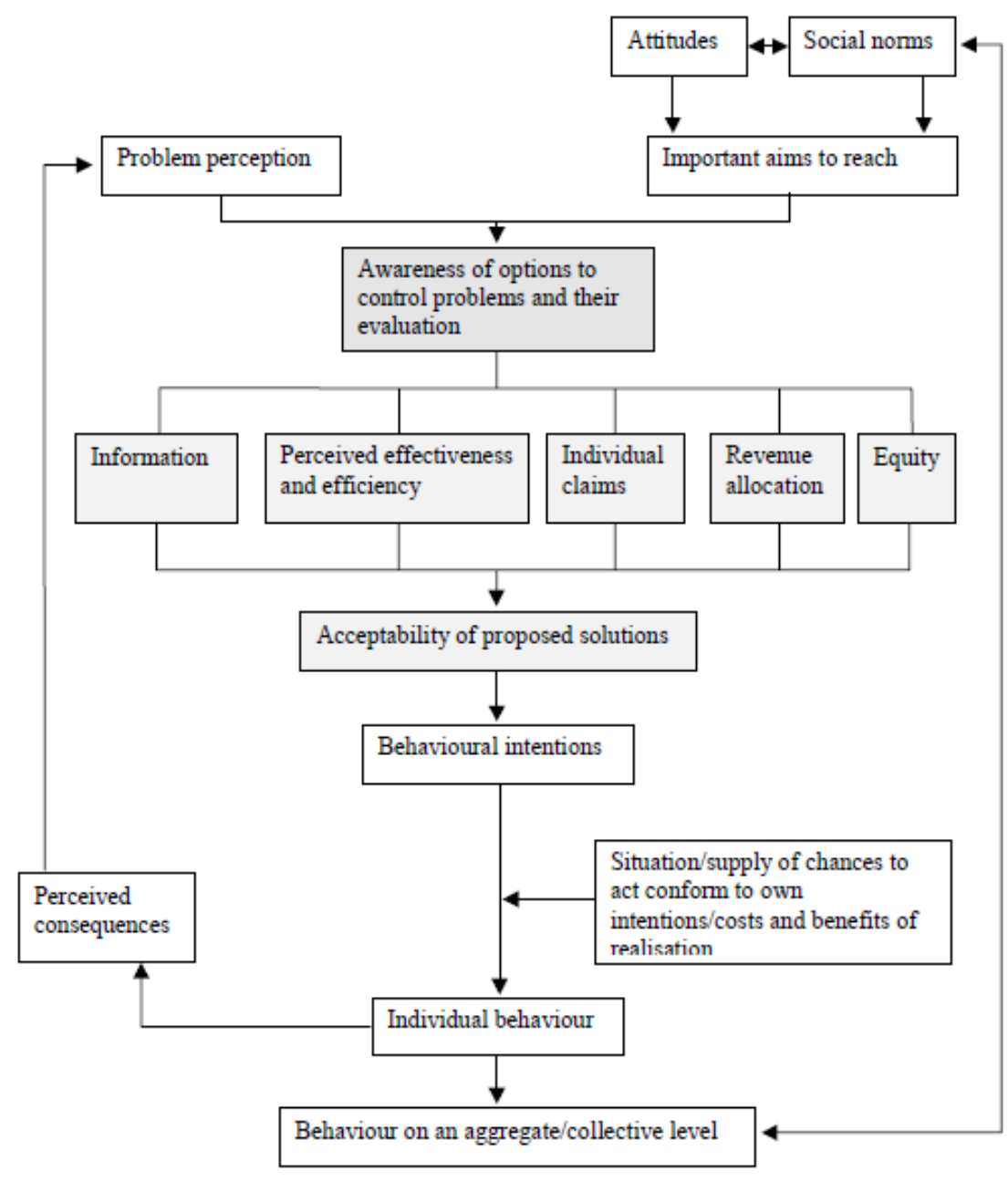

Figure 2. 1 Structure of acceptability issues. Source of image: Schlag and Teubel (1997, p. 136).

When analysing a policy, people take a range of other factors into account as outlined in Figure 2.1. Individuals' attitudes and perceptions of social norms influence which aims they believe are important for policy to address (Schlag \& Teubel, 1997). However, these aims need to align with a certain level of problem perception before an individual has an awareness of the possible policy solutions. Many factors can influence a policy's level of acceptability to an individual (Schuitema, 2010). These factors include information they have about the policy, how they perceive the policy's effectiveness and efficiency, any individual claims they have in relation to the policy, how revenue will be allocated and if the policy is equitable(Schlag \& Teubel, 1997). The wide and complex range of factors 
influencing a policy's acceptability to an individual needs to be considered for successful policy to be implemented.

The values and beliefs individuals hold about cars adds another element to acceptability levels of a policy. Some people use cars for reasons beyond a convenient mode of transportation. People may drive out of habit, for the symbolism that owning a car represents, or for emotional reasons that conforming to social norms or displaying their status and values gives them (Rajan, 2006; Steg, 2005). Steg (2005) found that driving a car often has strong symbolic and emotional role, rather than a purely instrumental one. The 'theory of the meaning of material possessions' also suggests that material goods can fulfil a range of social, instrumental, symbolic and emotional purposes (Dittmar, 1992). These purposes are driven by selfexpression or have symbolic categorical functions (Dittmar, 1992, 2004). The categorical function refers to how an item can be used to communicate group membership and status, while the self-expressive function refers to how an item can reflect an individual's unique qualities, values or attitudes (Gatersleben \& Steg, 2012). The car can be multipurpose in its functions, allowing the owner to prove their belonging to a group, or emphasise their individuality. Either way, many car owners view their vehicle as an extension of themselves.

The car is often seen as one of the most significant objects of wealth in modern societies (Hagman, 2006). Car advertisements not only highlight the instrumental values a car has like fuel efficiency or price, but affective values by emphasising the fun of driving, and symbolic values by showing the envy that others are likely to have if you drive a certain type of car (Gatersleben \& Steg, 2012). However, the lack of mention in regards to obligations, obstacles and restrictions of car ownership creates a divergence between what is advertised and the real world. The multiple values that cars have can lead to strong resistance from drivers when policies aim to reduce car use. While policy makers might only consider the 
policy to be a reduction in the instrumental function of car, the policy may simultaneously damage the symbolic and emotional functions that the driver has placed on the car. These losses can then create larger negative outcomes for the individual that were not anticipated.

\section{$2.5 \quad$ Social dilemmas}

The social dilemma paradigm can help explain environmental attitudes and behaviours observed in policy acceptability. Environmental problems are often characterised by a conflict between individual benefits and negative environmental outcomes. According to the social dilemma perspective, an individual is better off when they choose behaviour that is in their own best interest, but all individuals are best off when everybody chooses to cooperate and do what is best for the larger group (Dawes, 1980). This means an individual can choose to act in their own self-interest to receive the greatest personal benefit to themselves (defect), or act in a way that benefits the larger group at a (continently) smaller benefit to the individual (cooperate). If all individuals choose to defect than the individual benefit to each person is lower than the benefit they would have received if they all had chosen to cooperate (von Borgstede, Johansson, \& Nilsson, 2012).

Transport policies often try to deal with large-scale social dilemmas where people act independently and with high levels of anonymity, often due to limited communication between individuals (von Borgstede et al., 2012). This means that people are not identifiable at an individual level for the choices they make and as such cannot be held accountable for any externalities they create. Defection is often chosen when a group is weakly united or geographically separated as the consequences of doing so are not obvious to other group members (von Borgstede et al., 2012). In these situations, often selfish choices are favoured as burdens are spread out to a number of people and no one is directly identifiable as the perpetrator (von Borgstede et al., 2012). When someone acts according to their individual interest they often receive a short-term gain, but if more people 
behave in the same way, then in the long-term, larger negative consequences will become apparent.

Often transport pricing policies highlight this divergence between personal and societal interests (Schuitema, 2010). Using a transport pricing policy context, price setting is an attempt to restrict the long-term problems for the public (such as traffic congestion) by reducing an individual's shortterm advantage (paying for a resource, i.e. parks or road, at a higher cost) (Schade \& Schlag, 2000). Choosing to drive and park may be beneficial for the individual in terms of time, but creates negative externalities for society through congestion and pollution. If an individual chooses not to drive then they may spend more time using an active or public mode of transportation, but they are benefiting society through less pollution and congestion. However, if everyone chose to drive, higher levels of congestion and pollution would increase to a point where driving would no longer be beneficial to the individual as these effects would begin to impact upon them too. Often behaviours that would be beneficial for society do not occur due to a lack of knowledge about this potential advantage (Dawes, 1980). When people find transport pricing policies acceptable, this may indicate they understand the potential advantages and are willing to contribute to the societal benefit at the expense of giving up individual short-term benefits of car use (Schuitema, 2010). Although, people often see policies as unacceptable because they do not want to give up their individual benefits of car use; in other words, they choose their own self-interest over the collective good.

Not everyone in a community will choose to drive. This may be for a variety of reasons from cost management to environmental concern. The distinction between attitudes and beliefs of those who use cars and those who do not will vary, but little research has been done in the area (Jaensirisak, Wardman, \& May, 2005). This leaves a gap in the research as to how public in general view the acceptability of parking. In a democratic 
society all groups should be regarded equally to determine the overall acceptability of a pricing policy (Jaensirisak et al., 2005). Jaensirisak et al. (2005) used a stated preference survey to gather information from 830 respondents in Leeds and London around acceptability levels of differing road pricing schemes. Overall, road pricing was more acceptable to non-car users, those who perceived pollution and congestion to be very serious issues, those who believed road pricing would be effective and those who did not accept current conditions, while older people were more likely to find all charges unacceptable (Jaensirisak et al., 2005).

Environmental awareness can be a factor that affects how a person views different policies. Acceptability of policies that benefit the environment is generally higher when people are aware of and concerned about environmental problems (Eriksson, Garvill, \& Nordlund, 2006). As problems are more likely to be visible to those with a higher problem awareness, policies are more likely to be acceptable when they tackle serious environmental concerns (Schuitema \& Jakobsson Berstad, 2012). Loukopoulos, Jakobsson, Gärling, Schneider, and Fujii (2005) surveyed a sample of 553 employees at Goteborg University by email to gauge levels of environmental concern, what they perceived to be the issues caused by car traffic in Gothenburg, and consequences of different TDM measures. It was found that those with higher environmental concern believed environmental policies would increase urban environmental quality more than did those with a lower environmental concern (Loukopoulos et al., 2005). This leads to the conclusion that environmental concern may be an important factor in acceptability levels of parking policies. The current study examines whether parking policies are more likely to be acceptable to individuals with greater environmental concern and problem awareness. 


\subsection{Motives in social dilemmas: Greed-Efficiency-Fairness (GEF) hypothesis}

Individuals are not purely driven by maximising their own self-interests when making choices in social dilemmas (von Borgstede et al., 2012). The GEF hypothesis predicts that there are three conflicting motives in social dilemmas: greed, efficiency and fairness. The hypothesis outlines that even if humans are greedy, this is constrained by a desire to use resources efficiently and for outcomes to be fair and equitable for all (Wilke, 1991). It is argued that the acceptability of transport policies can be predicted using the GEF hypothesis, which explains why some people support policies that at an individual level seem to be negative, but at a societal level have many benefits. It is believed a policy will be more acceptable when the outcome relates positively to the individual (greed) and wider society (efficiency) in a fair way (Schuitema \& Jakobsson Berstad, 2012).

Research suggests that acceptability of transport pricing policies can be enhanced using the GEF hypothesis. Schade and Schlag (2000) conducted an empirical survey on public acceptability levels of different pricing strategies with between 285 and 400 motorists in the European cities of Athens, Como, Dresden and Oslo. They found that acceptability of a pricing strategy increased when there was more perceived social pressure to accept the strategy, when the strategy was evaluated as effective, when there were more personal advantages expected, and when there was societal approval of aims of the policy (Schade \& Schlag, 2000).

Schuitema (2010) surveyed 507 Dutch commuters who experienced congestion at least twice a week. Results suggest that kilometer charging based on car weight was seen to be rather unacceptable. However, revenue use did influence acceptabilty levels. The policy was considered least acceptable when revenue went to a general fund, followed closely by road infrastructure. The policy was more acceptable when funds were allocated within the transport system, either to improving public 
transportation or to measures that are directly beneficial to the car user (decrease fuel taxes or abolish road taxes). From these results, Schuitema (2010) suggests acceptability of pricing policies can be increased by compensating individuals for negative consequences of the policy via appropriate revenue allocation (for example lowering car registration costs). Policy acceptability could also be increased by highlighting the positive outcomes of the policy for collective problems and increasing the fairness of policy (Schuitema, 2010).

Similarly, Fujii, Gärling, Jakobsson, and Jou (2004) found that acceptance of a road pricing policy increased if it is viewed as fair, effective in solving important problems (e.g. air pollution and congestion) and if there is a fair political decision-making process. This study surveyed residents in Kyoto, Japan (150 responses) and residents in Taichung City, Taiwan (60 responses), to investigate an Asian perspective of the Jakobsson, Fujii, and Gärling (2000) Swedish study.

Likewise, Schlag and Teubel (1997) concluded from empirical findings that public acceptance of a new policy increases when the policy has objectives that meet major concerns, is perceived as effective, reliability functional and equitable, the revenue is allocated fairly, people have confidence in it and there is a marketing strategy. Each of the three motives in the GEF hypothesis will next be discussed in more detail.

\subsubsection{Greed and individual policy outcomes}

Greed is considered the defecting choice in a social dilemma. Individual payoffs are maximised with greed which is often seen when individuals are faced with uncertainty (von Borgstede et al., 2012). Greed is enhanced when there are unknown outcomes or an unknown situation, so the drive to increase self-enhancement becomes most important. This can be based on either the survival instincts to remain alive, or social comparison motives to try to avoid being worse off than others (von Borgstede et al., 
2012). Uncertainty is often present when individuals are faced with environmental issues due to their unknown outcomes. When an individual is driven by a greed motive, policy measures will be perceived as unacceptable when individuals expect a negative consequence for themselves (Jakobsson et al., 2000) such as an infringement on their freedom or high costs for non-compliance (Schuitema \& Jakobsson Berstad, 2012).

In transport policies, the greed motive can be appeased by compensation for the negative consequences of the policy (Schuitema, 2010). A policy that aims to punish environmentally harmful behaviour (push measure) will be more acceptable if a simultaneous policy that rewards proenvironmental behaviour (pull measure) is implemented. This way, desired changes are being facilitated and made more attractive and may provide financial compensation for any negative individual consequences from the push measure (Schuitema \& Jakobsson Berstad, 2012). The Stockholm congestion charge encompassed both push and pull measures by developing public transport facilities at the same time as introducing the congestion charge (Schuitema, Steg, \& Forward, 2010). The current study examines if perceived personal outcomes of a parking policy influence overall levels of acceptability of the parking policy.

\subsubsection{Efficiency and collective policy outcomes}

Efficiency is the cooperative choice in a social dilemma that aims to maximise collective payoffs by doing what is best for society. Wilke (1991, pp. 170) describes efficiency as "the desire to use a resource in an intelligent way". It is often linked to the distribution principle of equity as it restrains an individual's greed in favour of social fairness (von Borgstede et al., 2012). The impact on the motive of efficiency on behaviour depends on which specific goal a group is working towards in a particular situation, as it relates to how fairness will be defined (von Borgstede et al., 2012). Individuals with higher valuations of common social aims show higher 
levels of acceptability of road pricing (Schade \& Schlag, 2000) as they expect that collective problems will reduce when the policy is introduced (Garling et al., 2008).

Effectiveness refers to the level to which the aims of the measure can be reached (Schade \& Schlag, 2000). Lower perceived effectiveness generally relates to lower levels of acceptability of a measure (Schade \& Schlag, 2000). When policies have clear objectives that are likely to be achieved, the perceived effectiveness and thus acceptability will increase (Schuitema, Steg, \& Rothengatter, 2010). Push measures are often more likely to result in positive behaviour change than pull measures and as such are believed to be more effective (Schuitema \& Jakobsson Berstad, 2012).

Changes in perceived effectiveness tend to change once a policy is introduced. A reduction in collective problems once a policy is implemented can create unforeseen benefits for the individual, as was the case of the transport pricing policies in London and Stockholm discussed previously. As such, acceptability levels tend to increase after policy implementation, as people experience positive outcomes that were not originally part of their perceived effects (Schade \& Schlag, 2000; Schlag \& Teubel, 1997; Schuitema, 2010; Schuitema, Steg, \& Forward, 2010). Efficiency can be highlighted in policies by stressing the expected positive outcomes, particularly for society (Schuitema, 2010). The current study examines if perceived effectiveness of reaching the policy aim influences overall acceptability levels of parking policies.

\subsubsection{Fair distribution of policy outcomes}

Fairness reflects the aim of distributing outcomes according to the principles of equity, equality and need, which can restrain individual greed (von Borgstede et al., 2012). These three principles differ slightly, but each can influence how fair a policy is seen to be. Equity reflects distributing a resource between individuals according to merit and proportion of their 
input (von Borgstede et al., 2012). Equity is associated with efficiency as it goes beyond outcomes that benefit an individual, to the outcomes that benefit society. This can often be seen in competitive situations, such as businesses when the goal is productivity. Equality aims to split resources evenly among groups members and is dominant when there is a goal of strong social relations (von Borgstede et al., 2012). The need principle aims to help others who are in need and is dominant when well-being and personal development of individuals are the goal (von Borgstede et al., 2012). As push measures are considered more coercive than pull measures, push measures are generally seen as less fair (Gärling \& Schuitema, 2007).

Fairness judgments are based in comparing policy outcomes to a reference point (Schuitema \& Jakobsson Berstad, 2012). Little is known about what kind of cost-benefit distribution people prefer in regards to fairness of transport pricing policies, but it can be investigated from an intrapersonal, interpersonal and intergenerational point of reference (Schuitema, 2010). Intrapersonal comparisons use an internal reference point to compare policy outcomes, independent of the outcomes of others, either with an internal norm, or with their own outcomes before and after policy implementation (Schuitema \& Jakobsson Berstad, 2012). Interpersonal comparisons compare individual outcomes to that of other individuals or groups in the population (Schuitema, Steg, \& van Kruining, 2011), as with social comparison. Equity, equality and need principles can be used to compare outcomes for groups (Schuitema \& Jakobsson Berstad, 2012). Intergenerational comparisons compare the outcomes to those of future generations and the effects on the environment, reflecting the view of environmental justice (Schuitema \& Jakobsson Berstad, 2012). Transport policy should distribute the costs and benefits in a way that is fair to all members of the general public (Schuitema, 2010). The current study examines if revenue allocation is a factor of fairness that influences overall acceptability levels of specific parking policies. 


\subsubsection{Revenue allocation}

Importantly for transport pricing policies, how revenues are distributed and to which areas they are allocated (e.g. public transport infrastructure versus general funds) will alter perceived levels of fairness which influence levels of policy acceptability. Acceptability of transport pricing depends on the allocation of revenues. Generally acceptability levels increase when revenues from pricing policies are allocated to benefit car users (Schuitema \& Steg, 2008). Often transport pricing involves a monetary transfer from a private person to an often public fund, which is thought to reduce public acceptability levels (Ubbels \& Verhoef, 2006). It is expected that the more car users benefit from the revenue allocation, the more acceptable that transport policy is to them, often when revenues remain within the transport system (Schuitema, 2010).

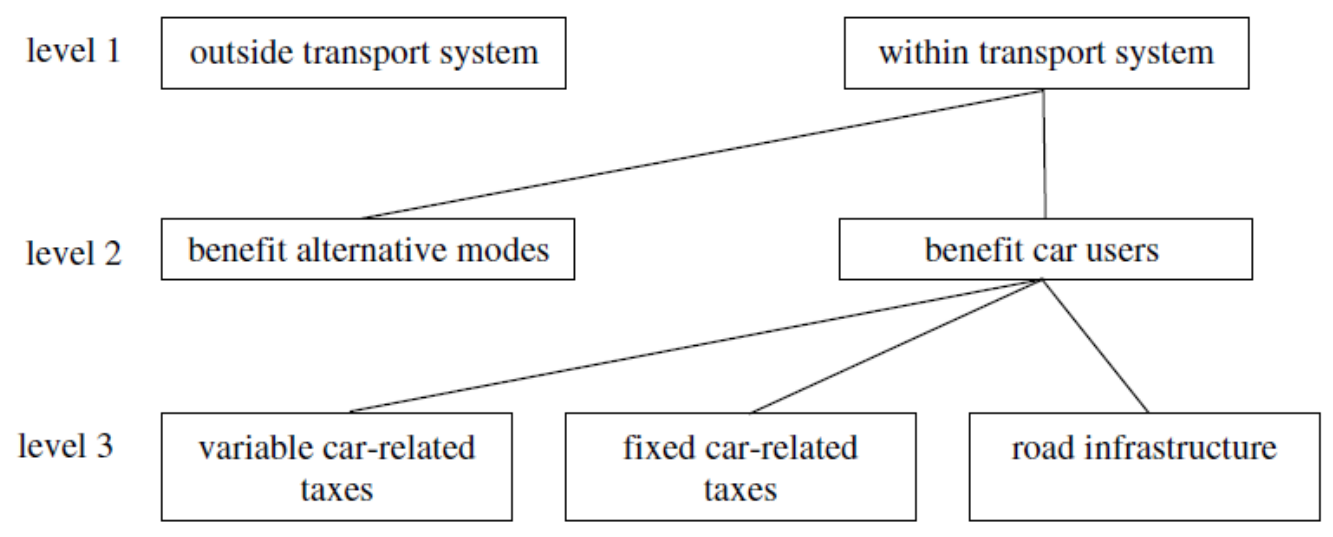

Figure 2. 2 Classification of revenue allocations. Source of image: Schuitema and Steg (2008, p. 222).

The acceptability of revenue allocation within the transport system differs between studies. Figure 2.2 demonstrates the classification of revenue allocation levels that are often seen in transport pricing policies and have been investigated by previous studies. Schuitema and Steg (2008) found acceptability levels will generally increase when users expect to benefit from the allocation of the revenues (at level 2 in Figure 2.2), specifically for car users (level 3), by the decrease in fixed car taxes (road taxes) and variable car taxes (fuel taxes). Others, including Thorpe (2002), found 
investment in public transport to be the most acceptable use of collected revenues (level 2). When the London congestion charge was introduced it was argued that for the charge to be acceptable to the public, the revenues needed to be spent on improving London's transport system (level 2). Acceptability levels of the congestion charge reached 67 percent when revenues were to be invested in public transport (Banister, 2003). Lowest benefits to the individual occur when revenue is allocated to the general public fund, thus acceptability is often at its lowest levels (Schuitema \& Steg, 2008). In some studies investing revenues in road infrastructure is viewed as almost as unacceptable as revenue allocated to the general public funds as there is a low direct benefit to the car user (Schuitema, 2010).

This research aims to explore a range of parking policies acceptability to residents of the Greater Wellington Region and in light of these levels, what aspects of the policy could be influencing these judgments. It is hypothesised that under the GEF hypotheses, acceptability levels will be highest when the policy is perceived to benefit all of society a fair way, either through its perceived outcomes, or revenue allocation.

\subsection{Current international parking policy}

Cars are parked 80 percent of the time, but most studies have concentrated on the problems caused by vehicles in motion (Marsden, 2006) leaving a gap in the research. Some state that this percentage is even higher with the private car being parked up to 95 percent of its lifetime (Hagman, 2006). Current literature identifies parking within the realms of sustainability and urban design and is viewed as a factor in the quality of an urban space, but little research regarding the attitudes to parking provisions has been done (Stubbs, 2002). Parking policy is an aspect of urban form that is the connection between land use and transport policies (Marsden, 2006). Effective parking policies can contribute to the efficient use of the transport network, lower $\mathrm{CO}_{2}$ emissions and create urban 
environments that are more compact and of higher quality from wellorganised use of public space (Shoup, 2005).

Parking policy was once only concerned with traffic management to increase the efficiency of the road system (Still \& Simmonds, 2000). The previous solution to lack of available parking was to expand by building more roads and increasing parking access. This aligned with creating minimum-parking standards to ensure that a park would always be available at the exact destination of each car journey. Now the newer solution to efficient parking, though over 50 years old, is to regulate via economic means by charging individual drivers to use limited parking spaces (Hagman, 2006). Parking payments have become the more accepted form of payment for a scare resource than road congestion charges are for roads which motorists often perceive to have been already paid for through road taxes (Ryan \& Turton, 2008). Parking pricing is also seen to be easier to implement than road pricing as it is a recognised and established system of charging in many places in the world (Arnott \& Rowse, 1999)

The price charged to park in a parking space will depend on the objectives of the policy. Outcomes range from increasing accessibility and traffic flow, maximising turnover and revenue gathering, to minimising car use and nuisance (Marsden, 2006). Parking policy is normally seen by local authorities as a balance between the outcomes of revenue gathering, managing transport demand and avoiding deterring visitors or damaging urban vitality (Marsden, 2006). Price, quantity and restrictions of parking are needed to intersect at a point that makes an area accessible and attractive as a destination, meets demand requirements and is profitable, while still keeping public space attractive and useful for the benefit of the public. 
Button and Verhoef (1998) note the following reasons as justification for parking policy:

- On-street parking affects road capacity.

- The cost of parking is a large, if not the largest monetary component of a car trip.

- Parking pricing is an important part of urban policy, especially in areas where congestion pricing is not enforced.

- Cruising for parking is a major contributor to traffic congestion in the CBD.

Parking policy needs to take into account all of these aspects if issues with parking are going to be addressed through specific policies.

\section{$2.8 \quad$ Issues with parking}

Parking policy objectives are often in conflict. What the local government is aiming to achieve in its parking policies and what the general public wants to achieve can vary greatly. It is lack of public acceptability that most often hinders the implementation of new policies (Schuitema, 2010). Marsden (2006) identifies the following objectives to parking policies that are frequently perceived to be in conflict:

- Using parking as a means of regenerating a part of an urban area.

- Using parking as a means of restraining vehicle traffic and improving environmental quality or to encourage non-car modes of transport.

- The need to secure revenue to cover the costs of a parking operation or in order to fund other activities.

There are varying opinions about the acceptability of parking in the CBD that may be explained by individual beliefs and attitudes. Individual travel patterns often converge in time and place, meaning there is rivalry for space, not only between drivers, but for different activities (Hagman, 2006). Parking is an issue for many car owners that is often personified as 
irritation towards parking wardens (Hagman, 2006). Due to the amount of traffic on the roads, parking spots become highly in demand at certain places and at certain times. Parking then represents a limitation to where a driver can stop, which is in conflict with the personal sense of freedom some get from driving (Hagman, 2006). This limitation that an individual feels can then impact on the way they view parking policies and how acceptable they find them.

Public knowledge around the goals and the perceived limitations and impacts of parking policies influences individual acceptability levels. Collis and Inwood (1996) interviewed 410 members of the public who commuted to Bristol CBD. Both reducing parking spaces and increasing parking fees were viewed as unacceptable by most of those interviewed. However, they found most people were unaware of the concept of using parking as a way to reduce car use. It was noted that even though the policy was unacceptable from an individual perceptive, some individuals did think the proposed policy changes would encourage more public transport use, and believed these policies would increase the quality of life within Bristol.

Parking competes for limited road space and creates conflict in acceptability levels between drivers that whose views differ when acting as residents, commuters or shoppers. Parking for shoppers is seen to be positively related to retail vitality, as sufficient parking in refurbished car parks is believed to attract shoppers who prefer parking for a few hours (Still \& Simmonds, 2000). Behavioural and attitudinal studies tend to conclude a strong relationship between parking provision and economic vitality, however aggregate statistical studies find this relationship to be very weak (Still \& Simmonds, 2000). Still and Simmonds (2000) note one reason this contradiction may occur comes down to methods used to determine the strength of the relationship. Aggregate studies focus on the net effects from the policy seen in terms of land use and the composition of activities at a given point in time. These studies do not show activities 
that have closed or moved; hence they may not show the full extent of negative outcomes that come from changing parking provisions. Attitudinal studies focus on the gross effect on individual firms and households. These studies may miss out potential policy benefits at a societal level, such as increases in environmental quality and therefore show a more negative relationship between parking restrictions and economic vitality. Shoppers are able to modify parking duration and location to limit parking charges. However they are unlikely to change to a less preferable location and will first alter price, convenience, duration of use of a parking space or will change to another mode of transport (Marsden, 2006). Negative reaction to minor suggestions of shoppers changing their destination or reducing the number of trips made as a response to changing parking restrictions makes implementing parking policies extremely politically sensitive (Marsden, 2006).

In suburban locations, firms' provision of parking for their workers is an expectation, while in the $\mathrm{CBD}$, where parking is expensive, it is a significant bonus (Still \& Simmonds, 2000). When parking restrictions are put in place, the primary behavioural response by commuters is to shift parking locations. This highlights the need for area-wide strategies to avoid parking issues migrating to areas on the outskirts of the CBD (Marsden, 2006). In 1992, The State of California created legislation to address traffic congestion and air pollution caused by employer paid parking with various levels of success. A parking cash out programme was created that requires employers to offer a cash allowance to employees at the same rate to the parking subsidy that the employer would otherwise pay to provide the employee with a parking space (Shoup, 1995). To combat possible spillover parking problems to local neighbourhoods, employees needed to certify that they would comply with guidelines set out by the employer, including not parking in other areas where these issues may occur (Shoup, 1995). 


\subsection{Parking policy in New Zealand}

Parking policy depends on the goals of politicians and citizens (Benenson et al., 2008). Transport debates are important to New Zealand, a country where almost 86 percent of the population live in urban areas (Statistics New Zealand, 2014a). In New Zealand, car use accounts for 90 percent of total passenger transport energy (Trodahl \& Weaver, 2007) and contributes to the high levels of GHGs attributed to the transport sector (Chapman, 2007).

Most transportation research is conducted in large cities as in the case of studies previously noted in this chapter. These studies differ from the New Zealand context due to differences in population size and density. For example, high-density cities often largely comprise residents who make fewer and shorter car trips and walk or use public transport more frequently (Buchanan, Barnett, Kingham, \& Johnston, 2006). These larger cities often implement congestion charges or cordons as a means to reduce traffic. These are less feasible for smaller cities where administration costs may be too high. There is a gap in research conducted in New Zealand in regards to public perceptions of parking policies. This research aims to explore this gap using Wellington and the residents of the Greater Wellington Region as a specific study context.

\subsubsection{Wellington parking}

In New Zealand cities, 15 percent of jobs are located in the CBD (Kenworthy, 2006). However, Wellington differs to this norm as a small-tomedium-sized city that sees 65 percent of its workforce commute into the CBD (New Zealand Transport Agency, 2012), a characteristic of a larger city. Despite a reputation for having the best public transport system in the country, 53 percent of commuters choose to travel to work by car (Statistics New Zealand, 2014a). Wellington residents are on average less car-orientated than residents of other areas of New Zealand (Wellington 
City Council, 2010), but the number of car commuters is still predicted to continue to increase (Wellington City Council, 2007).

According to the parking policy for the Wellington CBD area, on-street parking is primarily to support retail and entertainment facilities, community recreational facilities and events and to assist in servicing commercial and professional events (Wellington City Council, 2007). As such, commuter and resident parking is not a priority for on-street parking within the CBD, but both are significant in the wider inner-residential area (Wellington City Council, 2007).

\subsubsection{WCC transport strategy and parking policy}

The most recent Wellington City Council (2006) Transport Strategy focussed on road networks, public and active transportation and urban form as main factors to assist the wider 10 year objectives to make the city more liveable, more prosperous, more sustainable, better connected, healthier and safer. Transport not only dictates how people get to, from and around the city, but affects liveability and economic growth of the city, influencing where people choose to live (Wellington City Council, 2006). Of the specific objectives outlined in the WCC Transport Strategy (2006), parking policy directly relates to Wellington:

- Becoming more liveable. Wellington will be easy to get around, pedestrian friendly and offer quality transport choices. A balanced parking provision is needed that will include short-term parking, park-and-ride and park-and-walk facilities.

- Becoming sustainable. Wellington will minimise the environmental effects of transport and support the environmental strategy by continuing a modal shift of commuter traffic to public transport, walking and cycling.

- Becoming better connected. Wellington will have a highly interconnected public transport, road and street system that support urban development and social strategies. 
- Becoming healthier through the transport choices made. This means reducing dependence on motor vehicles for short trips and enhancing air quality and transport noise.

Environmental and resource challenges will need addressing in the coming years to adapt to these transport objectives of sustainability, liveability, connectivity and a healthy population in the Wellington Region. The Central City Framework (Wellington City Council, 2010) identifies a need for transport choices to become more efficient and for emissions volumes and pollution to decrease. WCC recognises that to do this more efficient approaches to transport, traffic management and parking are required and that decisions around the allocation of space for competing private and public transport modes need to be made (Wellington City Council, 2010). The WCC Transport Strategy (2006) had previously recognised that road space within the CBD is at a premium and choices need to be made about how that space is used for private cars, buses, cyclists and pedestrians. Despite documents acknowledging the WCC intentions to do so, few decisions about competing space and limiting car use have been finalised in policy. Push measures (increasing the cost of car use and decreasing space for cars) and pull measures (financial incentives for reducing car use and attractive alternatives) are options available to meet the objectives (Rajan, 2006).

Current principles of Wellington City Council's Parking Policy (2007, pp. 5-6) are as follows:

“i. Parking should be managed so that it supports the Council's Strategic outcomes for economic development, urban development, transport, environmental, social and recreation, and cultural wellbeing." This principle implies that many areas of wellbeing need to be equally taken into account as updated parking policies are considered. 
"ii. Parking also has the equally important role of supporting a better land transport system for New Zealand that is integrated, safe, responsive and sustainable." This principle implies that a carorientated transport network should not be the only mode focus of the transport system.

"iii. Street space is a scarce resource and priority for use for parking needs to be considered against other uses and depends on the location, type of street, time of day and day of week." This principle ties to the idea that public space should be used in a democratic way and that parking may not always be the best use of space. "iv. Revenue from parking needs to reflect the parking policy and the Council's strategic direction. Pricing is an effective tool in maintaining a certain level of availability of the on-street spaces. However, the price of a parking space needs to continue to recognise the cost of supplying and maintaining the road and street space asset. This should be communicated to the community to foster greater awareness and understanding of the rationale for charging for parking." This idea ties to how acceptable the public finds various forms of revenue use in combination with parking fees.

These principles align with and would support an adaptation away from car dependency in Wellington CBD. Further push measures such as price increases or parking space reduction could be implemented to discourage car use in to the CBD.

In Wellington CBD the total number of on-street parking spaces (over 3000) available is high compared with other similarly sized cities (Wellington City Council, 2007). Wellington City Council (nd) view that having sufficient parking for workers is vital in retaining a competitive advantage in the region, but do note that an oversupply of cheap longterm parking does encourage car use which increases negative 
externalities. Businesses in the CBD are not required to provide on-site parking so do not have minimum-parking requirements, but when parking is provided it must not exceed a maximum of one space per $100 \mathrm{~m}^{2}$ gross floor area, thus a maximum requirement (Wellington City Council, 2006).

A 15 percent vacancy rate or lower is an indicator of an effective parking system and is managed at this rate through changes to pricing, time limits and enforcement (Wellington City Council, 2007). This confirms with international best practice as per traffic engineers' recommendations of aiming for at least one out of every seven on-street parks to be vacant to allow easy parking and movement. An efficient parking system is where the occupancy rate is between 85 and 95 percent (Shoup, 2005). This study explored how acceptable residents find the current parking policy and how this influences how they use the current parking facilities in everyday life.

Even in keeping with international best practice, there is a gap in the research as to how the public in the Greater Wellington Region view the acceptability of parking. Without this information it is difficult to assess what changes could be made to the city's parking policies that would be accepted by the public and at the same time work as a push factor to move people away from personal car use. To investigate this gap the following research questions and sub-questions were asked:

1. What are Wellington Regions residents' acceptability levels?

2. What aspects of the policy influence these judgments?

a. What parking mechanisms and policy are in place in the CBD?

b. What are the reasons for drivers parking in the CBD over other areas or transport modes?

c. What are the acceptability levels of a range of parking policies to the public?

d. What is the public's perceived effectiveness of parking policies?

e. What are the public's perceived consequences of a range of parking policies? 
f. Does level of environmental concern influence parking policy acceptability levels? 


\section{Chapter 3: Method}

Wellington was chosen as the location for this research as there was relatively little research about public acceptability of parking policies in this area. Current parking policies in Wellington vary between pay-and-display, coupon and residential parking zones. Of particular interest to this research are the more than 3000 WCC run on-street pay-and-display parking spaces in the CBD (Snapper, 2014). This area requires the appropriate fee as outlined in Figure 3.1 from Monday to Thursday 8am-6pm and Friday 8am$8 \mathrm{pm}$. There is no fee required on the weekends, but time restrictions (generally a two hour maximum) still apply from 8am-6pm. Thorndon Quay is the exception as this area has longer maximum time restrictions and a fee is required from 8am-9pm daily. These parking spaces are areas of public space that are directly controlled by WCC and are areas where parking policies could be modified to discourage individual car use in the CBD. How acceptable Wellington Region residents find potential parking policy changes therefore needs to be investigated.

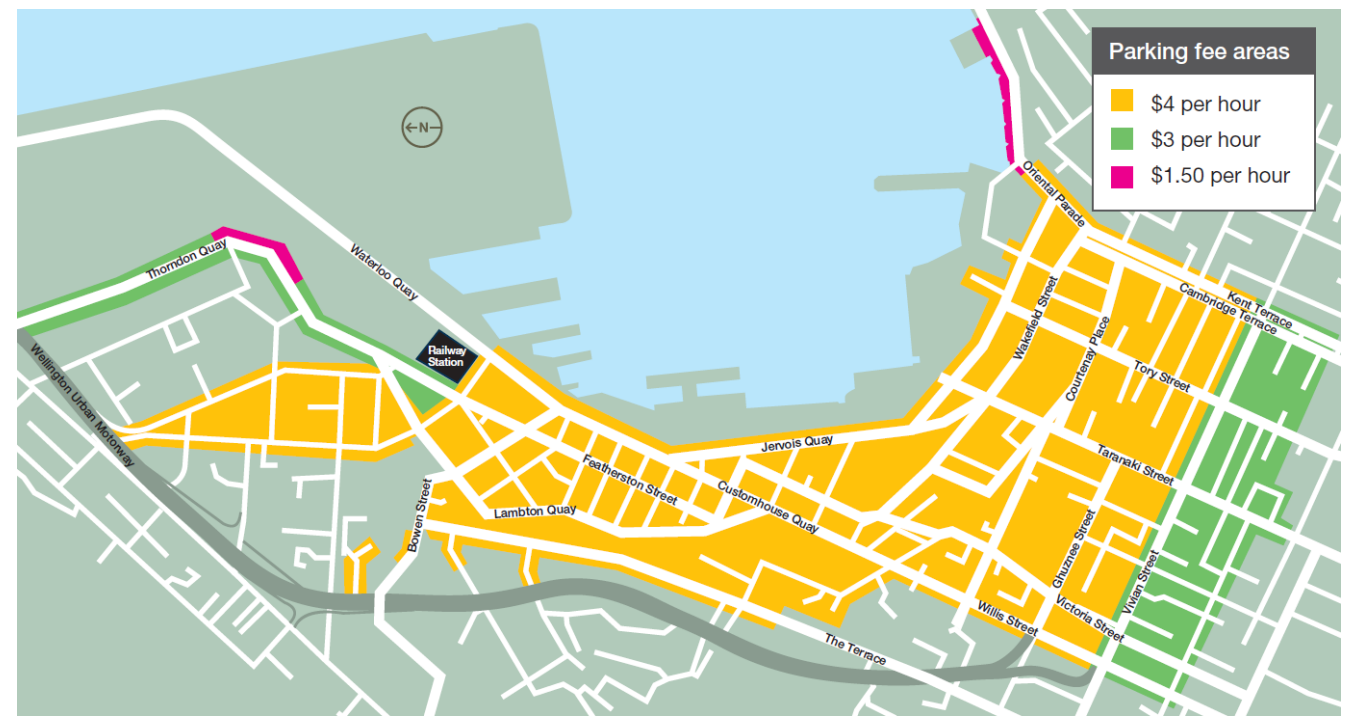

Figure 3. 1 Parking fee areas central city. Source of image: Wellington City Council (2014).

\subsection{Research question}

The main aim of this research is to explore what influences acceptability levels of residents in the Greater Wellington Region in regards to parking 
policy. These residents are the people who live in the area and are most likely to use the parking facilities in the CBD on a regular basis. The central questions of this research are 'what are Wellington region's residents' acceptability levels of parking policies?' and 'what aspect of the policy influences these judgments?'

\subsubsection{Sub-questions}

Six sub-questions have been used to identify factors that could play a part in parking policy acceptability levels (these can be found listed at the end of the previous chapter (Chapter 2: Literature Review)). The sub-questions $a$ and $b$ aim to gather information around current parking policy and how people use the car for transportation at present (these questions form sections 1 and 2 of the survey). Sub-questions $c, d$, e and $f$ aim to gather information about what particular policy measures and personal characteristics contribute to making parking policy more acceptable. These included how people rate the perceive effectiveness and personal consequences of the proposed policy and their personal level of environmental concern (the questions form sections $3,4,5$ and 6 of the survey).

\subsection{Rationale}

This research aims to examine what are the acceptability levels of a range of parking policy to Wellington Region residents' and what factors influence these levels. To get an understanding of how residents in the Wellington Region viewed various parking policies a survey was used to gather quantitative data. As with other research that explores acceptability of transport pricing policies, key variables thought to affect acceptability were examined. A quantitative method was chosen as it allows for variables to be gathered and compared to each other from a large number of participants in a short time frame. In this research the main variables were the policy characteristics of level of fee and revenue use allocation that were chosen to be systematically varied. This was done to identify 
how the overall evaluation of the parking policy differed as these specific characteristics changed.

An online survey was created to capture personal opinions and views related to the six sub-questions about parking from a range of residents in the Wellington Region. A wide range of residents were needed to compile data that could characterise how Greater Wellington Region residents view parking policies. In this case, an anonymous survey was chosen over interviews to allow a larger number of respondents to give answers to a set of predetermined questions. This method also allowed for statistical analysis to be conducted. A between-subjects design was used, and participants were asked to evaluate one of nine policy measures. A minimum of 225 respondents was needed to allow statistical analysis to examine any differences in evaluation between these different policy measures.

A main benefit of online surveys over more traditional paper surveys is cost and efficiency (Bethlehem \& Biffignandi, 2012; Hewson, Yule, Laurent, \& Vogel, 2002). There is little to no cost in covering a large geographic area such as the Greater Wellington Region when surveys are conducted online allowing for a greater reach. There is an additional cost saving in time as data entry is not required (Hewson et al., 2002). Furthermore, there is an increased convenience for respondents as they can complete the survey at a time and place that is convenient to them (Bethlehem \& Biffignandi, 2012).

A disadvantage of online surveys is that it limits the sample to members of the public who are computer literate and have access to the internet. Latest Census data shows that internet access in the Wellington Region is around $81 \%$, which is higher than the general New Zealand population at 77\% (Statistics New Zealand, 2014a). This percentage has been on the rise and is expected to maintain further growth, nearly doubling in amount 
since 2001 (44\%) (Statistics New Zealand, 2014a). Limiting the survey to those with internet access in the Wellington Region no longer excludes the overall majority that it once did. However, online surveys may still introduce selection, in that younger participants may be more likely to respond as they are more used to this type of survey format.

As the surveys are self-selected and self-administered there is the potential for some bias from respondents with a strong interest in the topic, or for respondents to answer in a way that they believe makes them look favourable, but does not reflect their true opinions (Bethlehem \& Biffignandi, 2012; Evans \& Mathur, 2005). This may mean that results are not truly representative of the general public in the Wellington Region. To allow for all residents in the region to have a say, the scope of the survey was not limited to drivers. As land used for parking is public space, it is believed that to be the most democratic to all residents of a specific area, everyone should have the chance to give feedback on how and why this space is used.

\subsection{Survey design}

A self-administered web survey was designed and launched using Qualtrics software. Questions were used to gauge individual opinions, which could be answered either by a set of predefined multi-choice answers or by collecting attitudinal data via a numerical scale (1-7). This was done to allow answers to be comparable. Questions with multi-choice answers had an 'other' option to allow respondents to add an answer that best reflected their personal situation, without being confined to a set of predicted answers. A comment section at the end of the survey gave respondents the chance to add anything they felt was left out of the survey or aspects about parking policy they wanted to clarify or highlight.

The survey was designed in such a way as to account for respondents viewing the survey in different forms due to computer differences and to 
prevent survey fatigue. Ethics approval was granted from Victoria University of Wellington Human Ethics Committee on 7th June 2015 before the research was carried out. This approval can be found in Appendix A1. The survey was designed to be confidential and anonymous at all times. This meant that participants could not be identified personally and only aggregated data (e.g. means, correlations) would be reported. Participants were given this and other information about the survey in a participant information sheet that can be found in Appendix A2. Participants consented to taking the survey by indicating with a tick box that they had read the information provided for participants and that they accepted all conditions at the start of the survey. This can be seen in Appendix A3. Participants who did not consent to take part in the survey were directed to an end of survey message. At the end of the survey respondents were given the option to receive a summary of the research.

A total of 20 questions were created, but respondents were only asked those questions that were relevant to them according to their answers as programmed in to Qualtrics during the design phase of the survey. Participants were guided through the survey according to individual responses to previous questions, with the aim to gather information from each respondent that made sense to their specific situation. For example: 'Do you own/have access to a car?' If they answered yes then the participant was presented with 'How often do you use a car for any purpose?' If there answer was no, then the participant was directed to the next relevant question 'Do you park in Wellington CBD (including as a passenger)?'

Definitions were given at the start of the survey to be clear on what the various concepts and terms used in the survey were referring to, stating that for the purposes of this survey the following definitions would be used: 
- Cars: light four-wheeled vehicles including cars, vans, utes and SUVs (sports utility vehicles).

- Parks: on-road car parking spaces, unless otherwise stated.

\subsection{Pilot survey}

A pilot survey was sent out and completed by 25 people to identify specific issues with both the question format and online layout. The main issue identified was that the original survey asked for feedback on all 9 policy scenarios which took a long time for the respondents to answer, and allowed for ranking of the policies. This was the main area that was reworked for reasons that are discussed in the following survey question section, and to make the length and reading time required during the survey more manageable for the respondents.

Amendments to the pilot survey were also made to include questions and answers appropriate for non-drivers and those people who do not park in the CBD. Other issues that the pilot survey brought up related to those individuals who park in the CBD but not on a regular basis (i.e. once or twice every few months). Answers were modified to allow for these types of situation. Another issue that arose from this pilot study was that mothers highlighted their changes in car use in terms for example of transporting their children. They noted how children had drastically changed their transport patterns creating a rift between what they would like to do and what is practical to do. This was seen as an issue beyond the scope of the survey but is an issue in how parking policy acceptability may change over time. Overall, the survey was simplified and shortened as a result of feedback received.

\subsection{Survey questions}

20 questions were created within six different sections: personal transportation, current car parking in Wellington CBD, specific parking 
policies, revenue allocations, personal characteristics and demographic information. The full survey can be found in Appendix A4.

\subsubsection{Personal transportation}

The first section dealt with questions concerning current personal transportation choices. Seven questions were asked to gauge the current choices respondents make in regards to their daily mode of transportation. Respondents were asked to identify what travel modes they used for the following activities: work/study, recreation/leisure, and shopping.

They were also asked what factors they considered to be important when making transportation choices by ticking any one or more of the following: cost, convenience, reliability, duration, frequency and environmental consideration. Participants were also asked to indicate how often cars were used in their daily travel journeys and asked about their ownership or access to cars. If their answers showed they did have ownership or access to a car, the survey then guided these participants to questions about frequency of car use and how often they would park in the CBD.

From here, if parking in the $\mathrm{CBD}$ did occur, respondents were then asked to identify to what extent they used specific on-road and off-road parking options on a weekly basis and to indicate the average duration of how long they would occupy each type of park.

Within Wellington CBD, there is a variety of on-road and off-road options available for car parking so the different choices people make in where they choose to park needed to be explored. On-road parking is the focus of this study as this is the area that is directly controlled by the WCC and is a key use of public land use in the CBD. Off-road parks do not have the same level of council control once they are built as they are often on private property and owned by private companies. However, off-road parking use 
details were asked for to get to the larger context of where people park in the CBD.

\subsubsection{Current parking policy}

The second section was a question regarding the state of current car parking in Wellington CBD. While the previous section dealt with the physical transportation choices people were making, attitudes towards current parking needed to be further explored.

Opinions about the current state of parking in Wellington CBD were gathered using a series of statements where respondents were asked to rank how strongly they agreed or disagreed with each statement on a scale from 1-7. These statements included the number of parking spaces available, the pricing and location of these parks and whether they consider parking a good use of public space or whether they thought parks would be better utilised by pedestrian or cycling paths.

These statements were recoded during data analyses whereby lower scores (1) showed a negative view towards current parking and high scores (7) showed a positive view to current parking.

\subsubsection{Opinion about parking policies}

The third section comprised questions evaluating nine specific parking policies using a between-subjects design. Each respondent was randomly allocated to one of nine different policy groups that differed in terms of parking fee (3 levels) and revenue use allocation (3 levels). These policies and their specific measures are outlined in Table 3.1. 


\begin{tabular}{|l|l|l|l|}
\hline \multicolumn{3}{|l|}{ Fee } \\
\hline Revenue Use & $\begin{array}{l}\text { \$4 } \\
(\mathrm{N}=103)\end{array}$ & $\begin{array}{l}\text { \$4.50 } \\
(\mathrm{N}=111)\end{array}$ & $\begin{array}{l}\text { \$5 } \\
(\mathrm{N}=105)\end{array}$ \\
\hline $\begin{array}{l}\text { Maintaining road and street } \\
\text { space } \\
(\mathrm{N}=107)\end{array}$ & $\begin{array}{l}\text { Policy 1 } \\
\mathrm{N}=33\end{array}$ & $\begin{array}{l}\text { Policy 2 } \\
\mathrm{N}=37\end{array}$ & $\begin{array}{l}\text { Policy 3 } \\
\mathrm{N}=37\end{array}$ \\
\hline $\begin{array}{l}\text { Improving quality of public } \\
\text { transport (N=109) }\end{array}$ & Policy 4 & Policy 5 & Policy 6 \\
\hline $\begin{array}{l}\text { General Fund } \\
\text { (N=103) }\end{array}$ & $\mathrm{N}=37$ & $\mathrm{~N}=37$ & $\mathrm{~N}=35$ \\
\hline
\end{tabular}

Table 3.13 by 3 between-subject policy design.

For all policies, it was stated that these parks were in the CBD and had a maximum duration of 2 hours. However, the price per hour of these policies was systematically varied and differed in terms of parking fee of $\$ 4.00, \$ 4.50$ or $\$ 5.00$. These fees were chosen as the current price of parking in the CBD is $\$ 4.00$ (with only the outskirts of the CBD being any lower at $\$ 3.00$ or $\$ 1.50)$. This price is unlikely to decrease in the CBD so this was set as the minimum fee level. Higher fees were set to align with previous parking fee increases of between $50 \mathrm{c}$ and $\$ 1$ in recent years.

The use of revenue gathered from these fees was also systematically varied between policies. Three different types of revenue allocations were specified to describe where the money gained from the policy would go. The revenue use was either allocated to maintaining road and street space, improving the quality of public transport or the general public fund. These revenue allocations were chosen to reflect a benefit for car users (maintaining road and street space), a benefit for the general public (who may or may not be the park users but may benefit from improving the quality of public transport) and an undefined benefit going towards a general public find.

Each respondent was randomly assigned to receive one of the nine policy scenarios (in Table 3.1) and were then asked three questions: how acceptable they found the parking policy (1-very unacceptable to 7-very 
acceptable), how effective they see the parking policy to be in reducing car traffic and congestion into and within Wellington CBD (1-very ineffective to 7- very effective), and how this policy would impact them personally (1very negatively to 7-very positively). Only one policy was shown to each respondent so that they could not compare the policies. If all nine scenarios were shown then all prices and revenue allocations would be seen by the respondent, allowing them to rank their preferences.

It is hypothesised that the highest levels of acceptability will be gained from parking policies that have the lowest fee level and have revenue allocated in a way that is most beneficial for the respondent. For a driver this would mean lowering the costs associated with car use or revenue allocated towards maintaining the road. For those respondents who do not drive, improving public transport is thought to have higher acceptability levels.

\subsubsection{Revenue use in pricing policies}

The fourth section asked respondents to give their opinion as to how acceptable they thought different types of revenue allocation from an unspecified pricing policy are on a seven-point scale (1-very unacceptable to 7-very acceptable). A specific pricing policy was not specified in order to see if levels of acceptability changed when what was at issue was not a pricing policy that specifically targeted car users. As there are many possibilities as to where revenue may be allocated, further options were given in addition to the revenue uses selected for the parking policy scenarios. The respondents were asked to identify how acceptable they found revenue use from pricing policies if money was allocated to benefiting individual car users (construct new roads, decrease fuel costs, decrease car registration costs), benefiting the general public (improve the quality of public or active transportation and its infrastructure) or going towards a general fund. 


\subsubsection{Environmental awareness and concern}

The fifth section aimed to uncover some personal characteristics about the respondents. This included their attitude towards cars, level of environmental concern and their level of understanding about the relationship between cars and the environment.

The first series of statements asked respondents to identify on a sevenpoint scale if they agreed or disagreed with nine statements (1-strongly disagree to 7-strongly agree) to gauge their perception of cars. These were recoded during data analyses so the lower the score the less positive they were about cars (1), while the higher the scores (7) the more positive their view on cars.

To gauge 'environmental awareness' each respondent was given the 15 statements from the New Ecological Paradigm (NEP) Scale as revised by Dunlap, Van Liere, Mertig, and Jones (2000) from the original NEP Scale (Dunlap \& Van Liere, 1978). The NEP Scale is now one of the most widely used measure of environmental concern and has been used across many nations for over 30 years (Dunlap, 2008). During data analyses the scores were recoded using the seven-point scale so that the lower the number (1) the less environmentally aware the respondent was and the higher the number (7) the more environmentally aware the respondent was.

A series of six statements were also given to gauge understanding of how respondents view the relationship between cars and their impacts on the environment on a seven-point scale. During data analyses the scores were recoded to show the lower the number (1) the less the respondent saw a strong relationship between car use and environmental impacts and the higher the number (7) the more the respondent saw there was a relationship. 
All of the nine parking policies are hypothesised to have higher levels of acceptability among those who have higher levels of environmental concern. Previous research suggests that acceptability of policies that benefit the environment is generally higher among people who are aware of, and concerned about, environmental problems (Eriksson et al., 2006; Schuitema \& Jakobsson Berstad, 2012). Therefore, a high level of environmental concern may mean that these individuals are more willing to accept a policy that may create a cost for them at an individual level, but will help in resolving an environmental issue.

\subsubsection{Socio-demographic information}

The last section asked a series of socioeconomic questions to gather an idea of the demography of the respondents to see if the sample represented an average Wellington Region resident by asking for gender, age, suburb of residence, ethnicity, employment status and income. This section also included a general comment box to bring up other concerns or issues that were not brought up in the survey.

\subsection{Recruitment method}

A voluntary self-selection recruitment method was used whereby the invitation to complete the survey was open (Manfreda \& Vehovar, 2008). Recruitment was done via a link on social media (Facebook) which was posted on various private and public pages. Links to the survey were also sent by email to contacts at Victoria University, Wellington City Council and Greater Wellington Regional Council. A snowball sampling strategy was used whereby people who received the email with the link to the survey were asked to forward it on to other potential participants. The survey was open from 25 June 2014 to 12 August 2014.

\subsection{Responses and sample characteristics}

Due to the method of distribution and survey type being self-selected it was hard to gauge a non-response rate. The Qualtrics report of those who 
started and completed the survey was given of the 404 who started the survey. Of these, 385 responses were deemed usable after deleting data of 19 participants who had not completed over $50 \%$ of the questions or who had completed the survey in less than five minutes. A total of 332 of responses were complete and these were used in the final data analysis. IP addresses were checked for double entries but none were detected. To maintain confidentiality the IP addresses were then deleted.

None of the respondents' answers to where they lived placed them outside the Greater Wellington Region, though answers were not recorded for 90 cases. The suburbs of the Southern Ward had the most respondents (24.1\%), followed by Lambton Ward (22.1\%), Eastern Ward (16.3\%), Western Ward (12.6\%), Northern Ward (11.2\%), Lower Hutt (6.8\%), Porirua (2.4\%), Upper Hutt (2\%), South Wairarapa (1.4\%) and Kapiti Coast (1\%).

Socioeconomic questions were asked to gather information about income, age and gender of the sample of participants taking part in the survey. The overall frequency results could then be compared with the Wellington Region data from the 2013 Census (Statistics New Zealand, 2014a). Of the respondents, $45.2 \%$ were male and $54.8 \%$ female. This was broadly in line with 2013 Census data where males accounted for $48 \%$ of the population in the Wellington Region and females 52\% (Statistics New Zealand, 2014a).

\begin{tabular}{|l|l|l|}
\hline Age Group & Survey (percentage) & $\begin{array}{l}2013 \text { Census } \\
\text { (percentage) }\end{array}$ \\
\hline $18-24$ & $10.3 \%$ & $10.2 \%$ \\
\hline $25-34$ & $24.8 \%$ & $17.7 \%$ \\
\hline $35-44$ & $24.5 \%$ & $19.5 \%$ \\
\hline $45-54$ & $20.5 \%$ & $19.4 \%$ \\
\hline $55-64$ & $15.2 \%$ & $14.9 \%$ \\
\hline $65+$ & $4.6 \%$ & $17.9 \%$ \\
\hline
\end{tabular}

Table 3. 2 Comparison of age groups between survey respondents and the 2013 Census data for the Wellington Region.

Table 3.2 shows the age group percentage comparisons between survey respondents and latest Census data. The most frequent respondent was in 
the age group, $25-34$, followed by $35-44$ (24.5\%), and $45-54$ (20.5\%).

Excluding the data for the under 19s, the 2013 Census data showed a similar average spread over the age groups with the median respondent was in the 25-34 age group in the survey and the 35-44 age group in the Census. The largest inconsistency was the smaller percentage of the over 65 age group in the survey. As this was an online survey, this may have something to do with lower levels of technological abilities or equipment in this older age group (as note in the rationale).

\begin{tabular}{|l|l|l|}
\hline Ethnicity & $\begin{array}{l}\text { Survey } \\
\text { (percentage) }\end{array}$ & $\begin{array}{l}2013 \text { Census } \\
\text { (percentage) }\end{array}$ \\
\hline European & $78.7 \%$ & $79.6 \%$ \\
\hline Māori & $4.3 \%$ & $13.0 \%$ \\
\hline Asian & $2.7 \%$ & $10.5 \%$ \\
\hline Pacific Peoples & $2.0 \%$ & $8.0 \%$ \\
\hline $\begin{array}{l}\text { Middle Eastern/Latin } \\
\text { American/ African }\end{array}$ & $1.3 \%$ & $1.4 \%$ \\
\hline Other & $11 \%$ & $1.8 \%$ \\
\hline
\end{tabular}

Table 3. 3 Comparison of ethnicity between survey respondents and the 2013 Census data for the Wellington Region.

Table 3.3 shows ethnicity percentage comparisons between survey respondents and latest Census data. The typical respondent was European (78.7\%), followed by 'other' (11\%). The 2013 Census data shows a similar percentage $(76.9 \%)$ of those in the Wellington Region identified with a European ethnicity. A higher percentage identified as Māori, Asian and Pacific People in the Census data, but a lower percentage identified as 'other (1.8\%) (Statistics New Zealand, 2014a). Comments at the end of the survey suggest some of these are respondents who identified as 'other' preferred to identify as 'New Zealanders' or 'New Zealand Pakeha'. Of those respondents who identified as 'other' in the Census, $97.2 \%$ identified 'New Zealander' as their ethnicity (Statistics New Zealand, 2014a). 


\begin{tabular}{|c|c|c|c|c|c|}
\hline Employment & $\begin{array}{l}\text { Survey } \\
\text { (percentage) }\end{array}$ & $\begin{array}{l}2013 \text { Census } \\
\text { (percentage) }\end{array}$ & $\begin{array}{l}\text { Income per } \\
\text { year }\end{array}$ & $\begin{array}{l}\text { Survey } \\
\text { (percentage) }\end{array}$ & $\begin{array}{l}2013 \text { Census } \\
\text { (percentage) }\end{array}$ \\
\hline $\begin{array}{l}\text { Total } \\
\text { employed }\end{array}$ & $79.2 \%$ & $64.9 \%$ & $\begin{array}{l}0- \\
\$ 20,000\end{array}$ & $16.6 \%$ & $34.8 \%$ \\
\hline $\begin{array}{l}\cdot \text { Full time } \\
\text {-Part time } \\
\text {-Self- } \\
\text { employed }\end{array}$ & $\begin{array}{l}60.4 \% \\
7.9 \% \\
10.9 \%\end{array}$ & $\begin{array}{l}\text { N/A } \\
N / A \\
N / A\end{array}$ & $\begin{array}{l}\$ 20,001- \\
\$ 50,000\end{array}$ & $17.3 \%$ & $32.4 \%$ \\
\hline Unemployed & $1.3 \%$ & $5.0 \%$ & $\begin{array}{l}\$ 50,001- \\
\$ 70,000\end{array}$ & $20.1 \%$ & $13.6 \%$ \\
\hline $\begin{array}{l}\text { Total not in } \\
\text { labour force }\end{array}$ & $19.5 \%$ & $30.0 \%$ & $\begin{array}{l}\$ 70,001- \\
\$ 100,000\end{array}$ & $22.1 \%$ & $9.8 \%$ \\
\hline $\begin{array}{l}\text {-Tertiary } \\
\text { student } \\
\text { - Retired }\end{array}$ & $\begin{array}{l}16.2 \% \\
3.3 \%\end{array}$ & $\begin{array}{l}\text { N/A } \\
\text { N/A }\end{array}$ & $\$ 100,000+$ & $23.9 \%$ & $9.2 \%$ \\
\hline
\end{tabular}

Table 3. 4 Comparison of employment and income between survey respondents and the 2013 Census data for the Wellington Region.

Table 3.4 shows employment and income percentage comparisons between survey respondents and latest Census. The most frequent respondent is employed (79.2\%) which is higher than the Wellington Region figure of $64.9 \%$ (Statistics New Zealand, 2014a). Respondents also had a higher proportion with income over $\$ 100,000$ a year $(23.9 \%)$ than Census data states (9.2\%). This may mean that the average respondent who took part in the survey was in higher paid employment than the general population in the Wellington Region. This could be in part due to the recruitment strategy that targeted local councils and universities.

Overall while the sample is representative in terms of gender, it is not representative in terms of income and age when compared to the Wellington Region 2013 socioeconomic census data. Therefore, these results cannot be generalised to the wider Wellington population.

\subsection{Analysis of online survey data}

The software package SPSS was used to analyse the responses in the data. A codebook was created in SPSS from the data recorded by Qualtrics. Data that was analysed was only from those respondents who had a sufficient number of answered questions (over 50\%). Missing data was then excluded 
pairwise in the analysis on a per question basis. Therefore when a respondent had chosen not to answer a question, the missing answer was excluded from analysis of that question only. The variable validity and reliability of the models were checked using SPSS and are reported in the results section. Questions were recoded where necessary and as described in the method to allow for overall mean scores to be recorded for certain questions and to aid in analysing results. 


\section{Chapter 4: Results}

In this section, the main findings of the survey will be discussed. First, correlational analyses were conducted to examine the relationships between the main variables of interest, such as policy acceptability, perceived effectiveness and environmental concern. Then, to examine differences between the different policy measures, ANOVAs were conducted. Finally, comments by participants (open-ended questions) about parking policies are also reported.

\subsection{Current parking mechanisms and policy in the CBD}

The first part of the survey asked respondents about their opinions regarding current practice for CBD parking. Six statements were used to gauge how positively or negatively respondents viewed current CBD parking policies on a seven-point scale (1-strongly disagree to 7-strongly agree). The percentages of each response were then added to come to an overall percentage of either disagreement (strongly disagree, disagree, somewhat disagree) or agreement (strongly agree, agree, somewhat agree) with the statement. There was also a 'neither agree nor disagree' category to allow for a "neutral" answering option.

The majority of respondents somewhat agreed, agreed or strongly agreed that there are sufficient parking spaces in Wellington CBD $(50.7 \%)$, that onroad parking spaces would be better utilised by cycleways $(55.3 \%)$ and that parking is available close to destinations in Wellington CBD (63.5\%).

Respondents generally somewhat disagreed, disagreed or strongly disagreed that car parks are a good use of public space $(45.8 \%)$ that onroad parking spaces would be better utilised by pedestrian paths $(47.8 \%)$, and that parking spaces are reasonably priced (51.8\%). These results show that respondents have both positive and negative views about parking in the $\mathrm{CBD}$ under current policies. 


\subsection{Reasons for parking in the CBD}

The survey was open to all residents of the Greater Wellington Region with $88.7 \%$ of respondents identifying that they owned or had access to a car. This is in line with the 2013 Census of $88.3 \%$ of household having access to a motor vehicle (Statistics New Zealand, 2014a). Of these respondents, $45 \%$ reported using a car daily, and another $31.6 \%$ reported using a car several times a week. Overall, $90 \%$ of those with access to a car reported using it at least once a week.

When respondents were asked to indicate how important six given factors (environmental consideration, cost, duration of journey, frequency of service, convenience and reliability) are when making transport choices on a seven-point scale (1-not at all important to 7-extremely important), all factors were shown to have some importance overall. Environmental consideration was given the least importance $(M=4.88)$, followed by cost $(M=4.98)$. Duration of journey was seen as somewhat important $(M=5.34)$, as was frequency of service $(M=5.54)$. Convenience and reliability were considered the most important factors when making transport choices with the highest equal means of 5.88 .

Respondents' use of different transportation modes was also explored in the survey. For mode of transportation to work and study, cars were used the most by respondents (34.4\%), followed by bicycles (24.8\%). In journeys for leisure and recreation, cars are used by $54.1 \%$ of the respondents, followed by bicycles at $20.5 \%$. Car use increases to $71.8 \%$ of respondents when shopping, followed by walking or running at $13.3 \%$.

72.3\% of all respondents park in the Wellington CBD, including those who do so as passengers. Of these respondents, weekday parking behaviours at 'on-road' facilities are as follows:

- $53.2 \%$ use pay-and-display zones at least once a week. Of these respondents $60.7 \%$ park in these zones for less than 2 hours. 
- $14 \%$ use coupon zones at least once a week. Of these respondents $50.9 \%$ park in these zones for less than 2 hours.

- $\quad 9.9 \%$ use residents' zones at least once a week. Of these respondents $74 \%$ park in these zones for more than 6 hours.

Respondents' weekday parking behaviour at 'off-road' facilities are as follows:

- $48.4 \%$ use shop parking areas at least once a week. Of these respondents $81.3 \%$ park in these zones for less than 2 hours.

- $32.7 \%$ use a parking building at least once a week. Of these respondents 39.1\% park in these zones for more than 6 hours.

- $25.1 \%$ use a private residence at least once a week. Of these respondents $69.6 \%$ park in these zones for more than 6 hours.

- $19.2 \%$ use private company park at least once a week. Of these respondents $66 \%$ park in these zones for more than 6 hours.

Based on this, it appears that most commonly used on-road car parks are pay-and-display zones used for less than two hours. This is the type of parking that this survey was targeting. The most common form of off-road parking was in shop parking areas for less than two hours.

\subsection{Correlational analyses of acceptability and other variables}

To examine the relationships between the variables, Spearman's correlation coefficient was calculated. Acceptability, perceived effectiveness and perceived consequence (impact) data for parking policies were all found to have a non-normal distribution, as became apparent in both Kolmogorov-Smirnov and Shapiro-Wilk statistics with $p<.05$. However, the Spearman's rho coefficient $(S R)$ was used for correlation statistics because it is relatively robust to violations of the distributional assumption of normality of the data (Field, 2000). Table 4.1 represents an overview of 
the eight main variables and the corresponding correlation with each of the other variables.

\begin{tabular}{|c|c|c|c|c|c|c|c|c|c|}
\hline & & 1 & 2 & 3 & 4 & 5 & 6 & 7 & 8 \\
\hline $\begin{array}{l}\text { Acceptability } \\
\text { (1) }\end{array}$ & $\begin{array}{l}S R \\
N\end{array}$ & $\begin{array}{r}1.000 \\
319\end{array}$ & & & & & & & \\
\hline $\begin{array}{l}\text { Effectiveness } \\
(2)\end{array}$ & $\begin{array}{l}S R \\
N\end{array}$ & $\begin{array}{r}.341^{* *} \\
316\end{array}$ & $\begin{array}{r}1.000 \\
316\end{array}$ & & & & & & \\
\hline $\begin{array}{l}\text { Consequence } \\
\text { (3) }\end{array}$ & $\begin{array}{l}S R \\
N\end{array}$ & $\begin{array}{r}.623^{* *} \\
317\end{array}$ & $\begin{array}{r}.347^{* *} \\
314\end{array}$ & \begin{tabular}{r|}
1.000 \\
317
\end{tabular} & & & & & \\
\hline $\begin{array}{l}\text { Fee } \\
(4)\end{array}$ & $\begin{array}{l}S R \\
N\end{array}$ & $\begin{array}{r}-.229^{* *} \\
319 \\
\end{array}$ & $\begin{array}{r}.024 \\
316 \\
\end{array}$ & $\begin{array}{r}-.117^{*} \\
317\end{array}$ & $\begin{array}{r}1.000 \\
319 \\
\end{array}$ & & & & \\
\hline $\begin{array}{l}\text { Revenue use } \\
\text { (5) }\end{array}$ & $\begin{array}{l}S R \\
N\end{array}$ & $\begin{array}{r}-.107 \\
319\end{array}$ & $\begin{array}{r}-.102 \\
316\end{array}$ & $\begin{array}{r}-.088 \\
317\end{array}$ & $\begin{array}{r}-.019 \\
319\end{array}$ & $\begin{array}{r}1.000 \\
319\end{array}$ & & & \\
\hline $\begin{array}{l}\text { Car opinion } \\
\text { (6) }\end{array}$ & $\begin{array}{l}S R \\
N\end{array}$ & $\begin{array}{r}-.371^{* *} \\
307\end{array}$ & $\begin{array}{r}-.167^{* *} \\
304\end{array}$ & $\begin{array}{r}-.388^{* *} \\
305\end{array}$ & $\begin{array}{r}.020 \\
307\end{array}$ & $\begin{array}{r}.008 \\
307\end{array}$ & $\begin{array}{r}1.000 \\
308\end{array}$ & & \\
\hline $\begin{array}{l}\text { NEP } \\
(7)\end{array}$ & $\begin{array}{l}S R \\
N\end{array}$ & $\begin{array}{r}.186^{* *} \\
294\end{array}$ & $\begin{array}{l}.073 \\
292\end{array}$ & $\begin{array}{r}.211^{* *} \\
294\end{array}$ & $\begin{array}{l}.033 \\
294 \\
\end{array}$ & $\begin{array}{l}.086 \\
294\end{array}$ & \begin{tabular}{|r|}
$-.409^{* *}$ \\
290
\end{tabular} & $\begin{array}{r}1.000 \\
295\end{array}$ & \\
\hline $\begin{array}{l}\text { Environmental } \\
\text { consequence } \\
\text { (8) }\end{array}$ & $\begin{array}{l}S R \\
N\end{array}$ & $\begin{array}{l}.336^{* *} \\
301\end{array}$ & $\begin{array}{r}.199^{* *} \\
299\end{array}$ & $\begin{array}{r}.356^{* *} \\
300\end{array}$ & $\begin{array}{l}.035 \\
301\end{array}$ & $\begin{array}{l}.093 \\
301\end{array}$ & $\begin{array}{r}-.648^{* *} \\
296\end{array}$ & $\begin{array}{r}.575^{* *} \\
292\end{array}$ & $\begin{array}{r}1.000 \\
302\end{array}$ \\
\hline
\end{tabular}

${ }^{* *}$ Correlation is significant at the 0.01 level (2-tailed).

*Correlation is significant at the 0.05 level (2-tailed).

Table 4. 1 Correlational statistics between eight variables. SR=Spearman's rho, $\mathrm{N}=$ number of participants. The scale for fee runs from 1 (low) to 3(high); revenue use runs from 1 (direct benefit to user) to 3(indirect benefit to user); All other scales run from 1 (negative) to 7 (positive).

As acceptability is the focus of this research, the relationships between acceptability and the seven other variables of interest are described below.

\subsubsection{Acceptability and perceived effects}

There was a positive correlation between policy acceptability and perceived effectiveness $(r=.34, p<.001)$. This means that as participants perceived that measures would be more effective in reaching the aim of the policy to reduce traffic congestion in and around Wellington CBD, acceptability levels of a measure increased. A positive correlation was found between policy acceptability and perceived consequence $(r=.62$, $p<.001)$. There was also a positive correlation between perceived 
effectiveness and perceived consequence $(r=.35, p<.001)$. This means that as acceptability or effectiveness levels of a policy increased, participants also perceived that it would result in more positive outcomes for them personally.

\subsubsection{Acceptability and policy measures}

There was a negative correlation between policy acceptability and the amount of the parking fee $(r=-.23, p<.001)$. Likewise, there was a negative correlation between the level of parking fee and the perceived consequences from the policy from the respondent $(r=-.12, p<.005)$. This means that acceptability levels and perceived positive consequences of the policy increased when there was a reduction in fee. No correlation was found between acceptability levels and revenue use.

\subsubsection{Acceptability and environmental concern}

There is a negative correlation between policy acceptability and opinions about car use $(r=-.37, p<.001)$. This means that participants with a more positive opinion about car use were less likely to find parking policies acceptable. A positive correlation was seen between acceptability of a policy and the NEP score $(r=.19, p<.001)$ and awareness of the environmental consequences of car use $(r=.34, p<.001)$. So, it appears that acceptability levels increase as participants' levels of environmental understanding and concern increase.

Likewise, perceived consequence of the policy showed similar results. Participants with more negative opinions about car use tended to perceive there would be more positive outcomes from the policy $(r=-.39, p<.001)$. Higher levels of environmental understanding in NEP $(r=.21, p<.001)$ and environmental consequences of car use $(r=.36, p<.001)$ scores were also positively correlated to perceived effectiveness of parking policies. 
There was a negative correlation between perceived effectiveness and people's opinion about car use $(r=-.17, p<.001)$. This means that participants with more negative views towards car use tended to perceive parking policies as more effective. Similarly, there was a positive correlation between perceived effectiveness and environmental consequences of car use $(r=.20, p<.001)$. This means that as participants' score of the environmental consequences of car use increases their perception of levels of policy effectiveness also increases.

Among the three variables used to measure environmental concern, correlations were also observed. There was a negative correlation between car opinion and both NEP $(r=-.41, p<.001)$ and environmental consequences of car use $(r=-.65, p<.001)$. This showed that respondents who had a negative opinion about cars had higher levels of environmental concern. Those respondents who had higher NEP scores also showed higher scores for environmental consequences of car use, as can be seen from the positive relationship $(r=.58, p<.001)$.

\subsection{Acceptability levels to the public of a range of parking policies}

Table 4.2 defines the parking fee and revenue use for each of the nine different policies. The study used a between-subjects design and each respondent was shown only one policy, chosen at random.

\begin{tabular}{|l|l|l|}
\hline Policy number & Fee & Revenue Use \\
\hline 1 & $\$ 4.00$ & Maintaining road and street space \\
\hline 2 & $\$ 4.50$ & Maintaining road and street space \\
\hline 3 & $\$ 5.00$ & Maintaining road and street space \\
\hline 4 & $\$ 4.00$ & Improving quality of public transport \\
\hline 5 & $\$ 4.50$ & Improving quality of public transport \\
\hline 6 & $\$ 5.00$ & Improving quality of public transport \\
\hline 7 & $\$ 4.00$ & General fund \\
\hline 8 & $\$ 4.50$ & General fund \\
\hline 9 & $\$ 5.00$ & General fund \\
\hline
\end{tabular}

Table 4. 2 Policy description of fee and revenue use. 


\subsubsection{Overall acceptability}

Table 4.3 reports the mean scores of acceptability levels that respondents gave to the nine policies, using a seven-point scale (1-very unacceptable to 7-very acceptable).

\begin{tabular}{|l|l|l|l|}
\hline Policy number & Mean & $\begin{array}{l}\text { Standard } \\
\text { Error }\end{array}$ & $\begin{array}{l}\text { Ranking of most } \\
\text { acceptable }\end{array}$ \\
\hline 1 & 5.06 & 0.23 & 2 \\
\hline 2 & 4.94 & 0.27 & 3 \\
\hline 3 & 4.45 & 0.27 & 6 \\
\hline 4 & 5.56 & 0.24 & 1 \\
\hline 5 & 4.75 & 0.24 & 5 \\
\hline 6 & 3.88 & 0.33 & 9 \\
\hline 7 & 4.78 & 0.24 & 4 \\
\hline 8 & 4.24 & 0.29 & 7 \\
\hline 9 & 4.00 & 0.31 & 8 \\
\hline
\end{tabular}

Table 4. 3 Mean acceptability of policy by policy number.

The most acceptable policy overall is policy 4 (\$4/improving quality of public transport) with a mean of 5.56 (somewhat acceptable), while the least acceptable policy overall is policy 6 (\$5/improving quality of public transport) with a mean of 3.88 (somewhat unacceptable). A one-way ANOVA $^{1}$ revealed a significant effect of policy number on acceptability of the parking policy $(F(8,310)=3.84, p=.0002)$. The F-ratio for the linear trend is significant $(F(1,317)=11.0, p=.001)$.

The Games-Howell procedure ${ }^{2}$ showed a significant difference $(p<.05)$ between policy $4(M=5.56)$ and policies $6(M=3.88), 8(M=4.24)$, and 9 $(M=4.00)$. This suggest that policy 4 (\$4/improving quality of public

\footnotetext{
${ }^{1}$ Non-parametric tests were also used to account for the lack of normal distribution, but the results were similar.

${ }^{2}$ The Levene Statistic (2.16) had a significance $p<.05$, so the homogeneity of variance was violated. Therefore the Brown-Forsyth F-ratio $(F(8,291.9)=3.85, p<.001)$ and Welch F$\operatorname{ratio}(F(8,128.7)=3.63, p=.001)$ are also reported.
} 
transport) is considered by participants as being significantly more acceptable than policies 6 ( $\$ 5 /$ improving quality of public transport), 8 ( $\$ 4.50 /$ general fund), and 9 ( $\$ 5 /$ general fund). This can be seen in Figure 4.1, which displays the average score for each policy.

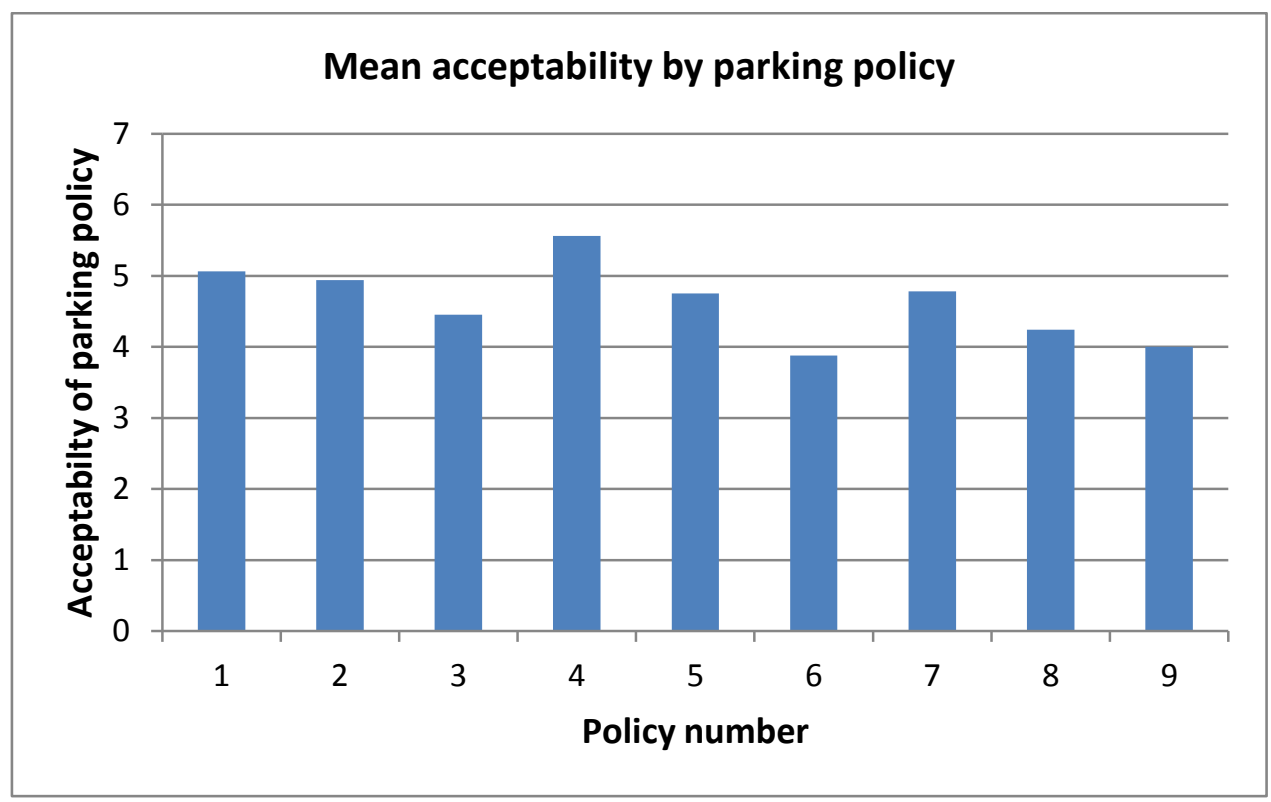

Figure 4. 1 Mean acceptability of policy by policy number.

No significant difference was found between acceptability levels among those who drove or had access to a car $(M=4.60)$ and those who did not $(M=5.00)$. However, a small difference can be observed in overall acceptability levels being slightly higher among those people who did not drive with a smaller range of higher acceptability levels from 3-7, than those respondents who did drive and had a bigger spread of acceptability levels from 1-7.

In relation to the research question, it does appear that acceptability levels were significantly different amongst the nine parking policies. To examine which aspects of the policy were influential in these differences, the effect of level of parking fee and type of revenue use allocation will be explored below 


\subsubsection{Acceptability by fee}

Table 4.4 reports the mean score of acceptability that respondents gave, as categorised by the three different parking fees, using a seven-point scale (1-very unacceptable to 7-very acceptable).

\begin{tabular}{|l|l|l|l|}
\hline Fee & Mean & $\begin{array}{l}\text { Standard } \\
\text { Error }\end{array}$ & $\begin{array}{l}\text { Ranking of most } \\
\text { acceptable }\end{array}$ \\
\hline$\$ 4.00$ & 5.15 & 0.14 & 1 \\
\hline$\$ 4.50$ & 4.68 & 0.15 & 2 \\
\hline$\$ 5.00$ & 4.12 & 0.177 & 3 \\
\hline
\end{tabular}

Table 4. 4 Mean acceptability of policy by fee.

The most acceptable fee overall is $\$ 4$ with a mean of 5.15 (somewhat acceptable), while the fee of $\$ 5$ was ranked the least acceptable overall with a mean of 4.12 (neither acceptable nor unacceptable). A one-way ANOVA $^{3}$ revealed a significant effect of fee on acceptability of the parking policy $(F(2,316)=10.14, p<.001))$. There is a significant linear trend $(F(1,317)=20.28, p<.001)$, indicating that as the parking fee increased, acceptability of the policy decreased proportionately.

The Games-Howell procedure ${ }^{4}$ showed a significance between $\$ 4$ and $\$ 4.50$, and $\$ 4$ and $\$ 5(p<.005)$. This shows that there is significant association between fee amount and acceptability level. When the fee is low $(\$ 4)$ there is a higher level of acceptability for the policy, while higher fees $(\$ 4.50 / \$ 5)$ have lower levels of acceptability. There is however, no significant difference between the two higher fees $(\$ 4.50 / \$ 5)$. This can be seen in Figure 4.2.

\footnotetext{
${ }^{3}$ Non-parametric tests were also used to account for the lack of normal distribution, but the results were similar.

${ }^{4}$ The Levene Statistic (5.51) had a significance $p<.05$, so the homogeneity of variance was violated. Therefore the Brown-Forsyth F-ratio $(F(2,305.57)=10.17, p<.001)$ and Welch F$\operatorname{ratio}(F(2,208.98)=10.43, p<.001)$ are also reported.
} 


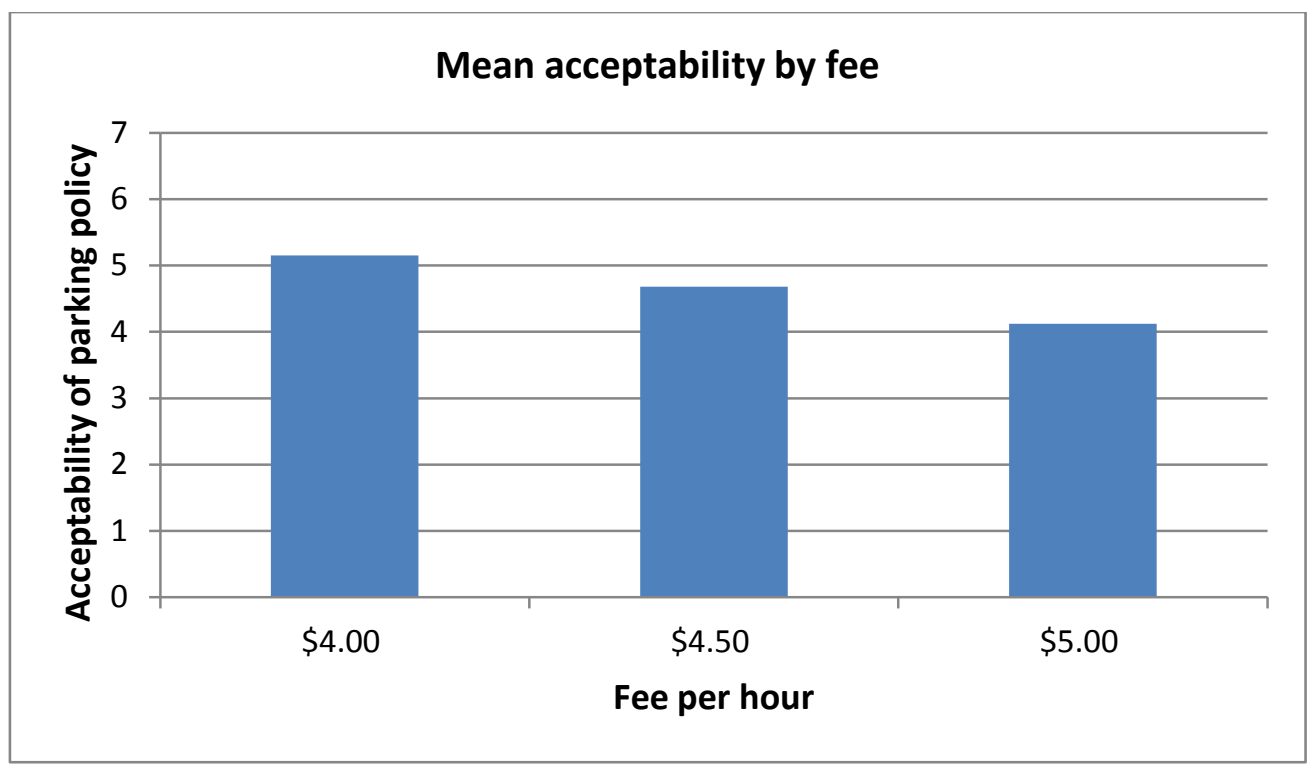

Figure 4. 2 Mean acceptability of policy by fee

In relation to the research question, it does appear that acceptability levels were significantly different amongst the three fee levels. The effect of revenue use will be explored next.

\subsubsection{Acceptability by revenue use}

Table 4.5 reports the mean score of acceptability that respondents gave, as categorised by the three different types of revenue use, using a sevenpoint scale (1-very unacceptable to 7-very acceptable).

\begin{tabular}{|l|l|l|l|}
\hline Revenue use & Mean & $\begin{array}{l}\text { Standard } \\
\text { Error }\end{array}$ & $\begin{array}{l}\text { Ranking of most } \\
\text { acceptable }\end{array}$ \\
\hline $\begin{array}{l}\text { Maintaining road } \\
\text { and street space }\end{array}$ & 4.81 & 0.15 & 1 \\
\hline $\begin{array}{l}\text { Improving quality of } \\
\text { public transport }\end{array}$ & 4.75 & 0.17 & 2 \\
\hline General fund & 4.33 & 0.16 & 3 \\
\hline
\end{tabular}

Table 4. 5 Mean acceptability of policy by revenue use.

Overall, all types of revenue use allocation were considered by participants to be neither acceptable nor unacceptable with means of around 4 . The most acceptable type of revenue use allocation overall was maintaining road and street space with a mean of 4.81 (neither acceptable nor unacceptable), while the least acceptable type of revenue overall was the 
general fund with a mean of 4.33 (neither acceptable nor unacceptable). A one-way ANOVA ${ }^{5}$ revealed no significant effect of revenue use on acceptability of the parking policy. This suggests that the type of revenue use did not appear to affect acceptability levels of parking policies.

Comparison tests also showed no significant association between the three types of revenue use and acceptability. However, these comparisons did show a significant linear trend $(F(1,317)=4.07, p<.05)$. This means that while there was no significant difference between the means of the three types of revenue use, there is a linear trend. This trend suggests that maintaining road and street space is the most acceptable form of revenue use, followed by improving quality of public transport, then the general fund. This can be seen in Figure 4.3.

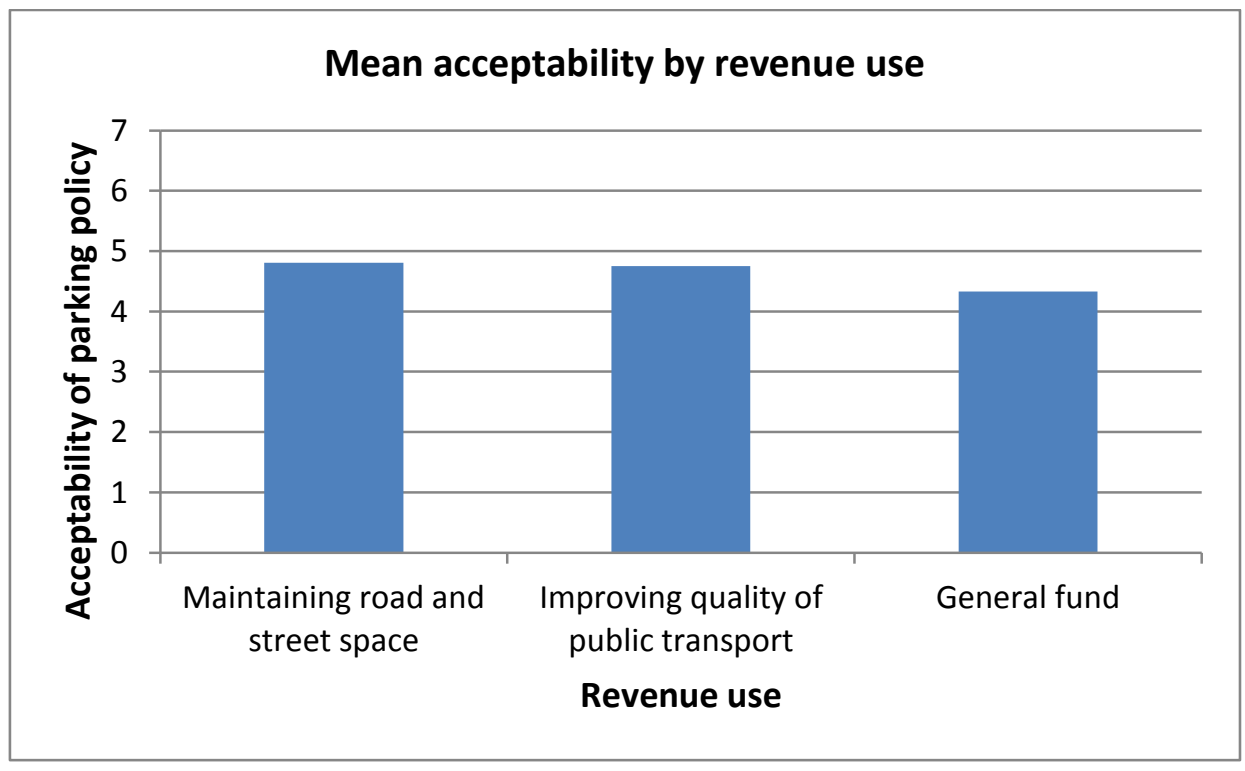

Figure 4. 3 Mean acceptability of policy by revenue use.

Other types of revenue use were then explored. Respondents were presented with the statement that the government is able to allocate the revenues of pricing policies in various ways. They were asked to identify how acceptable they found six specific allocations of the revenue from a general pricing policy, on a seven-point scale (1-very unacceptable to 7-

\footnotetext{
${ }^{5}$ Non-parametric tests were also used to account for the lack of normal distribution, but the results were similar.
} 
very acceptable). This question allowed respondents to view various types of revenue use and then rank their acceptability level for each type accordingly. This question did not restrict respondents' wider views of what they think public money should be spend on as the policy was away from the specific parking context.

Improving the quality of public transport was considered the most acceptable type of revenue use $(M=6.18, S D=0.99)$, followed by improving the quality of active transportation infrastructure $(M=6.09, S D=1.12)$. Allocating the revenue to general funds $(M=4.41, S D=1.60)$ and constructing new roads $(M=4.07, S D=1.86)$ were seen as neither unacceptable nor acceptable forms of revenue use. Decreasing car registration costs $(M=3.86, S D=1.92)$ and decreasing fuel costs $(M=3.6$, $S D=2.11$ ) were seen as somewhat unacceptable forms of revenue use.

Mauchly's test indicated that the assumption of sphericity had been violated $\left(x^{2}(14)=553.48, p<.001\right)$, therefore degrees of freedom was corrected using Greenhouse-Geisser estimates of sphericity $(\varepsilon=.55)$. Using ANOVA with repeated measures with a Greenhouse-Geisser correction, the mean scores for acceptability of revenue use were significantly different $(F(2.76,840.10)=163.00, p<.001)$. Post hoc tests using the Bonferroni correction revealed differences in acceptability levels $(p<.05)$.

Revenue use allocated for the general public fund was found to be significantly more acceptable than decreasing both car registration or fuel costs. However, it was significantly less acceptable than improving both the quality of public transport and active infrastructure. There was no difference found between general public fund and constructing new roads. Construction of new roads was seen to be significantly more acceptable than decreasing fuel costs, but significantly less acceptable than improving both the quality of public transport and active transport infrastructure. 
There was no difference found between construction of new roads and reducing fuel costs.

There was no significant difference between improving the quality of public transportation and improving the quality of active transport infrastructure, though both were the most acceptable form or revenue use allocation, with significant difference between them and all other types of revenue use. The results can be seen in Figure 4.4. It does seem that acceptability levels are highest for a non-specific pricing policy when revenues are allocated to active or public transportation and lowest when they are allocated to decreasing car costs.

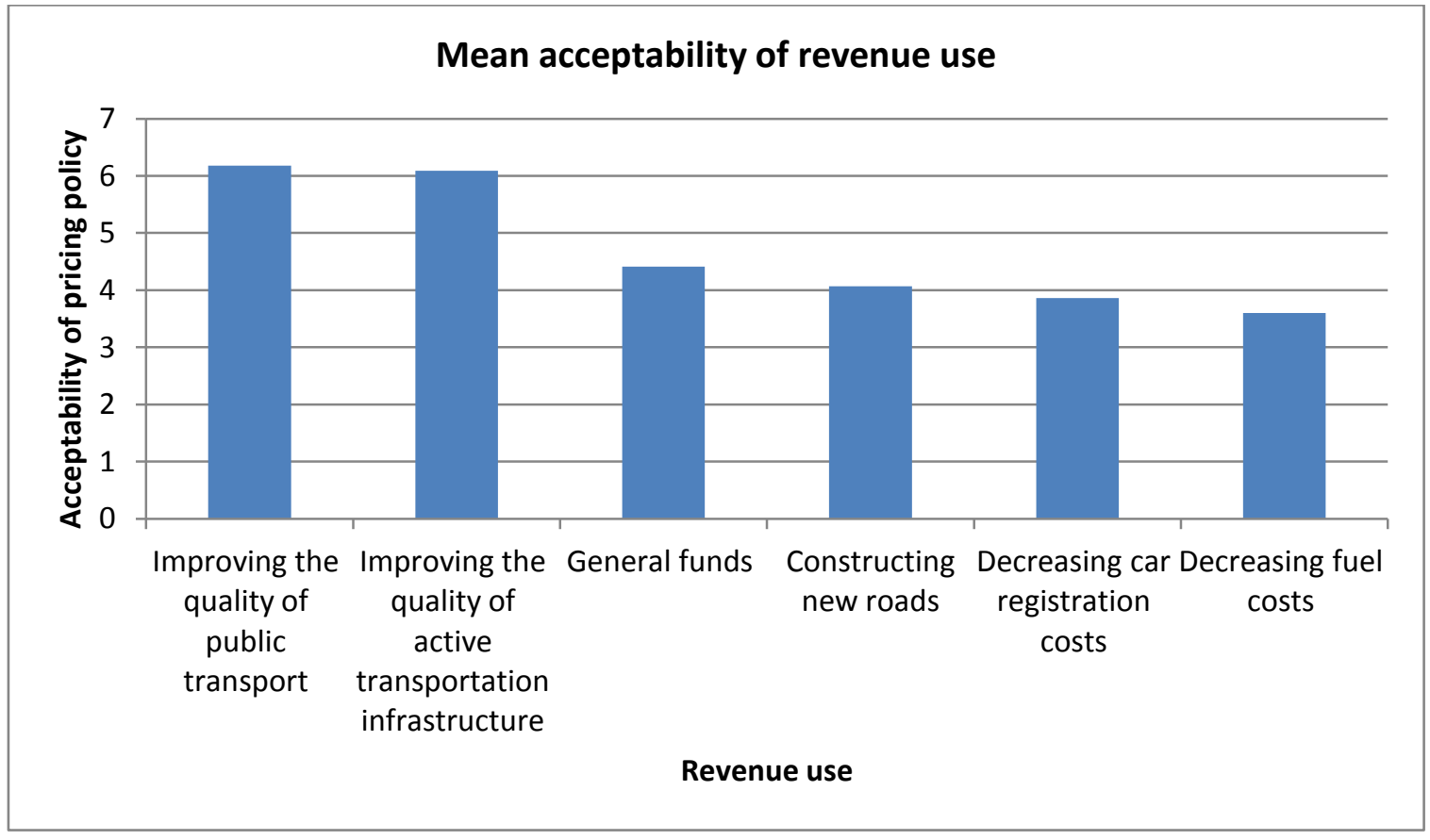

Figure 4. 4 Mean acceptability of general pricing policies by revenue use.

In relation to the research question it does appear that acceptability of parking policies are influenced by level of parking fee, and to a lesser extent, by type of revenue use. To examine if other aspects are influencing these measures, perceived effectiveness of each parking policy is explored below. 


\subsection{Perceived perception of parking policies to the public in terms of effectiveness}

\subsubsection{Overall perceived effectiveness}

Table 4.6 reports the mean score of perceived effectiveness that respondents gave to the 9 policies using a seven-point scale (1-very ineffective to 7-very effective).

\begin{tabular}{|l|l|l|l|}
\hline Policy number & Mean & Standard Error & $\begin{array}{l}\text { Ranking of most } \\
\text { effective }\end{array}$ \\
\hline 1 & 4.18 & 0.25 & 2 \\
\hline 2 & 4.13 & 0.27 & $3=$ \\
\hline 3 & 4.11 & 0.23 & 5 \\
\hline 4 & 4.43 & 0.22 & 1 \\
\hline 5 & 4.00 & 0.20 & 6 \\
\hline 6 & 3.91 & 0.25 & 7 \\
\hline 7 & 3.39 & 0.27 & 9 \\
\hline 8 & 4.13 & 0.26 & $3=$ \\
\hline 9 & 3.78 & 0.28 & 8 \\
\hline
\end{tabular}

Table 4. 6 Mean perceived effectiveness of policy by policy number.

\subsubsection{Perceived effectiveness by policy}

There was no significant difference between policies in terms of perceived effectiveness. The policy that was considered most effective overall is policy 4 (\$4/improving quality of public transport) with a mean of 4.43 (neither effective nor ineffective), while the least effective policy overall is policy 9 (\$5/general fund) with a mean of 3.78 (somewhat ineffective). A one-way ANOVA ${ }^{6}$ revealed no significant effect of specific policies on perceived effectiveness and comparison tests also showed no significance of perceived effectiveness between policies. This can be seen in Figure 4.5.

\footnotetext{
${ }^{6}$ Non-parametric tests were also used to account for the lack of normal distribution, but the results were similar.
} 


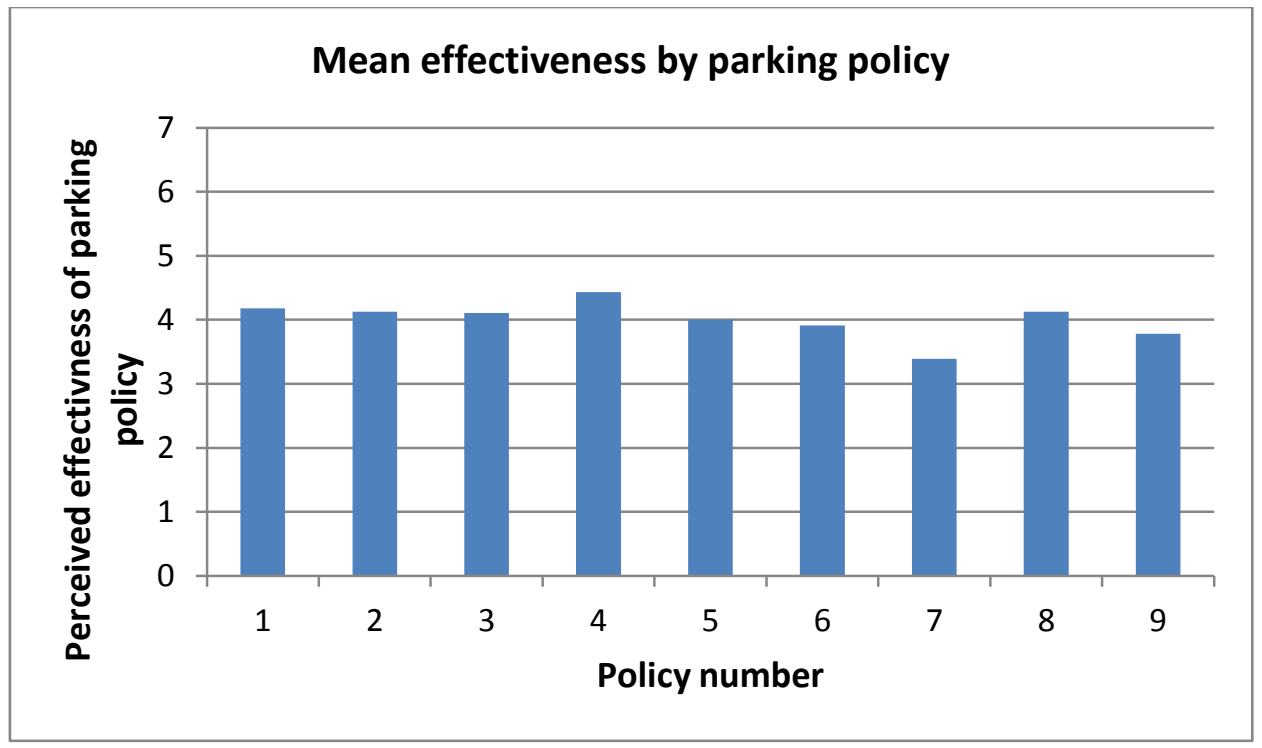

Figure 4. 5 Mean perceived effectiveness of policy by policy number.

Though no significant difference effects can be seen overall, the effects of parking fee and type of revenue use on perceived effectiveness are still explored independently below.

\subsubsection{Perceived effectiveness by fee}

Table 4.7 reports the mean score of perceived effectiveness that respondents gave, as categorised by the three different fees, using a sevenpoint scale (1-very ineffective to 7-very effective).

\begin{tabular}{|l|l|l|l|}
\hline Fee & Mean & $\begin{array}{l}\text { Standard } \\
\text { Error }\end{array}$ & Ranking of most effective \\
\hline$\$ 4.00$ & 4.01 & 015 & 2 \\
\hline$\$ 4.50$ & 4.09 & 0.14 & 1 \\
\hline$\$ 5.00$ & 3.94 & 0.14 & 3 \\
\hline
\end{tabular}

Table 4. 7 Mean perceived effectiveness of policy by fee.

The parking fee that was considered most effective overall is $\$ 4.50$ with a mean of 4.09 (neither effective nor ineffective), while the least effective fee is $\$ 5$ with a mean of 3.94 (somewhat ineffective). A one-way ANOVA ${ }^{7}$ showed no significant differences between the levels of fees on perceived effectiveness of the parking policy. Comparison tests also showed no

\footnotetext{
${ }^{7}$ Non-parametric tests were also used to account for the lack of normal distribution, but results were similar.
} 
significance in perceived effectiveness between fees. This can be seen in Figure 4.6.

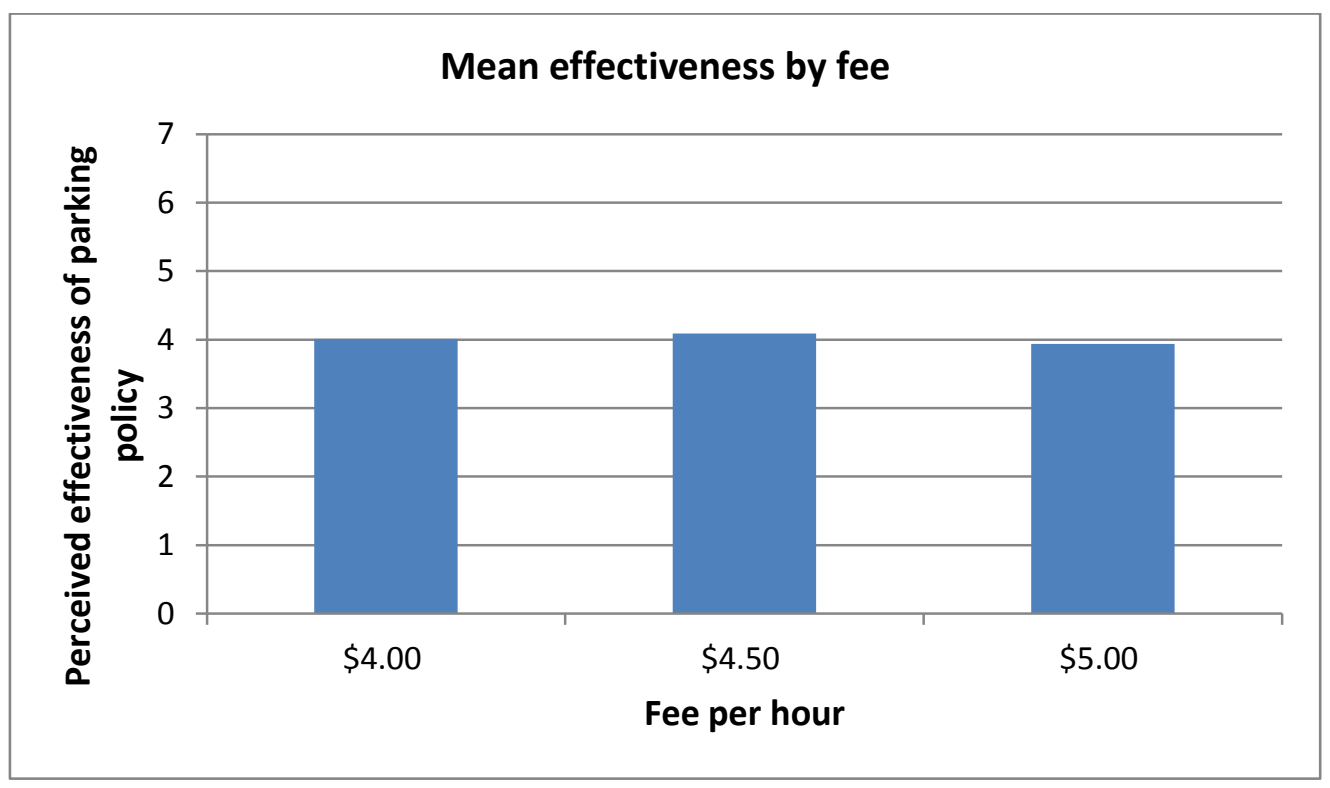

Figure 4. 6 Mean perceived effectiveness of policy by fee.

\subsubsection{Perceived effectiveness by revenue use}

Table 4.8 reports the mean score of perceived effectiveness that respondents gave, as categorised by the three different types of revenue use, using a seven-point scale (1-very ineffective to 7-very effective).

\begin{tabular}{|l|l|l|l|}
\hline Revenue use & Mean & Standard Error & $\begin{array}{l}\text { Ranking of most } \\
\text { effective }\end{array}$ \\
\hline $\begin{array}{l}\text { Maintaining road } \\
\text { and street space }\end{array}$ & 4.14 & 0.14 & 2 \\
\hline $\begin{array}{l}\text { Improving quality of } \\
\text { public transport }\end{array}$ & 4.41 & 0.13 & 1 \\
\hline General fund & 3.78 & 0.15 & 3 \\
\hline
\end{tabular}

Table 4. 8 Mean perceived effectiveness of policy by revenue use.

The type of revenue use that was considered most effective overall was improving the quality of public transport with a mean of 4.41 (neither effective nor ineffective), while the type of revenue use considered the least effective was the general fund with a mean of 3.78 (somewhat 
ineffective). A one-way ANOVA ${ }^{8}$ revealed no significant effect of type of revenue use on perceived effectiveness of the parking policy. Comparison tests also showed no significance in perceived effectiveness between types of revenue use. This can be seen in Figure 4.7.

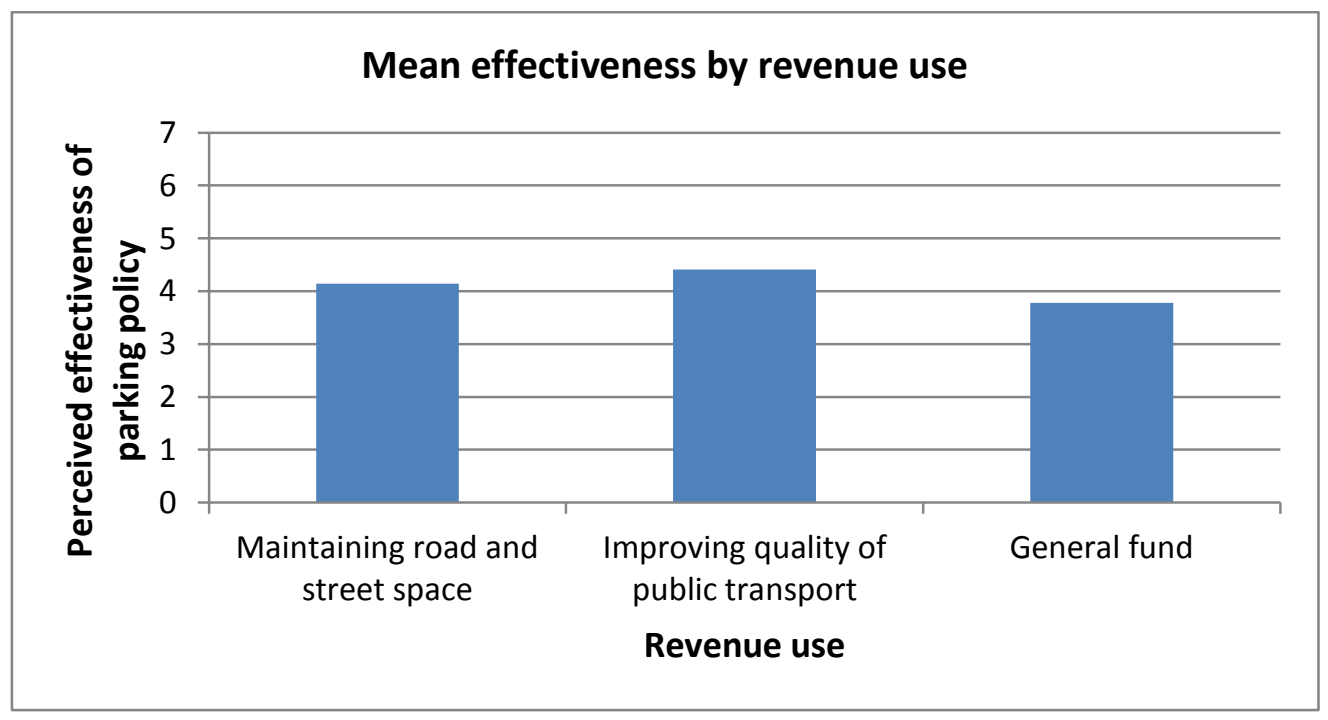

Figure 4. 7 Mean perceived effectiveness of policy by revenue use.

It does not appear that effectiveness of parking policies is influenced by fee level or type of revenue use allocation. To examine if another aspect is influencing these measures, perceived consequences of each parking policy is explored below.

\subsection{Perceived consequences of the public to a range of parking policies}

\subsubsection{Overall perceived consequences}

Participants were asked to indicate the extent to which they thought the policy would have consequences for them personally. The following table gives the mean score of perceived personal consequences that respondents gave to the policies using a seven-point scale (1-very negative to 7-very positive).

\footnotetext{
${ }^{8}$ Non-parametric tests were also used to account for the lack of normal distribution, but the results were similar.
} 


\begin{tabular}{|l|l|l|l|}
\hline Policy number & Mean & Standard Error & $\begin{array}{l}\text { Ranking of most } \\
\text { positive }\end{array}$ \\
\hline 1 & 4.00 & 0.16 & 2 \\
\hline 2 & 3.83 & 0.21 & 5 \\
\hline 3 & 3.86 & 0.19 & 4 \\
\hline 4 & 4.37 & 0.24 & 1 \\
\hline 5 & 3.88 & 0.18 & 3 \\
\hline 6 & 3.25 & 0.23 & 9 \\
\hline 7 & 3.66 & 0.23 & 6 \\
\hline 8 & 3.56 & 0.25 & 8 \\
\hline 9 & 3.60 & 0.22 & 7 \\
\hline
\end{tabular}

Table 4. 9 Mean perceived consequences of policy by policy number.

The policy that was perceived to have the most positive consequence on respondents personally is policy 4 (\$4/improving quality of public transport) with a mean of 4.37 (neither positive nor negative), while the policy that is perceived to have the most negative consequence on respondents overall is policy 6 ( $\$ 5 /$ improving quality of public transport) with a mean of 3.78 (somewhat negative).

A one-way ANOVA ${ }^{9}$ revealed a significant effect of policy on perceived consequences of the parking policy $(F(8,308)=2.07, p=.038))$ with a significant linear trend $F(1,315)=5.22, p=.023)$. The Games-Howell procedure ${ }^{10}$ showed a significant difference between policy 4 and policy 6 $(p<.005)$. This means that policy 4 (\$4/improving quality of public transport) is perceived to have more positive outcomes for the respondents than policy 6 ( $\$ 5 /$ improving quality of public transport). This can be seen in Figure 4.8 .

\footnotetext{
${ }^{9}$ Non-parametric tests were also used to account for the lack of normal distribution, but the results were similar

${ }^{10}$ The Levene Statistic (2.54) had a significance $p<.05$, so the homogeneity of variance was violated. Therefore the Brown-Forsyth F-ratio $(F(8,292.03))=2.088, p=0.087)$ and Welch F-ratio $(F(8,127.98)=1.78, p=.037)$ are also reported.
} 


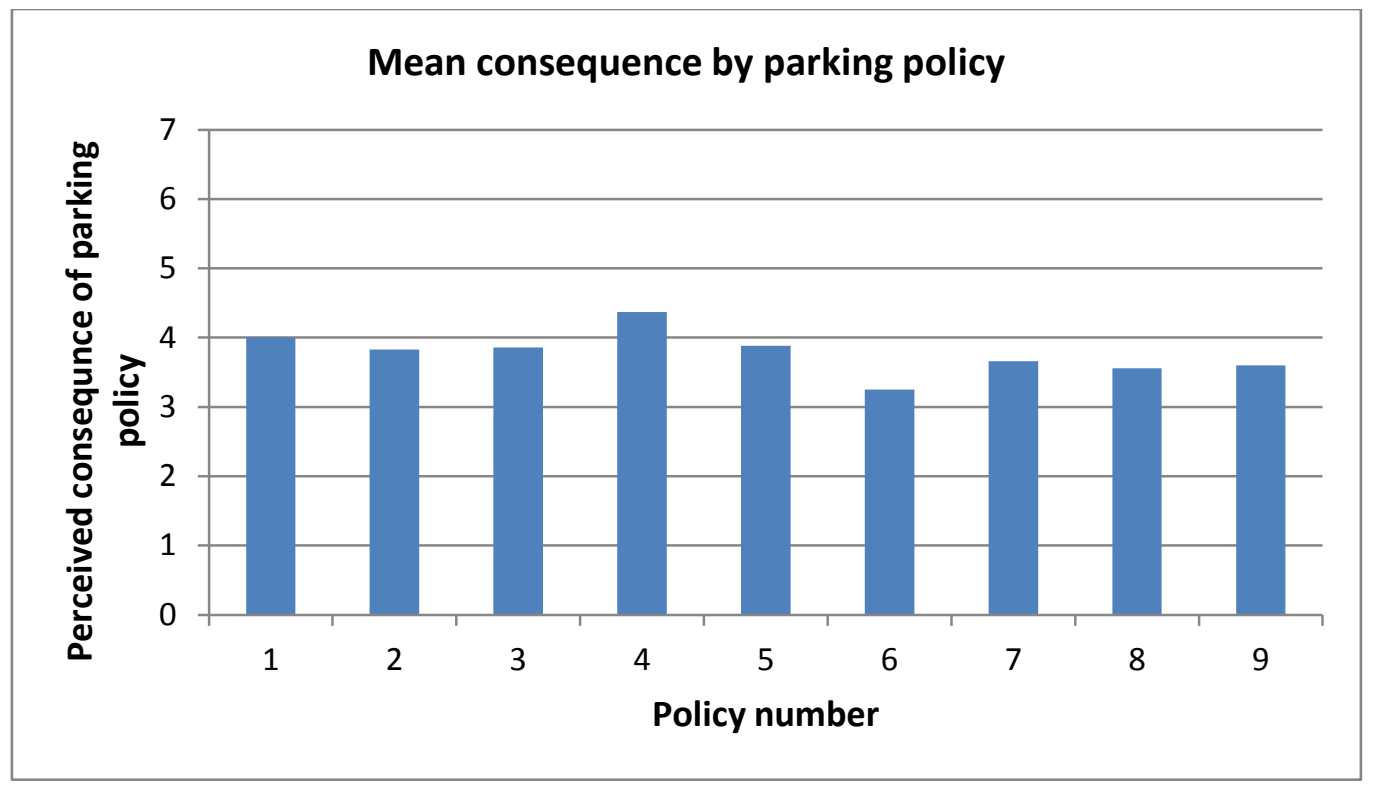

Figure 4. 8 Mean perceived consequences of policy by policy number.

In relation to the research question, it does appear that perceived consequences were significantly different amongst the nine parking policies. To examine which aspects of the policy were influential, the effects of fee and revenue use are explored below.

\subsubsection{Perceived consequences by fee}

Respondents were asked to rate how they perceived the policy would impact on them personally. Table 4.10 reports the mean score of perceived personal consequences that respondents gave, as categorised by the three different fees, using a seven-point scale (1-very negative to 7-very positive).

\begin{tabular}{|l|l|l|l|}
\hline Fee & Mean & Standard Error & Ranking of most positive \\
\hline$\$ 4.00$ & 4.02 & 0.12 & 1 \\
\hline$\$ 4.50$ & 3.76 & 0.12 & 2 \\
\hline$\$ 5.00$ & 3.57 & 0.12 & 3 \\
\hline
\end{tabular}

Table 4. 10 Mean perceived consequences of policy by fee.

The fee that was considered to have the most positive consequence on respondents personally is $\$ 4$ with a mean of 4.02 (neither positive nor negative), while the fee that would have the most negative consequence on respondents overall is $\$ 5$ with a mean of 3.57 (somewhat negative). A 
one-way ANOVA ${ }^{11}$ revealed a significant effect of fee on perceived consequences of the parking policy $(F(2,314)=3.095, p=.047))$. There is a significant linear trend $(F(1,315)=6.125, p=.014)$, indicating that as the fee increased, perceived positive consequences decreased proportionately. The Tukey procedure showed a significance between the fee levels of $\$ 4$ and $\$ 5(p<.005)$. This means that the consequences of the policy are seen as more positive when the fee is low $(\$ 4)$, and more negative when the fee is high $(\$ 5)$. This can be seen in Figure 4.9.

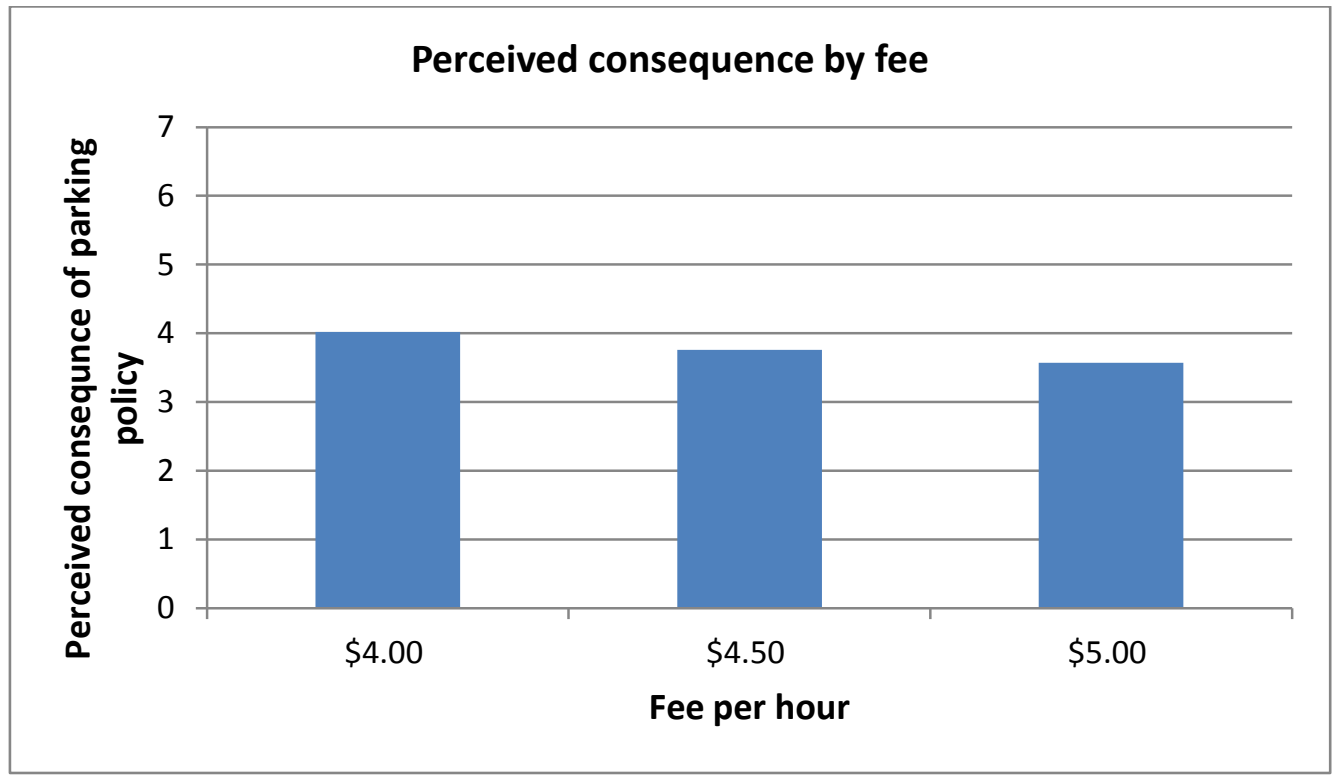

Figure 4. 9 Mean perceived consequences of policy by fee.

\subsubsection{Perceived consequences by revenue use}

Table 4.11 reports the mean score of perceived consequences that respondents gave, as categorised by the three different types of revenue use, using a seven-point scale (1-very ineffective to 7-very effective).

\footnotetext{
${ }^{11}$ Non-parametric tests were also used to account for the lack of normal distribution, but the results were similar.
} 


\begin{tabular}{|l|l|l|l|}
\hline Revenue use & Mean & $\begin{array}{l}\text { Standard } \\
\text { Error }\end{array}$ & Ranking of most positive \\
\hline $\begin{array}{l}\text { Maintaining road } \\
\text { and street space }\end{array}$ & 3.89 & 0.11 & 1 \\
\hline $\begin{array}{l}\text { Improving quality of } \\
\text { public transport }\end{array}$ & 3.85 & 0.13 & 2 \\
\hline General fund & 3.61 & 0.13 & 3 \\
\hline
\end{tabular}

Table 4. 11 Mean perceived consequences of policy by revenue use.

The type of revenue use allocation that was considered most positive overall was maintaining road and street space with a mean of 3.89 (somewhat negative), while the type of revenue use considered the least positive was the general fund with a mean of 3.61 (somewhat negative). A one-way ANOVA ${ }^{12}$ revealed no significant effect of revenue use on the perceived consequences of the parking policy. There was no significance found in comparison tests. This can be seen in Figure 4.10.

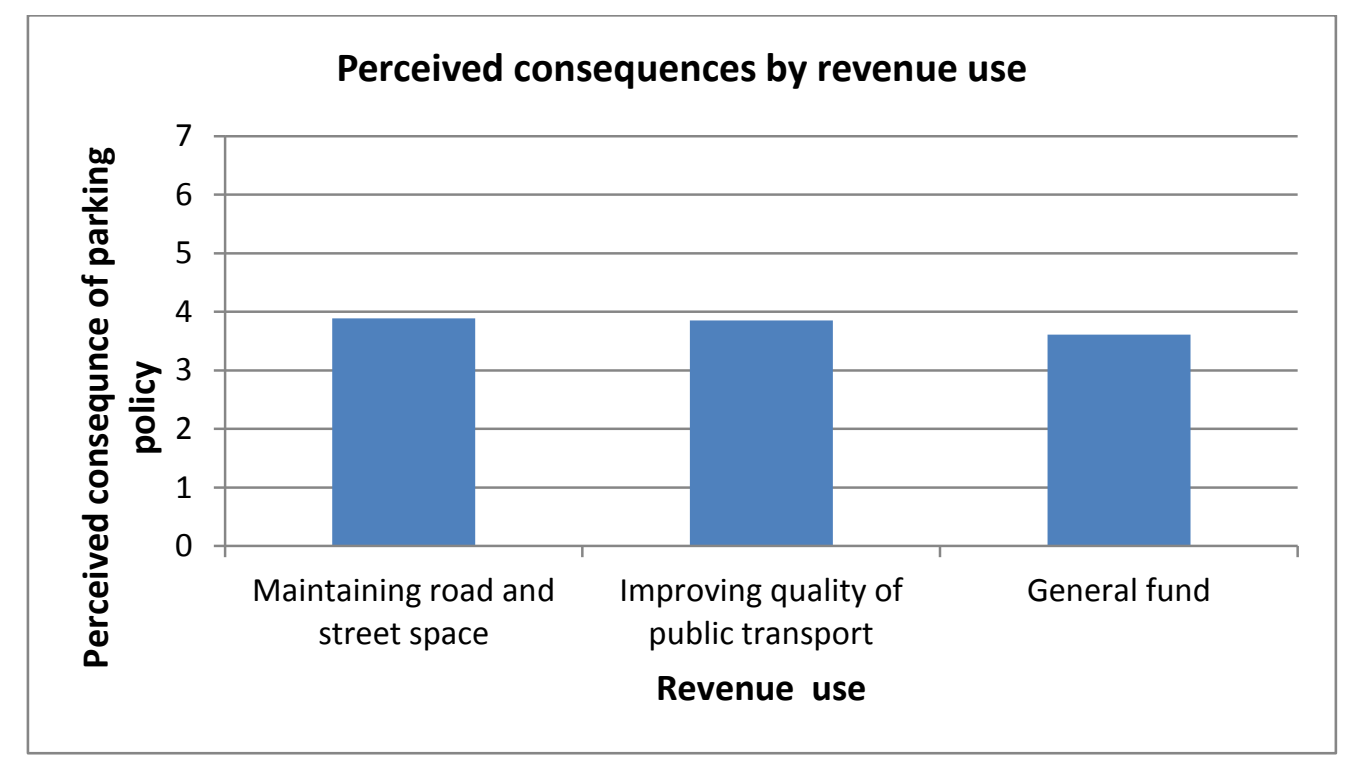

Figure 4. 10 Mean perceived consequences of policy by revenue use.

In relation to the research question, it does appear that perceived consequences of the parking policy are influenced by the level of parking fee, with a higher level of parking fee corresponding to a more negative perceived consequence.

\footnotetext{
${ }^{12}$ Non-parametric tests were also used to account for the lack of normal distribution, but the results were similar.
} 


\subsection{Environmental concern and acceptability levels of parking policies}

Three questions of the survey were used to gauge participants' level of environmental concern. These questions related to opinion of cars and their use, NEP and awareness of environmental consequences of car use. Table 4.12 reports the descriptive statistics of these variables which will now be explored in more detail.

\begin{tabular}{|l|l|l|l|}
\hline $\begin{array}{l}\text { Environmental } \\
\text { variable }\end{array}$ & Mean & $\begin{array}{l}\text { Standard } \\
\text { Deviation }\end{array}$ & $\begin{array}{l}\text { Cronbach's } \\
\text { Alpha }\end{array}$ \\
\hline Car opinion & 3.85 & 1.04 & 0.759 \\
\hline NEP & 5.21 & 0.98 & 0.895 \\
\hline $\begin{array}{l}\text { Consequences of } \\
\text { car use }\end{array}$ & 5.17 & 1.32 & 0.898 \\
\hline
\end{tabular}

Table 4. 12 Descriptive statistics of environmental variables.

\subsubsection{Car opinion}

To gauge how each respondent views and values car use, a series of nine statements was compiled. Respondents were asked to identify on a sevenpoint scale how strongly they agree or disagree with each statement. All of the responses were then recoded to a seven-point scale to show how positively or negatively respondents viewed cars and car use (1-strongly negative to 7-stongly positive). The reliability of internal consistency was acceptable $(\alpha=.759)$ so the responses from each statement were combined to get an average mean. This gave the average respondent a mean score of 3.85; a somewhat negative view of cars and car use. This was tested for reliability and resulted in a non-normal distribution (Kolmogorov-Smirnov and Shapiro-Wilk statistics with $p=.012$ ).

Spearman's rho coefficient $(S R)$ was used to account for the non-normal distributions. This produced a significant correlation relationship of -0.371 $(p<.000)$ between acceptability of parking policy and car opinion score. This suggests that as car use is viewed as increasingly positive, acceptability levels of parking policies decrease. 


\subsubsection{NEP}

The series of NEP statements were recoded to a seven-point scale (1-very low environmental concern to 7-very high environmental concern). The reliability of internal consistency was acceptable $(\alpha=.895)$, which allowed for an overall mean to be found $(M=5.21)$. This shows that on average, respondents had some level of environmental concern.

The resulting distribution was found to be non-normal using Shapiro-Wilk statistic ( $p=.002)$. Spearman's rho coefficient $(S R)$ was used to account for the non-normal distribution. This showed a significant correlation relationship of $0.186(p<.001)$ between acceptability and NEP score. This suggests that as NEP score increases, acceptability of parking policy increases.

\subsubsection{Environmental consequences of car use}

The series of statements regarding the environmental consequences of car use was recoded to a seven-point scale of 1-very low links between car use and environmental damage to 7-very strong links between car use and environmental damage. The reliability of internal consistency was acceptable $(\alpha=0.898)$. The overall mean was 5.17 showing that on average, respondents saw some links between car use and environmental damage. This variable did show a non-normal distribution, with both KolmogorovSmirnov and Shapiro-Wilk statistics with $p<.05$.

Spearman's rho coefficient $(S R)$ was used to account for the non-normal distributions. This showed a significant correlation relationship of 0.336 $(p<.000)$ between acceptability and the link between car use and environmental consequences. This suggests that as participants' understanding of the link between car use and environmental damage increases, their acceptability levels of parking policies increases too. 


\subsubsection{Overall environmental awareness}

In regards to the research question it does appear that there is a relationship between acceptability levels of parking policies and the level of environmental concern and awareness of the participants. The higher the level of this awareness (by either negative opinion of car use, or higher NEP and understanding of consequences of car use on the environment) the higher the acceptability will be of parking policy.

\subsection{Additional analysis}

Table 4.13 shows additional Spearman's rho correlation coefficients (SR) that are significant between the demographic data (age and income) and the environmental awareness and concern factors (personal opinions around cars, NEP and cars' impact on the environment). These variables were found to be related to one another. Variables of acceptability, effectiveness and consequences of the parking policy and the demographic variables of suburb of residence, gender, employment status and ethnicity were also compared against each other and to the variables stated above, but the associations were found to have no significance. 


\begin{tabular}{|c|c|c|c|c|c|c|}
\hline & & 1 & 2 & 3 & 4 & 5 \\
\hline $\begin{array}{l}\text { Age group } \\
\text { (1) }\end{array}$ & $\begin{array}{l}S R \\
N\end{array}$ & $\begin{array}{r}1.000 \\
302\end{array}$ & & & & \\
\hline $\begin{array}{l}\text { Income } \\
(2)\end{array}$ & $\begin{array}{l}S R \\
N\end{array}$ & $\begin{array}{r}.443^{* *} \\
287\end{array}$ & $\begin{array}{r}1.000 \\
289\end{array}$ & & & \\
\hline $\begin{array}{l}\text { Car opinion } \\
\text { (3) }\end{array}$ & $\begin{array}{l}S R \\
N\end{array}$ & $\begin{array}{r}.196^{* *} \\
296\end{array}$ & $\begin{array}{r}.201^{* *} \\
283\end{array}$ & $\begin{array}{r}1.000 \\
308\end{array}$ & & \\
\hline $\begin{array}{l}\text { NEP } \\
(4)\end{array}$ & $\begin{array}{l}S R \\
N\end{array}$ & $\begin{array}{r}-.199^{* *} \\
292\end{array}$ & $\begin{array}{r}-.182^{* *} \\
278\end{array}$ & $\begin{array}{r}-.409^{* *} \\
290\end{array}$ & $\begin{array}{r}1.000 \\
295\end{array}$ & \\
\hline $\begin{array}{l}\text { Environmental } \\
\text { consequence(5) }\end{array}$ & $\begin{array}{l}S R \\
N\end{array}$ & $\begin{array}{r}-.132^{*} \\
299\end{array}$ & $\begin{array}{r}-.194^{* *} \\
286\end{array}$ & $\begin{array}{r}-.648^{* *} \\
296\end{array}$ & $\begin{array}{c}.575^{* *} \\
292\end{array}$ & $\begin{array}{r}1.000 \\
302\end{array}$ \\
\hline $\begin{array}{l}\text { *Correlation is } \\
\text { Correlation is S }\end{array}$ & 111 & $\begin{array}{l}\text { at the } \\
\text { the } 0\end{array}$ & $\begin{array}{l}1 \text { leve } \\
\text { level ( }\end{array}$ & $\begin{array}{l}\text { cailed). } \\
\text { iled). }\end{array}$ & & \\
\hline
\end{tabular}

Table 4. 13 Correlation statistics between five variables. SR=Spearman's rho, $\mathrm{N}=$ number of participants. Scales measured from 1 (negative) to 7 (positive); age was measured from $1(18-26)$ to $6(65+)$; Income was measured from $1(\$ 0-\$ 20,000)$ to $5(\$ 100,000+)$.

Income was found to have a small negative correlation with perceived effectiveness of parking policies $(S R=-.130, p<.05)$. This suggests that as income levels increase, perceived level of the effectiveness of parking policies decreases. However, none of the other socio-demographic variables were found to be related to acceptability, perceived effectiveness or perceived consequences of the parking policy.

Age and income both have a negative correlation to opinions about the consequences of car use on the environment. This suggests that as age and income increases, the level of awareness of the environmental impact of cars on the environment decreases. A one-way ANOVA showed a significant effect of income level on the impacts of cars on the environment $(F(4,281)=8.62, p<.001)$. The Tukey procedure showed a significant difference between the $\$ 100,000$ plus income level and all four of the other income levels $(p<.005)$. The mean the consequences of car use on the environment was significantly lower for the lower income brackets (\$0$\$ 20,000 M=5.48 ; \$ 20,000-\$ 50,000 M=5.56 ; \$ 50,000-\$ 70,000 M=5.24$; 
$\$ 70,000-\$ 100,000 M=5.30)$ than those who earn $\$ 100,000+(M=4.61)$.

These results suggest that respondents with the highest incomes have the lowest understanding of the environmental impacts of car use. However, there was no significant difference found in the perceived levels of environmental consequences of car use between the lower income groups.

Age and income also showed a significant negative correlation with NEP. This suggests that as age and income level increases, NEP levels decrease. A one-way ANOVA showed an effect of age on $\operatorname{NEP}(F(5,286)=2.81, p<.05)$, with a significant linear trend $(F(1,290)=13.44, p<.001)$. This suggests that as age increases, NEP level decreases and can be seen in the age group means (18-24 $M=5.50 ; 25-35 M=5.43 ; 35-44 M=5.22 ; 45-54 M=5.10 ; 55-65$ $M=4.87 ; 65+M=4.90)$.

A one-way ANOVA showed a significant effect of income on NEP $(F(4,273)=5.26, p<.001)$, with a linear trend $(F(1,276)=9.03, p<.05)$. The Tukey procedure showed a significant difference between the $\$ 100,000$ plus group and three of the other income levels $(\$ 0-\$ 20,000, \$ 20,000$ $\$ 50,000$ and $\$ 70,000-\$ 100,000)(p<.005)$. The means for NEP are generally higher for the lower income brackets $(\$ 0-\$ 20,000 M=5.43 ; \$ 20,000-$ $\$ 50,000 M=5.44 ; \$ 50,000-\$ 70,000 M=5.13 ; \$ 70,000-\$ 100,000 M=5.42)$ than those who earn $\$ 100,000+(M=4.80)$. This suggests that respondents with higher incomes have lower NEP scores. However, there was no significant difference found in the NEP levels between the lower income groups.

Both age and income show a positive correlation to car opinion, suggesting that as both age and average income increase, views of car use become more positive. A one-way ANOVA showed a significant effect of age on car opinion $(F(5,290=3.98, p<.05)$, with a significant linear trend $(F(1,294)=11.75, p<.001)$. The Tukey procedure showed a significant difference between the 18-24 age group $(M=3.31)$ with the $35-44(M=4.08)$ 
and the 55-64 (4.13) age groups $(p<.05)$. This suggests that as respondents' age increases, their opinion towards cars generally becomes more positive and can be seen in the age group means (18-24 $M=3.31 ; 25-35 M=3.60 ; 35-$ $44 M=4.08 ; 45-54 M=3.77 ; 55-65 M=4.13 ; 65+M=4.07)$.

A one-way ANOVA showed a significant effect of income on car opinion ( $F$ $(4,278)=3.99, p<.05)$, with a linear trend $(F(1,281)=8.31, p<.05)$. The Tukey procedure showed a significant difference between the $\$ 100,000$ plus group and three of the other income levels $(\$ 0-\$ 20,000, \$ 20,000-\$ 50,000$ and $\$ 70,000-\$ 100,000)(p<.005)$. The mean for car opinion are generally lower for the lower income brackets $(\$ 0-\$ 20,000 M=3.53 ; \$ 20,000-\$ 50,000$ $M=3.65 ; \$ 50,000-\$ 70,000 M=3.70 ; \$ 70,000-\$ 100,000 M=3.75)$ than those who earn $\$ 100,000+(M=4.22)$. These results suggest that as income levels increase, opinions towards car use become more positive.

\subsection{Participants' comments}

The comments section allowed for additional analysis in areas that were not directly covered in the survey. 237 comments were given overall that were then placed into one of seven categories: reasons for using cars, public transport (PT), active transport (AT), cars, roading, parking and other. The full table can be seen in Appendix A5.

Issues around cars that participants noted were the large number of cars per household in the region and in particular the number of large SUVs. Suggestions were made to give priority parking to smaller, fuel efficient and electric cars in the CBD. Other participants noted that motorcycles and scooter use could be encouraged as more favourable travel option than cars. Parking policy could be used to target specific types of vehicles, though how this works in practice is beyond the scope of this research.

Some participants noted that parking policy should be used to ban cars from the CBD either altogether, or during certain times, or require a certain 
number of passengers to enter the CBD and use parks. The idea of a congestion charge was also brought up. Some of these policies have been discussed in the literature review as examples of transport pricing policies in other cities. How these suggestions may work in a smaller city such as Wellington is unknown, though these types of policy changes may work in the future as public and active aspects of the transportation network improve.

Many issues and comments around current parking were noted with conflicting opinions. Some participants felt there needs to be a reduction in on-street parking, while others found it very hard to get parking and therefore believe there is not enough. Fees were another area that some felt were too high, while others see a need for an increase. Time limits were another aspect of policy that was not covered in this research, with both shorter and longer time limits to parking suggested. Also of note were participants who now go to malls or the suburbs for their shopping due to the free parking available at many locations.

The main reason participants said they needed to use cars was to transport the elderly, disabled, and children. Parking policies therefore need to target some of these concerns by keeping spaces specifically for these groups of people with lower mobility. Some participants noted a need to use cars to transport large items and shopping. Others carpooled or transported multiple passengers so it worked out cheaper for them to use a car than public transportation. These issues cannot be directly addressed by parking policies, but rather through making changes to the public transportation system.

Another issue raised as a main reason for using cars was issues with public transportation. The main concerns were around a high cost and lack of reliability and convenience. Improving active transportation and cycle infrastructure in particular was another main aspect that many participants 
suggested would decrease their use of cars. Again, while parking policy cannot directly impact on public and active transportation, it is an area that could be improved as a pull measure to create a reduction in car use in to and around the CBD. There was support for more park-and-ride and parkand-walk facilities which could be addressed by parking policies and assist in creating a more cohesive transport network. Weather was another factor in what mode of transport participants choose either daily or seasonally. A cohesive transportation network would allow these types of choices to be made on a daily basis.

\subsection{Results summary}

Current CBD parking policy in Wellington has aspects that are viewed both negatively and positively by different respondents. Most respondents drive at least weekly and often make transportation choices based on convenience and reliability.

Overall results suggest that acceptability of parking policies is influenced by different measures. The level of parking fees affects participants' levels of policy acceptability, with lower fees resulting in higher levels of acceptability. Revenue use allocation also affected acceptability levels, but not strongly. These results will be further explored in the discussion chapter.

Fees and revenue use did not appear to affect perceived effectiveness of parking policies, though fee level did have an influence on the perceived consequences the participants believed the policy outcomes would have for them personally. With higher fees, the consequences of parking policies were perceived to be more negative. How perceived effectiveness and consequences relate to acceptability will be examined in the discussion section. 
Participants' environmental awareness and concern was also shown to affect their level of parking policy acceptability. The higher their environmental awareness and concern, the higher the levels of acceptability were. How this finding can be used to increase policy acceptability will also be discussed in the following chapter. 


\section{Chapter 5: Discussion and Conclusion}

\subsection{Car parking behavior and context}

With the increase in negative consequences from car use such as pollution and congestion, it is becoming more and more important that transport policies encourage a reduction in car use. Pricing policies are one avenue for bringing about these necessary changes, but they are usually considered to be unpopular with the public. Unpopular policies in turn are less likely to be implemented. It is therefore important to better understand which factors determine public acceptability of pricing policies. Acceptability of transport pricing policies reflects a social dilemma between individual and collective interests. Individuals believe they are better off when they experience positive personal outcomes in the short-term and will often find the new policy unacceptable. However when society is considered, long-term positive collective outcome are favoured and the new policy is accepted (Dawes, 1980). The aim of the study was to get an understanding of how the public in the Wellington region view current and other potential car parking policies in Wellington CBD. The results could then be used as a way to increase levels of support for changes to parking policies to discourage the use of cars as a main mode of transportation into the CBD.

Previous research suggests that public acceptability of pricing policies is generally low. These types of policies are seen as unacceptable because they require a payment (in the form of a fee) from the individual. More generally, push measures that are aimed to discourage car use tend to be evaluated as less acceptable as they tend to create conditions that make car use more expensive. In this study the Greed-Efficiency-Fairness (GEF) hypothesis (Wilke, 1991) was used as a theoretical framework to examine how pricing policies could be adjusted to achieve higher levels of public acceptability and thus support. The hypothesis states that in a social dilemma, people tend to focus on maximising their individual outcomes; 
i.e. they are greedy. It has been suggested that acceptability of pricing policies is low because people do not want to pay more for using a car, or to be forced to stop using a car altogether (Schuitema, 2010). However, if pricing is used as a way to discourage car use, higher fees may be more acceptable if the corresponding revenues gathered are allocated in a specific way that benefits individual users or the wider society. Revenue gathered from the policy could then act as a form of compensation to car users for an increased fee and increase acceptability levels.

The GEF hypothesis also states that people do not always act 'greedily' as they have the desire to preserve collective resources (efficiency) and to distribute outcomes of the policy fairly (fairness). This means that people may be willing to accept a policy more if they believe the efficiency and fairness of the policy to be high. Understanding how these acceptability factors can be increased by changing specific policy characteristics would allow for new acceptable parking policies to be developed, that simultaneously act as a push measure to help decrease car use in Wellington CBD.

The main research question for this study was 'what parking policy characteristics are acceptable to Wellington Regions residents?' To understand what factors affected these acceptability levels, a further question was asked 'what aspects of the policy influence these judgments?' A quantitative approach was taken to answer these questions via an online survey. Revenue use and parking fee level were chosen as specific factors to be systematically varied to examine how they relate to overall policy acceptability. The following sub-questions were used to break down the main questions into topics to reflect specific aspects of parking policy.

1) Current parking policy ('what parking mechanisms and policy are in place in the CBD?' and 'what are the reasons for drivers parking in the CBD over other areas or transport modes?'). 
2) How factors change in relation to different policies ('what are a range of parking policies acceptability to the public to?', 'what is the perceived effectiveness to the public of how a policy will meet its aims?' and "what are the perceived consequences to the public to a range to parking policies?').

3) Whether environmental concern relates to acceptability of parking policies ('does environmental concern relate to parking policy acceptability levels?').

\subsection{Factors relating to acceptability}

The study used a 3 (price level) by 3 (revenue use) between-subjects design to outline nine different versions of the parking policy. The price in these policies was systematically varied- i.e. the parking fee was either $\$ 4.00$, $\$ 4.50$ or $\$ 5.00$. The revenue use allocated from these fees was also systematically varied between policies. Three different types of revenue allocations were selected to describe where the money gained from the policy would go. The revenue was either allocated to maintaining road and street space, improving the quality of public transport or the general public fund. Each respondent was randomly allocated to one of nine different policies. They were then asked to assess the policy in terms of its level of acceptability, perceived effectiveness in reducing car traffic and congestion in and around the CBD, and perceived personal consequences of the policy for them personally. These variables of acceptability, perceived effectiveness and perceived outcome are discussed next in relation to the GEF hypothesis and other variables.

\subsubsection{Policy acceptability and greed}

The GEF hypothesis states that people often focus on maximising their own outcomes due to the greed motive. It was hypothesised that acceptability of parking policies would be highest when car users pay the lowest fee (\$4), and when revenue use allocations benefit car users (maintaining road and street space). However, contrary to this hypothesis, policy 4 was 
considered the most acceptable policy overall with a fee at the current CBD price of $\$ 4$ an hour, and from which these fees were allocated to improving the quality of public transportation. Policy 6 was viewed as the least acceptable policy overall where the fee of parking increased to $\$ 5$, with the revenue still allocated towards improving the quality of public transportation. The additional \$1 an hour fee changed the most acceptable policy to the least acceptable, even with no change in revenue use allocation.

Schuitema (2010) suggests that the greed motive can be appeased if there is some form of compensation for any negative consequence that the policy outcomes create for the individual. Compensation may occur in a policy context by simultaneously introducing pull measures alongside push measures, or by using revenue collected from policies in a way that benefits individual users.

Further analysis showed how acceptable different measures were when policies with the same fee level or revenue allocations were viewed together. When acceptability of the parking policies was viewed by the fee charged for parking, $\$ 4$ was seen as the most acceptable fee level, while \$5 was the least. These results are in line with the hypothesis that policies are more acceptable when they benefit the individual car user. The most acceptable policy overall (policy 4 ) also had a fee level \$4. It can be concluded that the public find cheaper parking fees more acceptable, irrespective of where any gained revenue was allocated, and that the fee level made no significant statistical difference to the perceived effectiveness of the policy.

When acceptability of the parking policies was looked at by the allocation of revenue, maintaining road and street space was seen as the most acceptable form of revenue use, while revenue allocated to the general fund was the least acceptable. These results are in line with the hypothesis 
that predicts that car users would find parking policies more acceptable when revenue use from the fee is allocated to directly benefit the user. In this case, the type of revenue use that would directly benefit the car user was maintaining road and street space. This is comparable to Schuitema (2010) who recommends that to increase the acceptability of a pricing policy, an individual should be compensated for any negative consequence of the policy via appropriate revenue allocation. Schuitema and Steg (2008) also found that in transport pricing policies acceptability levels were higher when revenue allocated from fees was employed for the benefit of car users.

Revenue allocated to the general fund is a common characteristic of policies that are considered least acceptable. The general fund was seen as the least acceptable form of revenue allocation in this study and this was also found by Schuitema and Steg (2008). These results can be explained as a part of both the greed and fairness motives in the GEF hypothesis. Allocating revenue to a general fund means that fee payers are not aware of how their money is being used. Therefore, any benefit an individual and wider society may be receiving remains unclear. Consequently, the greed motive that drives a need to gain benefit from their money, and the fairness motive that drives a need for equal benefits and costs are not satisfied and the policy will be found unacceptable. However, Schuitema (2010) also noted in some cases acceptability levels of revenues allocated to general road infrastructure were just as low as those allocated to the public fund as there is still a low direct benefit seen by individual car users.

Other studies have found different results to this study. Thorpe (2002) found investment in public transportation to be the most acceptable type of revenue use, as did Banister (2003) when the London congestion charge was introduced. In this study, when the parking policies were assessed overall, the most acceptable was policy 4 where the revenue use for this policy was allocated to improving the quality of public transportation. Also 
in this study, when a wider range of revenue allocations were assessed for a non-specific pricing policy, improving the quality of public transport and improving the quality of active transport infrastructure were found to be most acceptable. The GEF hypothesis could be used to relate these results to both the fairness and efficiency motives. Considering that improving the quality of public transportation was the most acceptable form of revenue use highlights greater levels of understanding of what is best for the wider public, even when individual car park users may not directly benefit. From comments made at the end of the survey, it is also clear that many respondents believed they would find increases in parking prices more acceptable if improvements were made to public and active transportation.

The results regarding acceptability of revenue use were different when a comparison was made between results from the nine parking policies and the non-specific pricing policy. The non-specified pricing policy asked for acceptability levels overall in regards to six types of revenue allocation. This identified improving the quality of public transportation as the most acceptable form of revenue use, followed by improving the quality of active transportation infrastructure (as mentioned above). Using revenue to decrease car registration costs and decreasing fuel costs were the least acceptable forms of revenue allocation. These results suggest an increased level of acceptability for pricing policies when revenue use has the widest potential benefit for the majority of the population. Improving public and active transportation in the city has the potential to benefit most of the general population, while decreasing car registration costs and fuel costs would primarily benefit those who drive cars (and to a certain extent use other modes requiring fuel). This can be explained by the fairness motive of the GEF hypothesis where outcomes require fair distribution.

Acceptability can be seen to relate to the greed motive of the GEF hypothesis when individuals favour the lowest fees and revenue uses that are of direct benefit to the spender. However, having both of these 
measures in a policy can create a contradictory message to car users; you are being charged for using your car, which can be effective in changing behaviors to other modes, yet at the same time revenues are being allocated in a way that promotes car use, signaling an approval by the government to keep using cars (Schuitema, 2010). As is acknowledged by the social dilemma, what is best for the individual and what is best for society often differ. Therefore the effectiveness of policies needs to be considered.

\subsubsection{Policy effectiveness and efficiency}

Though no statistical differences were found between parking policy and effectiveness, policy 4 was considered to be the most effective policy overall in reducing car traffic and congestion into and within the Wellington CBD. It involved a fee of $\$ 4$ an hour from which revenue was allocated to improving the quality of public transport. This was the same policy that was considered to be most acceptable overall. Policy 9 was believed to be the least effective, with a fee of $\$ 5$ an hour and with the revenue allocated to the general fund. This policy was however not the same policy that was believed to be the least acceptable. Both policies had the same fee, but differed in terms of revenue use. These results can be explained through the efficiency motive of the GEF hypothesis. Even though people will often try to increase the benefit of an outcome to meet their own needs through the greed motive, the efficiency motive states that people will also try and preserve collective resources and will therefore consider the interests of the collective.

When the policies were analysed by fee no statistical differences were found. The fee that was considered to be slightly more effective was $\$ 4.50$; a $50 \mathrm{c}$ increase in current fee pricing. The perceived least effective fee was considered to be $\$ 5$. This suggests that to be effective in reducing traffic to and within Wellington $\mathrm{CBD}$, the price of parking does need to increase. When policies were analysed by revenue use, though not statistically 
different, the allocation that was seen to be most effective was improving the quality of public transportation. This suggests that to reduce traffic in the $\mathrm{CBD}$ there needs to be an improvement in public transportation. The least effective policies were seen to be those where revenue use went to a general fund. These were the same forms of revenue use that were seen in the most (improving the quality of public transportation) and least (general fund) effective policies overall.

In this study, the aim of the policy was to reduce car traffic and congestion into and within Wellington CBD. Schade and Schlag (2000) found that acceptability increases when a strategy is seen to be effective in reaching a specific aim. This would suggest that policies seen to be most effective, should be most acceptable. This was seen in results from the overall policy, as policy 4 had both the highest level of acceptability and highest level of perceived effectiveness. A positive correlation was also found between acceptability and effectiveness, suggesting that as a policy increases in perceived effectiveness, it also increases in overall acceptability.

However, when looking at factors that make up the policy, the most effective fee was $\$ 4.50$, while the most acceptable was $\$ 4$. Revenue use differed too, with maintaining road and street space seen as the most acceptable, while the most effective was improving the quality of public transportation. These differences between specific policy measures can be explained by the greed motive of the GEF hypothesis. In both instances when looking at the factors, fee and revenue use are more acceptable when they will benefit the car user, even if this differs as to what would make the policy most effective. However, the similarities between policies overall can be seen as reflecting the efficiency motive of the GEF hypothesis, where what is best for the general public overrides any individual preferences. 
Acceptability often increases after policy implementation (then becoming acceptance) as individuals see the benefits the policy is having on them personally. Schuitema (2010) reported this change occurring in Stockholm before and after the congestion charge trial and suggests that effectiveness should be highlighted by stressing the positive policy outcomes for the general public in addition to benefits for the individual before implementation. The higher the level of perceived effectiveness a policy has, the higher its acceptability levels will be. How effective individuals believe a policy will be and what kind of impact they believe it will have on them and others, will also influence how fair a policy is seen to be.

\subsubsection{Policy outcomes and fairness}

The fairness motive of the GEF hypothesis can be a factor in how acceptable a policy is, as people not only try and maximise their own outcomes, but have a desire to distribute outcomes of a policy in a fair way. Fair distribution of policy outcomes implies an equal distribution of the costs and benefits among all members (Wilke, 1991). How revenues gathered from a pricing policy are allocated is one factor that can impact on an individual's sense of fairness. A level of fairness to all groups of the public should be considered; however the greed motive can be in conflict with this. Schuitema (2010) identified the fairness principles of environmental justice and equality to be relevant factors for transport pricing policy acceptability, both of which are associated with concern for collective outcomes.

Policy 4 had the highest levels of acceptability and effectiveness and was also perceived to create the most positive outcomes for respondents personally. This policy had a fee of $\$ 4$ an hour and revenues allocated to improving quality of public transportation. Policy 6 was seen to have the least overall acceptability and was perceived to have the most negative outcomes on respondents. This policy had a fee of $\$ 5$ an hour and revenue allocated to improving quality of public transportation. 
Acceptability is influenced by individual beliefs about outcome and consequences (Eagly \& Chaiken, 1993; Schuitema, Steg, \& Forward, 2010). Thus, the extent to which respondents perceived outcomes of a policy will impact themselves personally will affect how acceptable they find the policy. This can be seen in the similarities between policies that are seen as highly acceptable and those that are perceived to create positive individual outcomes. Jakobsson et al. (2000) also found that policy measures will be perceived as unacceptable when individuals expect a negative outcome for themselves. This can be explained as the greed motive in the GEF hypothesis whereby people are more accepting of a policy when it is likely create a positive outcome for them. This can be an issue in the case of social dilemmas where personal and societal benefits are often at odds. However, even a fairness motive may also have an element of underlying self-interest to some extent as an individual's benefit will also increase when policy outcomes are distributed on the basis of environmental justice or equity (Schuitema, 2010). Equal outcome distribution will mean that individuals will get an equal amount of positive outcomes compared to others, without feeling guilty or treating others unfairly.

The fee considered to provide the most positive consequence was $\$ 4$, while a fee of $\$ 5$ was perceived to result in the most negative consequences. Revenue use that was considered to be the most positive overall was maintaining road and street space, while allocating it to the general fund was considered the most negative. These fees and revenue uses were also reflected in the acceptability scores and seem to link to the greed motive. This was also seen by Schade and Schlag (2000) who found that the more personal advantages are expected from a strategy, the more acceptable it is found to be. Schuitema (2010) also found the more car users benefit from the revenue allocation, the more acceptable the policy is to them, generally when revenues are allocated within the transport system. Again this form of compensation can be used to increase levels of perceived positive outcomes from the policy. Of note are findings by De 
Groot and Steg (2006) that suggest that individual consequences from increasing the costs of car use hardly change when negative impacts (e.g. decrease in freedom, money and comfort) are compensated by positive impacts (e.g. improved environmental quality).

\subsubsection{GEF hypothesis and parking policies}

The GEF hypothesis was proposed as a theoretical framework to explain the acceptability of parking policies. The hypothesis states that people do not always try to maximise their own outcome (greed), but they also have the motives to preserve collective resources (efficiency) and to distribute outcomes of the policies fairly (fairness) (Wilke, 1991). The results suggest that the GEF motives of greed, efficiency and fairness all relate to the acceptability of parking policies.

Policy 4 was considered the most acceptable and effective policy that would result in the most positive outcomes. This policy had the lowest fee and had the revenue use of improving the quality of public transportation that is the highest in societal benefit (fairness). This result highlights the links between how people connect their beliefs in how acceptable a potential policy is with the impact they believe it will have on them personally (greed) and how effective they believe it to be at solving an issue (efficiency).

Policy 6 was considered the least acceptable policy and was believed to result in the most negative personal consequences. It had a fee of $\$ 5$ and revenue use of improving the quality of public transportation. Policy 9 was considered the least effective. It still had a fee of $\$ 5$ but it had revenue use that went to the general fund.

\subsubsection{Environmental concern}

A relationship was found between levels of acceptability of parking policies and how people viewed cars and their use. Acceptability of policies 
increased as the view of car use becomes more negative. When testing for individual opinion of cars in the survey, questions included instrumental, symbolic and emotional purposes of the car. Results suggest that those who had a more positive view of car use saw the car as more than a mode of transportation, and therefore had a strong resistance to any policy that tries to limit their car use, so found parking policies less acceptable. Steg (2005) suggests that there are many motives beyond instrumental, including social and affective, that influence how car users feel about cars and recommends that all of the motives for car use should be considered by policy makers.

As environmental concern (NEP) scores increase, results showed a corresponding increase in parking policy acceptability. This idea of higher levels of environmental awareness was again reflected with those who had found parking policies to be more acceptable also having higher scores in having an understanding of the link between car use and environmental damage. This may reflect the people who are willing to contribute to a societal benefit at the expense of giving up individual short-term benefits of car use as Schuitema (2010) suggests. Increasing environmental concern may also relate to increasing levels of environmental justice as part of the fairness motive of the GEF hypothesis. Schuitema (2010) found that the fairness principle of environmental justice was the most important factor in determining policy acceptability and overall fairness.

Increasing age and income were seen to correlate to higher scores of positive opinions of cars, and lower NEP and links between cars and environmental damage. This suggests that older members of the public have less concern or awareness of environmental impacts from car use. Jaensirisak et al. (2005) found that older people are less likely to find road pricing policies acceptable. Schade and Schlag (2003) found that higher acceptability levels are made when people are aware of the negative outcomes from car use. Other studies by Eriksson et al. (2006) and 
Schuitema and Jakobsson Berstad (2012) found that policies that benefit the environment are generally more acceptable when people have higher problem awareness of environmental issues. Making people more aware of the problems and possible solutions of car use may increase acceptability of parking policies.

\subsection{Current Wellington CBD car parking policy}

Like many parts of the urban world, Wellington has a large proportion of the population using cars for day-to-day transport, adding to congestion and pollution issues. The majority of respondents has access to and uses a car weekly, with convenience and reliability ranked as the main factors considered in mode choice. Though there was no statistically significant difference in mean acceptability levels between car and non-car users, non-car users showed slightly higher levels of acceptability in the overall spread. Other studies including Jaensirisak et al. (2005) also found higher levels of acceptability to road pricing among non-car users.

The latest Census journey to work data states 53.5 percent of the population use a car as the mode of transportation to work (Statistics New Zealand, 2014a). This is a figure that has the potential to decrease in favour of active and public transportation options. While parking policy was chosen as a potential push measure, simultaneous pull measures are likely to aid in this transition. Respondents' comments highlighted this need suggesting more focus on public and active transport improvements in addition to changing parking policies such as raising fees, or reducing the number of parking spaces.

Current car parking policy in Wellington can be seen in various forms. Options in parking comprise both on-road and off-road parks, with various fees, time limit and vehicle restrictions at different locations. This study focused on the on-road parks within the CBD of which most have a two hour time restriction and require a fee of up to $\$ 4$ an hour (see Figure 3.1 
for fee map). Over half of respondents who park within the CBD use these pay-and-display zones at least once a week. Results suggest that the majority of respondents view the current parking situation as satisfactory, in that the policy provides sufficient spaces, close to destinations at a reasonable price.

Wellington CBD does not have minimum-parking standards, so available parking is not in complete excess. This can be seen by results suggesting that people are willing to pay for parking, especially at times when parking is limited. However, current parking policy allows for fee parking in the CBD during weekends and nights (though time limits still apply). Comments made suggest this is a large issue for some people who find parking during these times difficult, though conversely others support the policy saying these are the only times they drive to the CBD to avoid paying for parking. Current parking fees and parking time limits were also seen to put some people off driving to the CBD. Some respondents suggested that they prefer to do their shopping at the malls in Lower Hutt and Porirua as it is more convenient for parking. Marsden (2006) suggests that shoppers can modify their parking behavior to limit parking fees, but will make other adjustments before they change to a less desirable shopping location. Economic consequences of policy change were not specifically addressed in this study. Previous research shows differences between behavioral studies and aggregate statistical studies (Still \& Simmonds, 2000). Behavioral studies tend to show negative economic outcomes of restrictive parking policies, while aggregate studies tend to show more positive outcomes. However, minor suggestions of loss of customers to shopping areas makes parking policies even more politically sensitive (Marsden, 2006) and enhances the need for greater levels of public acceptability.

How acceptability levels would change if any new parking policies were implemented is not known. In the case of the Stockholm congestion charge, acceptability before the trial was low (Schuitema, Steg, \& Forward, 
2010). However, after the charge was implemented and pull measures such as increased public transport and park-and-ride facilities were also put in place, acceptability levels increased (Schuitema \& Jakobsson Berstad, 2012). This could be similar in Wellington: if the right combination of push and pull measures were implemented together, acceptability of parking policy changes may increase.

\subsection{Limitations}

Though the survey was open to all residents of the Greater Wellington Region, those who did take part may have had a particular interest in the topic. This may mean that results cannot be generalised to the wider population as they may be swayed to a particular direction. However, comparing Census data with demographic data gathered from the survey showed to some extent how the survey sample and the wider population differ. This did demonstrate some differences between the sample and the wider population. However, the survey did still capture views across a range of the population who are interested in parking issues and therefore still allows for insights into residents' perceptions of parking in Wellington CBD.

A major factor in how parking is viewed in Wellington relates to the growing debate around cycling infrastructure. Cyclists in Wellington have been pushing for more cycle lanes, in and around the city. Part of this argument is to remove on-road parking to make way for this infrastructure. A recent survey reported that the majority of Wellington respondents would be willing to lose parking on one side of the road to create space for safer cycle lanes (Pettit \& Dodge, 2014). The majority of respondents in this survey also stated that that on-road parking space would be better utilized by cycleways (and to a lesser extent pedestrian walking space). As a specific question about cycling was not asked, it is unclear from results how many respondents classify themselves as cyclists. However, the additional respondent comments made suggest participants have arguments for and 
against these potential changes. This illustrates how parking space versus cycle infrastructure is a wider contributing issue in parking acceptability.

The results examining acceptability levels were found by using hypothetical scenario-based policies. Scenario studies are useful to understand which factors may affect the acceptability of policies before they are implemented (Schuitema, 2010). As Wellington CBD has not yet had any of the hypothetical changes implemented, scenarios were seen as a useful way to gauge opinions of a range of parking policies. This allows for comparison between several policies and their varied policy measures. Scenario studies do rely on a respondent's ability to understand and visualise the consequences of such hypothetical policies. However, the issue with transport pricing policies is the lack of acceptability they often receive from the public before implementation. As such, using hypothetical scenarios does allow for an appropriate level of understanding of acceptability levels of a policy that has not yet been introduced. How these levels of acceptability would change if these hypothetical policies were introduced remains unknown. Previous literature does suggest acceptance levels would increase if the aims of the new policy were met.

Some specific types of parking policy variables were not covered in the survey but were mentioned in survey participants' comments. Time limits seemed to be another way in which people make choices about their car use. How this variable influences policy acceptability could be an area for future research.

\subsection{Recommendations and conclusion}

Schade and Schlag (2000) suggest that people can have a strong emotional response when charges are implemented to road areas that they consider to be free public goods. Parking can be highlighted as a form of specific use of public space, rather than a space seen as a right to store private property. Results suggest that people considered both their own personal 
outcomes as well as the outcomes for society when they evaluated the acceptability of parking policies. As such, local councils need to highlight the positive outcomes of parking policies at a collective level in addition to how these outcomes will benefit car users at an individual level, to appeal to all three measures of the GEF hypothesis (greed, efficiency and fairness).

Parking policy needs to combine push measures such as increasing parking fees and decreased parking spaces with related pull services that make other modes of transportation more favourable. As Steg and Vlek (2009) suggest, pricing policies can be used to decrease the price of desired behaviours and increase the price of undesirable behaviour. One such policy that may complement CBD parking policy is park-and-ride or parkand walk-areas. Additional comments suggested that these types of facilities need to be expanded. This was not limited to increasing parking at train or bus stations, but to parking zones at the edge of the CBD that are currently zoned as coupon parking.

In terms of fee, acceptability levels are at their greatest when fees are at their lowest. To investigate potential fee increases further, availability levels of parking throughout the week needs to be examined. Current CBD parking policy relates mostly to pay-and-display zones that allow a maximum of two hours parking duration with a fee of $\$ 4$ an hour. However, current policy also allows free parking in evenings and weekends. The number of parking spaces available in each of these situations changes and needs to be further examined to identify if the vacancy rate is consistent with international standards of below 15 percent. Fee levels could then reflect the demand for parking spaces during different times. If higher vacancy rates are seen, then removing parking spaces could also be seen as a valid option.

As higher fees are slightly less acceptable, more attention needs to be given to where the revenue from these fees is allocated. To create a policy that is effective in reducing car traffic, using revenue to assist in improving 
other modes of transport can be seen as a reciprocal pull factor. Results suggest that improving the quality of public transportation would be seen as not only acceptable, but effective and would have the highest personal benefits to the public from the policy outcomes.

Policy is political, so for policy to be accepted, causes and solutions to problems need to achieve credibility in public communities (Walters \& Holling, 1990). For any changes to parking policies to be made acceptable, other examples of successful transport pricing policies should be referred to. In the Stockholm example, a trial was conducted over 7 months. It is likely that this gave the residents of the city time to experience the positive outcomes of the policy, such as reductions in congestion and pollution levels. This changed their original low acceptability levels held before the trial, to higher levels that resulted in permanent implementation of the policy after a positive referendum result. This process could be a way to change current CBD parking policies within Wellington. The public need a chance to experience a policy themselves to see if their perceived effectiveness, consequences, outcomes and acceptability levels are the same in reality as what they imagine them to be.

The Wellington CBD parking policy could be updated in a number of ways. This update would allow parking in the CBD to become more aligned with the vision the WCC has outlined in their transport strategy and other documentation in facilitating a move away from private car use. Several recommendations can be made to start changes that would see parking policy act as a push measure to move individuals away from car use. Firstly, the fee of parking spaces could be increased or the number of parking spaces reduced. Even a slight rise in fee of 50c, or creating slightly less available parking would make people reconsider their travel choices. Secondly, revenue raised from these fees that is above what is needed to maintain and run the parking system should be allocated to improving active and public transportation in some way. This would mean that not 
only is there a push measure implemented to direct individuals away from car use, but there is a reciprocal pull measure implemented that supports wanted travel behaviours. Improving active and public transportation with revenue from parking by various means including subsidising public transport fares, or creating new active transport infrastructure, would then help to increase the acceptability of a parking policy. Thirdly, these changes to policy could be made in a policy trial situation. During this trial, the positive policy outcomes for individuals and society should be highlighted. If these are then experienced in the trial period, increasing acceptability to make the policy permanent may be gained.

This research aimed to give more context to how New Zealand urban residents view the acceptability of parking policies. The results supported other studies that show public acceptability levels of pricing policies increase when people believe they will personally benefit from policy outcomes, but this can also happen when they see a potential benefit to the wider public. To gain higher acceptability levels, local government needs to highlight the positive effects of new policies and create opportunities for these outcomes to be experienced by the public in the form of policy trials. 


\section{References}

Arnott, R., \& Rowse, J. (1999). Modeling parking. Journal of Urban Economics, 45(1), 97-124.

Banister, D. (2003). Critical pragmatism and congestion charging in London. International Social Science Journal, 55(176), 249-264.

Benenson, I., Martens, K., \& Birfir, S. (2008). PARKAGENT: An agent-based model of parking in the city. Computers, Environment and Urban Systems, 32(6), 431-439.

Berrittella, M., Certa, A., Enea, M., \& Zito, P. (2007). An analytic hierarchy process for the evaluation of transport policies to reduce climate change impacts. Nota di Lavoro, Fondazione Eni Enrico Mattei. Retrieved from http://hdl.handle.net/10419/74293

Bethlehem, J., \& Biffignandi, S. (2012). Handbook of web surveys (Vol. 567). New Jersey: John Wiley \& Sons.

Brog, W., \& John, G. (2001, 3 August 2001). Personalised Marketing - the Perth Success Story. Paper presented at the Marketing Public Transport Conference, Auckland, New Zealand.

Buchanan, N., Barnett, R., Kingham, S., \& Johnston, D. (2006). The effect of urban growth on commuting patterns in Christchurch, New Zealand Journal of Transport Geography, 14(5), 342-354.

Button, K. J., \& Verhoef, E. T. (1998). Road pricing, traffic congestion and the environment: Issues of efficiency and social feasibility. Cheltenham, UK: Edgar Elgar.

Chapman, L. (2007). Transport and climate change: a review. Journal of Transport Geography, 15(5), 354-367.

Collis, H., \& Inwood, H. (1996). Attitudes to road pricing in the Bristol area. Traffic Engineering \& Control, 37(10), 580-584.

Dawes, R. M. (1980). Social dilemmas. Annual Review of Psychology, 31, 169-193.

De Groot, J. I. M., \& Steg, L. (2006). The role of value orientations in evaluating quality of life consequences of a transport pricing policy. 
Transportation Research Part D: Transport and Environment, 11(2), 160-165.

Dittmar, H. (1992). The social psychology of material possessions: To have is to be. Hemel Hempstead, UK: Harvester Wheatsheaf.

Dittmar, H. (2004). Are you what you have. The Psychologist, 17(4), 206210.

Dunlap, R. E. (2008). The new environmental paradigm scale: From marginality to worldwide use. The journal of environmental education, 40(1), 3-18.

Dunlap, R. E., \& Van Liere, K. D. (1978). The “new environmental paradigm". The journal of environmental education, 9(4), 10-19.

Dunlap, R. E., Van Liere, K. D., Mertig, A. G., \& Jones, R. E. (2000). New trends in measuring environmental attitudes: Measuring endorsement of the new ecological paradigm: A revised NEP scale. Journal of Social Issues, 56(3), 425-442.

Eagly, A. H., \& Chaiken, S. (1993). The psychology of attitudes. Orlando, FL, US: Harcourt Brace Jovanovich College Publishers.

Eagly, A. H., \& Chaiken, S. (2007). The advantages of an inclusive definition of attitude. Social Cognition, 25(5), 582-602.

Eriksson, L., Garvill, J., \& Nordlund, A. M. (2006). Acceptability of travel demand management measures: The importance of problem awareness, personal norm, freedom, and fairness. Journal of environmental psychology, 26(1), 15-26.

Evans, J. R., \& Mathur, A. (2005). The value of online surveys. Internet Research, 15(2), 195-219.

Ewing, R., Bartholomew, K., Winkelman, S., Walters, J., \& Chen, D. (2007). Growing cooler: The evidence on urban development and climate change. Washington, D.C.: ULI-the Urban Land Institute.

Ferguson, E. (2004). Zoning for parking as policy process: A historical review. Transport Reviews, 24(2), 177-194.

Field, A. (2000). Discovering statistics using SPSS for Windows: Advanced techniques for the beginner. London: Sage Publications. 
Fujii, S., Gärling, T., Jakobsson, C., \& Jou, R.-C. (2004). A cross-country study of fairness and infringement on freedom as determinants of car owners' acceptance of road pricing. Transportation, 31(3), 285-295.

Gärling, T., Eek, D., Loukopoulos, P., Fujii, S., Johansson-Stenman, O., Kitamura, R., ... Vilhelmson, B. (2002). A conceptual analysis of the impact of travel demand management on private car use. Transport Policy, 9(1), 59-70.

Garling, T., Jakobsson, C., Loukopoulos, P., \& Fujji, S. (2008). Public acceptability of road pricing. In E. T. Verhoef, M. C. J. Bliemer, L. Steg \& B. Van Wee (Eds.), Pricing in road transport: A multidisciplinary perspective (pp. 193-208). Cheltenham, UK and Northampton, MA: Edward Elgar.

Gärling, T., \& Schuitema, G. (2007). Travel demand management targeting reduced private car use: Effectiveness, public acceptability and political feasibility. Journal of Social Issues, 63(1), 139-153.

Gatersleben, B., \& Steg, L. (2012). Affective and symbolic aspects of environmental behaviour. In L. Steg, A. E. Van Den Berg \& J. I. M. De Groot (Eds.), Environmental Psychology: An introduction (pp. 165174). Oxford: Wiley-Blackwell.

Gehl, J. (2004). City to waterfront : public spaces and public life study (pp. 81). Wellington.

Hagman, O. (2006). Morning queues and parking problems. On the broken promises of the automobile. Mobilities, 1(1), 63-74.

Haque, M. M., Chin, H. C., \& Debnath, A. K. (2013). Sustainable, safe, smart-three key elements of Singapore's evolving transport policies. Transport Policy, 27(0), 20-31.

Hensher, D. A. (2008). Climate change, enhanced greenhouse gas emissions and passenger transport: What can we do to make a difference? Transportation Research Part D: Transport and Environment, 13(2), 95-111.

Hensher, D. A., \& Li, Z. (2013). Referendum voting in road pricing reform: A review of the evidence. Transport Policy, 25(0), 186-197. 
Hewson, C., Yule, P., Laurent, D., \& Vogel, C. (2002). Internet research methods: A practical guide for the social and behavioural sciences London: SAGE Publications.

leromonachou, P., Potter, S., \& Warren, J. P. (2006). Norway's urban toll rings: Evolving towards congestion charging? Transport Policy, 13(5), 367-378.

Institution of Highways and Transportation. (2005). Parking strategies and management. Essex: HQ Media Services Ltd.

Jaensirisak, S., Wardman, M., \& May, A. D. (2005). Explaining variations in public Aacceptability of road pricing schemes. Journal of Transport Economics and Policy, 39(2), 127-153.

Jakobsson, C., Fujii, S., \& Gärling, T. (2000). Determinants of private car users' acceptance of road pricing. Transport Policy, 7(2), 153-158.

Kitamura, R., Fujii, S., \& Pas, E. I. (1997). Time-use data, analysis and modeling: toward the next generation of transportation planning methodologies. Transport Policy, 4(4), 225-235.

Leape, J. (2006). The London congestion charge. The Journal of Economic Perspectives, 20(4), 157-176.

Li, F., \& Guo, Z. (2014). Do parking standards matter? Evaluating the London parking reform with a matched-pair approach. Transportation Research Part A: Policy and Practice, 67, 352-365.

Litman, T. (2009). Transportation cost and benefit analysis: Techniques, estimates and implications. Victoria, Canada: Victoria Transport Policy Institute.

Loukopoulos, P., Jakobsson, C., Gärling, T., Schneider, C. M., \& Fujii, S. (2005). Public attitudes towards policy measures for reducing private car use: evidence from a study in Sweden. Environmental Science \& Policy, 8(1), 57-66.

Marsden, G. (2006). The evidence base for parking policies: A review. Transport Policy: Special Issue on Parking, 13(6), 447-457.

Millard-Ball, A. (2002). Putting on their parking caps. Planning. April, 2002, $16-21$. 
New Zealand Transport Agency. (2012). National land transport programme 2012-15 at a glance. Wellington: New Zealand Government.

Odeck, J., \& Bråthen, S. (1997). On public attitudes toward implementation of toll roads: The case of Oslo toll ring. Transport Policy, 4(2), 73-83. Odeck, J., \& Bråthen, S. (2002). Toll financing in Norway: The success, the failures and perspectives for the future. Transport Policy, 9(3), 253260.

OECD. (2013). Greening household behaviour: Overview from the 2011 survey OECD Studies on Environmental Policy and Household Behaviour: OECD Publishing.

Pearce, D. (2002). An intellectual history of environmental economics. Annual review of energy and the environment, 27(1), 57-81.

Pettit, T., \& Dodge, N. (2014). Cycling demand analysis. Wellington: Wellington City Council.

Potter, S. ( 2003). Transport energy and emissions: urban public transport. In D. A. Hensher, Button, K.J. (Ed.), Handbooks in Transport 4: Handbook of Transport and the Environment. (pp. 247-262). Amsterdam, Netherlands: Elsevier.

Prud'homme, R., \& Bocarejo, J. P. (2005). The London congestion charge: A tentative economic appraisal. Transport Policy, 12(3), 279-287.

Rajan, S. C. (2006). Climate change dilemma: technology, social change or both? An examination of long-term transport policy choices in the United States. Energy Policy, 34(6), 664-679.

Ryan, L., \& Turton, H. (2008). Sustainable automobile transport: Shaping climate change policy. Cheltenham, UK: Edward Elgar Publishing.

Schade, J., \& Schlag, B. (2000). Acceptability of urban transport pricing (pp. 157). Helsinki: VATT.

Schade, J., \& Schlag, B. (2003). Acceptability of urban transport pricing strategies. Transportation Research Part F: Traffic Psychology and Behaviour, 6(1), 45-61. 
Schlag, B., \& Teubel, U. (1997). Public acceptability of transport pricing. IATSS Research, 21, 134-142.

Schuitema, G. (2010). Priceless policies: Factors influencing the acceptability of transport pricing policies. (Doctoral dissertation), University of Groningen, Groningen.

Schuitema, G., \& Jakobsson Berstad, C. (2012). Acceptability of environmental policies. In L. Steg, A. E. Van Den Berg \& J. I. M. De Groot (Eds.), Environmental psychology: An introduction (pp. 255266). Oxford: Wiley-Blackwell.

Schuitema, G., \& Steg, L. (2008). The role of revenue use in the acceptability of transport pricing policies. Transportation Research Part F: Traffic Psychology and Behaviour, 11(3), 221-231.

Schuitema, G., Steg, L., \& Forward, S. (2010). Explaining differences in acceptability before and acceptance after the implementation of a congestion charge in Stockholm. Transportation Research Part A: Policy and Practice, 44(2), 99-109.

Schuitema, G., Steg, L., \& Rothengatter, J. A. (2010). The acceptability, personal outcome expectations, and expected effects of transport pricing policies. Journal of environmental psychology, 30(4), 587593.

Schuitema, G., Steg, L., \& van Kruining, M. (2011). When are transport pricing policies fair and acceptable? Social Justice Research, 24(1), 66-84.

Seik, F. T. (1997). An effective demand management instrument in urban transport: The area licensing scheme in Singapore. Cities, 14(3), 155-164.

Shoup, D. C. (1995). An opportunity to reduce minimum parking requirements. Journal of the American Planning Association, 61(1), 14-28.

Shoup, D. C. (2005). The high cost of free parking. Chicago: American Planning Asscociation, Planners Press. 
Snapper. (2014). Snapper your parking. Retrieved 10 June 2014, from http://www.snapper.co.nz/parking/

Statistics New Zealand. (2014a). 2013 Census tables about a place:

Wellington Region. Retrieved 13 November 2014, from

http://www.stats.govt.nz/Census/2013-census/data-tables/tablesabout-a-

place. aspx ?request_value $=24467 \&$ reportid=14\&tabname $=\#$

Statistics New Zealand. (2014b). Subnational population estimates: at 30 June 2014 (provisional). Retrieved 13 November 2014, from http://www.stats.govt.nz/browse_for_stats/population/estimates and_projections/SubnationalPopulationEstimates_HOTPAt30Jun14. aspx

Steg, L. (2005). Car use: lust and must. Instrumental, symbolic and affective motives for car use. Transportation Research Part a-Policy and Practice, 39(2-3), 147-162.

Steg, L., Dreijerink, L., \& Abrahamse, W. (2006). Why are energy policies acceptable and effective? Environment and Behavior, 38(1), 92-111.

Steg, L., \& Vlek, C. (2009). Encouraging pro-environmental behaviour: An integrative review and research agenda. Journal of environmental psychology, 29(3), 309-317.

Still, B., \& Simmonds, D. (2000). Parking restraint policy and urban vitality. Transport Reviews, 20(3), 291-316.

Stubbs, M. (2002). Car parking and residential development: Sustainability, design and planning policy, and public perceptions of parking provision. Journal of Urban Design, 7(2), 213-237.

Thorpe, N. (2002). Public acceptance of road-user charging. IATSS Research, $26,17-27$.

Trodahl, M., \& Weaver, S. (2007). Reducing road transport carbon emissions: Options for government policy School of Geography Environment and Earth Sciences Research Report (pp. 18): Victoria University of Wellington. 
Ubbels, B., \& Verhoef, E. (2006). Acceptability of road pricing and revenue use in the Netherlands. European Transport, 32, 69-94.

Verhoef, E., Nijkamp, P., \& Rietveld, P. (1997). Tradeable permits: their potential in the regulation of road transport externalities. Environment and Planning B, 24, 527-548.

von Borgstede, C., Johansson, L.-O., \& Nilsson, A. (2012). Social dilemmas: Motivational, individual and strauctual aspects influencing cooperation. In L. Steg, A. E. Van Den Berg \& J. I. M. De Groot (Eds.), Environmental psychology: An introduction (pp. 175-184). Oxford: Wiley-Blackwell.

Walters, C. J., \& Holling, C. S. (1990). Large-scale management experiments and learning by doing. Ecology, 71, 2060-2068.

Wellington City Council. (2006). Transport strategy. Wellington: Wellington City Council.

Wellington City Council. (2007). Parking policy. Wellington: Wellington City Council.

Wellington City Council. (2010). Central city framework. Wellington: Wellington City Council.

Wellington City Council. (2014). On-street parking: Meters and pay-anddisplay. Retrieved 04 April 2014, from http://wellington.govt.nz/services/parking-and-roads/parking/onstreet-parking/meters-and-pay-and-display

Wellington City Council. (nd). District plan. Retrieved from http://wellington.govt.nz/ /media/your-council/plans-policies-andbylaws/district-plan/volume01/files/v1chap07rules.pdf.

Wilke, H. A. M. (1991). Greed, efficiency and fairness in resource management situations. European Review of Social Psychology, 2(1), 165-187.

Willoughby, C. (2001). Singapore's motorization policies 1960-2000. Transport Policy, 8(2), 125-139. 
Willson, R. W. (1995). Suburban parking requirements: A tacit policy for automobile use and sprawl. Journal of the American Planning Association, 61(1), 29-42. 


\section{Appendices}

\section{Appendix 1. Ethics approval}

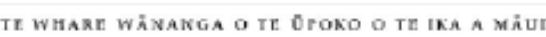

59

UN $*$ UNIVESITY of WELLINGTON

MEMORANDUM

Phone $\quad 0-4-4635676$

Fax $\quad 0-4-4635209$

Email Allison kirkmanifvuw.acna

\begin{tabular}{l|l}
\hline TO & Kate Coles \\
\hline COPY TO & Wokje Abrahamse \\
\hline FROM & Dr Allison Kirkman, Convener, Human Ethics Committee \\
\hline
\end{tabular}

\begin{tabular}{l|l}
\hline DATE & 7 June 2014 \\
\hline PAGES & 1 \\
\hline
\end{tabular}

SUBJECT $\quad$ Ethics Approval: 21063

Acceptability of Parking Policies in Wellington

Thank you for your application for ethical approval. Your application has been considered by the Convener of the Human Ethics Committee and identified as research involving anonymous participation.

Your application has been approved from the above date and this approval continues until 3 March 2015. If your data collection is not completed by this date you should apply to the Human Ethics Committee for an extension to this approval.

Best wishes with the research

Allison Kirkman

Human Ethics Committee

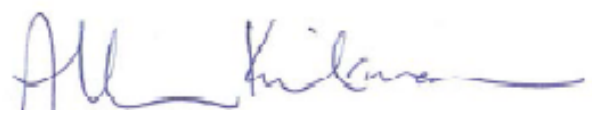




\section{Appendix A2. Participant information sheet}

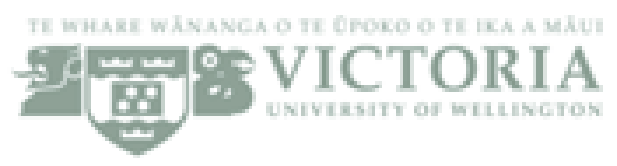

\section{Information Sheet}

\section{Wellington CBD Parking Policy Study}

Thank you for giving consideration to participating in this independent research study into the opinions and experiences of car parking in Wellington city. The study being conducted aims to find out more about what the Wellington publics views of parking policy are.

This study is being led by Kate Coles, a Master's student from the Environmenta Studies programme at Victoria University. Supervising this research is Dr. Wokje Abrahamse, a Lecturer in Environmental Studies at VuW.

This research aims to identify the accepta bility and perceived effectiveness of different parking policies, by both the public who use parking spaces within the Wellington $\mathrm{CD}$, and those who don't. We are interested in your experience of parking and how it may be improved. There are no right or wrong answers, we are interested in your opinion.

The information you provide will contribute to a wider research on transportation in Wellington and how it may be improved. We expect that the research findings will be made available to government organizations including regional and local councils.

The online survey should take around 15-20 minutes to complete, depending on the depth of detail you are interested in sharing with us.

If you have any further questions or would like further information about the project, please contact myself at kate.coles@vuw.ac.nz or Wokje at 044635217 , wokje.abrahamse@vuw.ac.nz

Thank you for your participation,

Kate Coles 


\section{Appendix A3. Consent to participate in research}

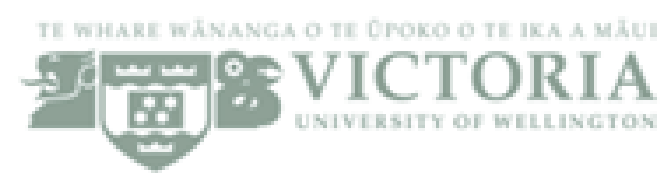

\section{Consent to Participate in Research}

\section{Wellington CBD Parking Policy Study}

Researcher: Kate Coles [Moster's student]

- I have been given, and have understood, the Information sheet explaining this research project.

- I have been given the opportunity to ask questions and receivesatisfactory answers in return.

- I understand that my responses will remain anomymous and that my responses will not be identifiable

- I understand that my responses will remain confidential, and every effort will be made to ensure that any data I provide cannot be attributed to me as an individual.

- I agree to take part in this research, through completing an online survey | prepared by the researchers identified above (and identified on the information sheet].

- I understand that I may withdraw myself (or any information I have provided] from this project, without having to give reasons, by e-mailing kate.coles@vuw.ac.nz by 31st August 2014.

- I understand that this survey is conducted online, and the data will be destroyed within 2 years of the conclusion of the project.

- I understand that the data I provide will not be used for any other purpose than the stated research study, or released to others.

Please indicate your consent to participate in the survey by ticking the box below

$\square \quad$ I agree to take part in this survey 


\section{Appendix A4. Online survey}

Note: Questions were viewed by survey participants according to their responses. Therefore, not all questions were viewed by participants.

For the purposes of this survey the following definitions will be used: cars: light four-wheeled vehicles including cars, vans, utes and SUVS parks: onroad carparking spaces, unless otherwise stated

\section{Section 1: Your Personal Transportation}

1) Thinking of an average journey, what is your main form of transportation for..... (If you use more than one travel mode per trip, choose the mode of transportation you use for the longest distance. For example, if you walk 5 minutes to the bus stop, then catch a bus for 20 minutes, indicate bus as your main form of transportation)

\begin{tabular}{|l|l|l|l|l|l|l|l|}
\hline & Car & Bicycle & $\begin{array}{l}\text { Walking/ } \\
\text { Running }\end{array}$ & Bus & Motorcycle & Train & Other \\
\hline $\begin{array}{l}\text { Work/ } \\
\text { Study } \\
\begin{array}{l}\text { Leisure/ } \\
\text { Recreation } \\
\text { Shopping }\end{array}\end{array}$ & 0 & 0 & 0 & 0 & 0 & 0 & 0 \\
\hline
\end{tabular}

2) For each of the following, please indicate how important they are to you when making transport choices

\begin{tabular}{|c|c|c|c|c|c|c|c|}
\hline & $\begin{array}{l}\text { Not at all } \\
\text { Important }\end{array}$ & $\begin{array}{l}\text { Very } \\
\text { Unimportant }\end{array}$ & $\begin{array}{l}\text { Somewhat } \\
\text { Unimportant }\end{array}$ & $\begin{array}{l}\text { Neither } \\
\text { Important } \\
\text { nor } \\
\text { Unimportant }\end{array}$ & $\begin{array}{l}\text { Somewhat } \\
\text { Important }\end{array}$ & $\begin{array}{l}\text { Very } \\
\text { Important }\end{array}$ & $\begin{array}{l}\text { Extremely } \\
\text { Important }\end{array}$ \\
\hline Cost & O & O & O & O & O & O & O \\
\hline Convenience & 0 & O & O & 0 & O & 0 & O \\
\hline $\begin{array}{l}\text { Reliability of } \\
\text { transport }\end{array}$ & O & O & O & O & O & O & O \\
\hline $\begin{array}{l}\text { Duration of } \\
\text { journey }\end{array}$ & 0 & O & 0 & O & O & O & O \\
\hline $\begin{array}{l}\text { Frequency of } \\
\text { service }\end{array}$ & O & O & O & O & O & O & 0 \\
\hline $\begin{array}{l}\text { Environmental } \\
\text { considerations }\end{array}$ & O & O & O & O & O & O & 0 \\
\hline
\end{tabular}


3) Do you own/have access to a car?

O Yes

No If No Is Selected, Then Skip To Q5.

4) How often do you use a car for any purpose?

O Never

O Less than Once a Month

O Once a Month

O 2-3 Times a Month

O Once a Week

O 2-3 Times a Week

O Daily

5) Do you park in Wellington CBD (including as a passenger)?

O Yes

No If No Is Selected, Then Skip To Q8.

6) Within Wellington $\mathrm{CBD}$, how often do you use the following onroad paid parking zones during weekdays?

\begin{tabular}{|c|c|c|c|c|c|c|c|c|c|c|}
\hline & \multicolumn{5}{|c|}{$\begin{array}{l}\text { How often do you use the following on- } \\
\text { road paid parking zones during } \\
\text { weekdays? }\end{array}$} & \multicolumn{5}{|c|}{ On average, how long do you park for? } \\
\hline & Daily & $\begin{array}{l}\text { 3-4 } \\
\text { days a } \\
\text { week }\end{array}$ & $\begin{array}{l}1-2 \\
\text { days a } \\
\text { week }\end{array}$ & Never & Occasionally & $\begin{array}{l}\text { Less } \\
\text { than } 2 \\
\text { hours }\end{array}$ & $\begin{array}{l}2-4 \\
\text { hours }\end{array}$ & $\begin{array}{l}4-6 \\
\text { hours }\end{array}$ & $\begin{array}{l}\text { More } \\
\text { than } 6 \\
\text { hours }\end{array}$ & $\begin{array}{l}\text { Not } \\
\text { applicable }\end{array}$ \\
\hline Coupon & $\mathrm{O}$ & O & O & O & O & O & O & O & O & O \\
\hline $\begin{array}{l}\text { Pay-and- } \\
\text { display }\end{array}$ & $\mathrm{O}$ & O & $\mathrm{O}$ & O & 0 & $\mathrm{O}$ & $\mathrm{O}$ & $\mathrm{O}$ & $\mathrm{O}$ & $\mathrm{O}$ \\
\hline $\begin{array}{l}\text { Residents } \\
\text { zone }\end{array}$ & O & O & $\mathrm{O}$ & $\mathrm{O}$ & $\mathrm{O}$ & $\mathrm{O}$ & $\mathrm{O}$ & $\mathrm{O}$ & O & O \\
\hline $\begin{array}{l}\text { Other } \\
\text { (please } \\
\text { state) }\end{array}$ & O & O & O & O & $\mathrm{O}$ & O & O & O & O & O \\
\hline
\end{tabular}


7) Within Wellington $C B D$, how often do you use the following offroad paid parking zones during weekdays?

\begin{tabular}{|c|c|c|c|c|c|c|c|c|c|c|}
\hline & \multicolumn{5}{|c|}{$\begin{array}{l}\text { How often do you use the following off- } \\
\text { road paid parking zones during } \\
\text { weekdays? }\end{array}$} & \multicolumn{5}{|c|}{ On average, how long do you park for? } \\
\hline & Daily & $\begin{array}{l}\text { 3-4 } \\
\text { days a } \\
\text { week }\end{array}$ & $\begin{array}{l}1-2 \\
\text { days a } \\
\text { week }\end{array}$ & Never & Occasionally & $\begin{array}{l}\text { Less } \\
\text { than } 2 \\
\text { hours }\end{array}$ & $\begin{array}{l}2-4 \\
\text { hours }\end{array}$ & $\begin{array}{l}4-6 \\
\text { hours }\end{array}$ & $\begin{array}{l}\text { More } \\
\text { than } 6 \\
\text { hours }\end{array}$ & $\begin{array}{l}\text { Not } \\
\text { applicable }\end{array}$ \\
\hline $\begin{array}{l}\text { Shop } \\
\text { parking } \\
\text { areas }\end{array}$ & O & O & $\mathrm{O}$ & $\mathrm{O}$ & O & O & O & $\mathrm{O}$ & O & $\mathrm{O}$ \\
\hline $\begin{array}{l}\text { Private } \\
\text { residence }\end{array}$ & O & $\mathrm{O}$ & $\mathrm{O}$ & $\mathrm{O}$ & O & O & $\mathrm{O}$ & $\mathrm{O}$ & O & $\mathrm{O}$ \\
\hline $\begin{array}{l}\text { Private } \\
\text { company } \\
\text { park }\end{array}$ & O & O & $\mathrm{O}$ & O & O & O & O & $\mathrm{O}$ & O & O \\
\hline $\begin{array}{l}\text { Parking } \\
\text { building }\end{array}$ & O & $O$ & $\mathrm{O}$ & O & O & O & O & O & O & O \\
\hline $\begin{array}{l}\text { Other } \\
\text { (please } \\
\text { state) }\end{array}$ & O & O & $\mathrm{O}$ & O & O & O & $\mathrm{O}$ & O & O & O \\
\hline
\end{tabular}




\section{Section 2: Your Opinion about Current Parking}

8) Read the following statements and state how strongly you agree or disagree with each statement

\begin{tabular}{|c|c|c|c|c|c|c|c|}
\hline & $\begin{array}{l}\text { Strongly } \\
\text { Agree }\end{array}$ & Agree & $\begin{array}{l}\text { Somewhat } \\
\text { Agree }\end{array}$ & $\begin{array}{l}\text { Neither } \\
\text { Agree } \\
\text { nor } \\
\text { Disagree }\end{array}$ & $\begin{array}{l}\text { Somewhat } \\
\text { Disagree }\end{array}$ & Disagree & $\begin{array}{l}\text { Strongly } \\
\text { Disagree }\end{array}$ \\
\hline $\begin{array}{l}\text { There are a } \\
\text { sufficient } \\
\text { number of } \\
\text { parking } \\
\text { spaces in } \\
\text { Wellington } \\
\text { CBD }\end{array}$ & O & O & O & O & O & O & O \\
\hline $\begin{array}{l}\text { Carparks are a } \\
\text { good use of } \\
\text { public space }\end{array}$ & O & O & O & O & O & O & O \\
\hline $\begin{array}{l}\text { The space } \\
\text { which on- } \\
\text { road parking } \\
\text { uses would be } \\
\text { better utilised } \\
\text { by cycleways }\end{array}$ & O & O & O & O & O & O & O \\
\hline $\begin{array}{l}\text { The space } \\
\text { which on- } \\
\text { road parking } \\
\text { uses would be } \\
\text { better utilised } \\
\text { by pedestrian } \\
\text { paths }\end{array}$ & O & O & O & O & O & O & O \\
\hline $\begin{array}{l}\text { Parking fees } \\
\text { are } \\
\text { reasonably } \\
\text { priced }\end{array}$ & O & O & O & O & O & O & O \\
\hline $\begin{array}{l}\text { Parking is } \\
\text { available } \\
\text { close to my } \\
\text { destinations } \\
\text { in Wellington } \\
\text { CBD }\end{array}$ & O & O & O & O & O & O & O \\
\hline
\end{tabular}




\section{Section 3: Your Opinion about Parking Policies}

9) Think about the following parking policy for Wellington CBD.

\section{Please indicate the following:}

- How acceptable you find the parking policy

- How effective you see the parking policy to be in reducing car traffic and congestion into and within Wellington CBD and

- How this policy would impact on you personally

NB: One of the following nine scenarios was randomly assigned to each participant to be policy that they would assess:

- The cost of parking is $\$ 4$ an hour with a maximum parking duration of 2 hours. Revenue collected from parking fees goes towards maintaining road and street space

- The cost of parking is $\$ 4.50$ an hour with a maximum parking duration of 2 hours. Revenue collected from parking fees goes towards maintaining road and street space.

- The cost of parking is $\$ 5$ an hour with a maximum parking duration of 2 hours. Revenue collected from parking fees goes towards maintaining road and street space.

- The cost of parking is $\$ 4$ an hour with a maximum parking duration of 2 hours. Revenue collected from parking fees goes towards improving the quality of public transport.

- The cost of parking is $\$ 4.50$ an hour with a maximum parking duration of 2 hours. Revenue collected from parking fees goes towards improving the quality of public transport.

- The cost of parking is $\$ 5$ an hour with a maximum parking duration of 2 hours. Revenue collected from parking fees goes towards improving the quality of public transport.

- The cost of parking is $\$ 4$ an hour with a maximum parking duration of 2 hours. Revenue collected from parking fees goes to the general public fund.

- The cost of parking is $\$ 4.50$ an hour with a maximum parking duration of 2 hours. Revenue collected from parking fees goes to the general public fund.

- The cost of parking is $\$ 5$ an hour with a maximum parking duration of 2 hours. Revenue collected from parking fees goes to the general public fund. 


\begin{tabular}{|c|c|c|c|c|c|c|c|}
\hline $\begin{array}{l}\text { How } \\
\text { acceptable } \\
\text { is this } \\
\text { parking } \\
\text { policy to } \\
\text { you? }\end{array}$ & $\begin{array}{l}\text { Very } \\
\text { acceptable }\end{array}$ & Acceptable & $\begin{array}{l}\text { Somewhat } \\
\text { acceptable }\end{array}$ & $\begin{array}{l}\text { Neither } \\
\text { acceptable } \\
\text { nor } \\
\text { unacceptab } \\
\text { le }\end{array}$ & $\begin{array}{l}\text { Somewhat } \\
\text { unacceptable }\end{array}$ & $\begin{array}{l}\text { Unaccepta } \\
\text { ble }\end{array}$ & $\begin{array}{l}\text { Very } \\
\text { unaccepta } \\
\text { ble }\end{array}$ \\
\hline $\begin{array}{l}\text { How } \\
\text { effective do } \\
\text { you think } \\
\text { this parking } \\
\text { policy is or } \\
\text { would be in } \\
\text { reducing car } \\
\text { traffic and } \\
\text { congestion } \\
\text { into and } \\
\text { within } \\
\text { Wellington } \\
\text { CBD? }\end{array}$ & $\begin{array}{l}\text { Very } \\
\text { effective }\end{array}$ & Effective & $\begin{array}{l}\text { Somewhat } \\
\text { effective }\end{array}$ & $\begin{array}{l}\text { Neither } \\
\text { effective } \\
\text { nor } \\
\text { ineffective }\end{array}$ & $\begin{array}{l}\text { Somewhat } \\
\text { ineffective }\end{array}$ & Ineffective & $\begin{array}{l}\text { Very } \\
\text { ineffective }\end{array}$ \\
\hline $\begin{array}{l}\text { How would } \\
\text { this parking } \\
\text { policy } \\
\text { impact on } \\
\text { you } \\
\text { personally? }\end{array}$ & $\begin{array}{l}\text { Very } \\
\text { positive }\end{array}$ & Positive & $\begin{array}{l}\text { Somewhat } \\
\text { positive }\end{array}$ & $\begin{array}{l}\text { Neither } \\
\text { positive } \\
\text { nor } \\
\text { negative }\end{array}$ & $\begin{array}{l}\text { Somewhat } \\
\text { negative }\end{array}$ & Negative & $\begin{array}{l}\text { Very } \\
\text { negative }\end{array}$ \\
\hline
\end{tabular}




\section{Section 4: Your Opinion about Pricing Policies in General}

10) The government can allocate the revenues of pricing policies in various ways.

How acceptable are the following types of revenue allocation to you?

\begin{tabular}{|l|l|l|l|l|l|l|l|}
\hline & $\begin{array}{l}\text { Very } \\
\text { acceptable }\end{array}$ & Acceptable & $\begin{array}{l}\text { Somewhat } \\
\text { acceptable }\end{array}$ & $\begin{array}{l}\text { Neither } \\
\text { acceptable } \\
\text { nor } \\
\text { unacceptable }\end{array}$ & $\begin{array}{l}\text { Somewhat } \\
\text { unacceptable }\end{array}$ & Unacceptable & Very \\
Unacceptable
\end{tabular}




\section{Section 5: Your Personal Opinions}

11) Please indicate to what extent you agree or disagree, with the following statements on car preferences

\begin{tabular}{|c|c|c|c|c|c|c|c|}
\hline & $\begin{array}{l}\text { Strongly } \\
\text { Disagree }\end{array}$ & Disagree & $\begin{array}{l}\text { Somewhat } \\
\text { Disagree }\end{array}$ & $\begin{array}{l}\text { Neither Agree } \\
\text { nor Disagree }\end{array}$ & $\begin{array}{l}\text { Somewhat } \\
\text { Agree }\end{array}$ & Agree & $\begin{array}{l}\text { Strongly } \\
\text { Agree }\end{array}$ \\
\hline $\begin{array}{l}\text { I cannot imagine my } \\
\text { life without a car }\end{array}$ & O & O & O & $\mathrm{O}$ & O & O & $\mathrm{O}$ \\
\hline $\begin{array}{l}\text { Only using a car gives } \\
\text { me acceptable } \\
\text { mobility }\end{array}$ & O & O & O & O & O & O & O \\
\hline I enjoy driving a car & $\mathrm{O}$ & $\mathrm{O}$ & O & $\mathrm{O}$ & $\mathrm{O}$ & $\mathrm{O}$ & $\mathrm{O}$ \\
\hline $\begin{array}{l}\text { I feel free and } \\
\text { independent when I } \\
\text { use my car }\end{array}$ & $O$ & O & O & 0 & O & O & O \\
\hline $\begin{array}{l}\text { A car is just like any } \\
\text { other item I own }\end{array}$ & $\mathrm{O}$ & $\mathrm{O}$ & $\mathrm{O}$ & O & O & 0 & O \\
\hline $\begin{array}{l}\text { A small, innovative car } \\
\text { is the smarter } \\
\text { alternative to a large } \\
\text { car }\end{array}$ & $\mathrm{O}$ & O & O & O & $\mathrm{O}$ & O & O \\
\hline $\begin{array}{l}\text { My car is an } \\
\text { expression of my } \\
\text { lifestyle }\end{array}$ & O & O & O & O & O & O & O \\
\hline $\begin{array}{l}\text { Due to high fuel } \\
\text { prices, I drive my car } \\
\text { less }\end{array}$ & O & O & O & O & O & O & O \\
\hline $\begin{array}{l}\text { I prefer not to use a } \\
\text { car }\end{array}$ & O & O & O & O & O & O & O \\
\hline
\end{tabular}


12) Please indicate to what extent you agree or disagree, with the following statements on environmental protection

\begin{tabular}{|c|c|c|c|c|c|c|c|}
\hline & $\begin{array}{l}\text { Strongly } \\
\text { Disagree }\end{array}$ & Disagree & $\begin{array}{l}\text { Somewhat } \\
\text { Disagree }\end{array}$ & $\begin{array}{l}\text { Neither } \\
\text { Agree nor } \\
\text { Disagree }\end{array}$ & $\begin{array}{l}\text { Somewhat } \\
\text { Agree }\end{array}$ & Agree & $\begin{array}{l}\text { Strongly } \\
\text { Agree }\end{array}$ \\
\hline $\begin{array}{l}\text { We are approaching the } \\
\text { limit of the number of } \\
\text { people the earth can } \\
\text { support }\end{array}$ & O & O & O & O & O & O & O \\
\hline $\begin{array}{l}\text { Humans have the right to } \\
\text { modify the natural } \\
\text { environment to suit their } \\
\text { needs }\end{array}$ & O & O & O & O & O & O & O \\
\hline $\begin{array}{l}\text { When humans interfere with } \\
\text { nature, it often produces } \\
\text { disastrous consequences }\end{array}$ & O & O & O & O & O & O & O \\
\hline $\begin{array}{l}\text { Human ingenuity will insure } \\
\text { that we do not make the } \\
\text { earth unlivable }\end{array}$ & O & O & O & O & O & O & O \\
\hline $\begin{array}{l}\text { Humans are severely } \\
\text { abusing the earth }\end{array}$ & O & O & O & 0 & O & O & O \\
\hline $\begin{array}{l}\text { The earth has plenty of } \\
\text { natural resources if we just } \\
\text { learn how to develop them }\end{array}$ & O & O & O & O & O & O & O \\
\hline $\begin{array}{l}\text { Plants and animals have as } \\
\text { much right as humans to } \\
\text { exist }\end{array}$ & O & O & O & O & O & O & O \\
\hline $\begin{array}{l}\text { The balance of nature is } \\
\text { strong enough to cope with } \\
\text { the impacts of modern } \\
\text { industrial nations }\end{array}$ & O & O & O & O & O & O & O \\
\hline $\begin{array}{l}\text { Despite our special abilities, } \\
\text { humans are still subject to } \\
\text { the laws of nature }\end{array}$ & O & O & O & O & O & O & O \\
\hline $\begin{array}{l}\text { The so-called "ecological } \\
\text { crisis" facing humankind has } \\
\text { been greatly exaggerated }\end{array}$ & O & O & O & O & O & O & O \\
\hline $\begin{array}{l}\text { The earth is like a spaceship } \\
\text { with very limited room and } \\
\text { resources }\end{array}$ & O & O & O & O & O & O & O \\
\hline $\begin{array}{l}\text { Humans were meant to rule } \\
\text { over the rest of nature }\end{array}$ & O & O & O & O & O & O & O \\
\hline $\begin{array}{l}\text { The balance of nature is very } \\
\text { delicate and easily upset }\end{array}$ & O & O & O & O & O & O & O \\
\hline $\begin{array}{l}\text { Humans will eventually learn } \\
\text { enough about how nature } \\
\text { works to be able to control it }\end{array}$ & O & O & O & O & O & O & O \\
\hline $\begin{array}{l}\text { If things continue on their } \\
\text { present course, we will soon } \\
\text { experience a major } \\
\text { environmental catastrophe }\end{array}$ & O & O & O & O & O & O & O \\
\hline
\end{tabular}


13) Please indicate to what extent you agree or disagree, with the following statements on environmental problems and car use

\begin{tabular}{|c|c|c|c|c|c|c|c|}
\hline & $\begin{array}{l}\text { Strongly } \\
\text { Disagree }\end{array}$ & Disagree & $\begin{array}{l}\text { Somewhat } \\
\text { Disagree }\end{array}$ & $\begin{array}{l}\text { Neither } \\
\text { Agree nor } \\
\text { Disagree }\end{array}$ & $\begin{array}{l}\text { Somewhat } \\
\text { Agree }\end{array}$ & Agree & $\begin{array}{l}\text { Strongly } \\
\text { Agree }\end{array}$ \\
\hline $\begin{array}{l}\text { Increasing car } \\
\text { traffic is not a big } \\
\text { problem for the } \\
\text { protection of the } \\
\text { environment }\end{array}$ & $\mathrm{O}$ & $\mathrm{O}$ & O & $\mathrm{O}$ & $\mathrm{O}$ & $\mathrm{O}$ & $\mathrm{O}$ \\
\hline $\begin{array}{l}\text { There is an } \\
\text { urgent need to } \\
\text { do something } \\
\text { about the } \\
\text { environmental } \\
\text { pollution caused } \\
\text { by car use }\end{array}$ & O & $O$ & O & O & O & $\mathrm{O}$ & $\mathrm{O}$ \\
\hline $\begin{array}{l}\text { I feel obligated to } \\
\text { use public } \\
\text { transport for } \\
\text { environmental } \\
\text { reasons }\end{array}$ & O & O & O & O & O & O & O \\
\hline $\begin{array}{l}\text { When I drive, } \\
\text { exhaust gases are } \\
\text { emitted which } \\
\text { have a negative } \\
\text { effect on the } \\
\text { global climate } \\
\text { system }\end{array}$ & $\mathrm{O}$ & $\mathrm{O}$ & $\mathrm{O}$ & $\mathrm{O}$ & $\mathrm{O}$ & $\mathrm{O}$ & $\mathrm{O}$ \\
\hline $\begin{array}{l}\text { Car use is one of } \\
\text { the main global } \\
\text { environmental } \\
\text { problems }\end{array}$ & $\mathrm{O}$ & $\mathrm{O}$ & $\mathrm{O}$ & $\mathrm{O}$ & O & O & O \\
\hline $\begin{array}{l}\text { When I drive, } \\
\text { exhaust gases are } \\
\text { emitted which } \\
\text { may endanger } \\
\text { other people's } \\
\text { health }\end{array}$ & 0 & O & O & O & O & 0 & 0 \\
\hline
\end{tabular}




\section{Section 6: Your Background Information}

To finish the survey we would like to get some background information about you, to get an idea of who is answering the survey. Feel free to skip any question you prefer not to answer.
14) What is your gender?
O Male
O Female

15) What is your age group?
O $18-24$
O 25-34
O $35-44$
O $45-54$
O $55-64$
O $65+$

16) What suburb do you live in?
17) What is your ethnicity?
O Māori
O Pacific Peoples
O Asian
O Middle Eastern/ Latin American/ African
O European
O Other

18) What is your current employment status?

Employed full-time

O Employed part-time

O Self-employed

O School student

O University / Polytechnic student

O Unemployed

O Retired

19) What is your income?

$0 \$ 0-\$ 20,000$

O $\$ 20,001-\$ 50,000$

O $\$ 50,001-\$ 70,000$

O $\$ 70,001-\$ 100,000$ 
O $\$ 100,000+$

20) Please write down any additional comments about parking in Wellington, that you feel were not covered in the survey:

Thank you for your time and input to this survey. If you would like a summary of report findings please tick the box below and enter contact details.

I I would like to receive a copy of the summary of the research report. Please enter your preferred contact details below 
Appendix A5. Comments from survey

\begin{tabular}{|c|c|}
\hline Topic & Number of comments about sub-topics \\
\hline $\begin{array}{l}\text { Reasons } \\
\text { for using } \\
\text { cars }\end{array}$ & 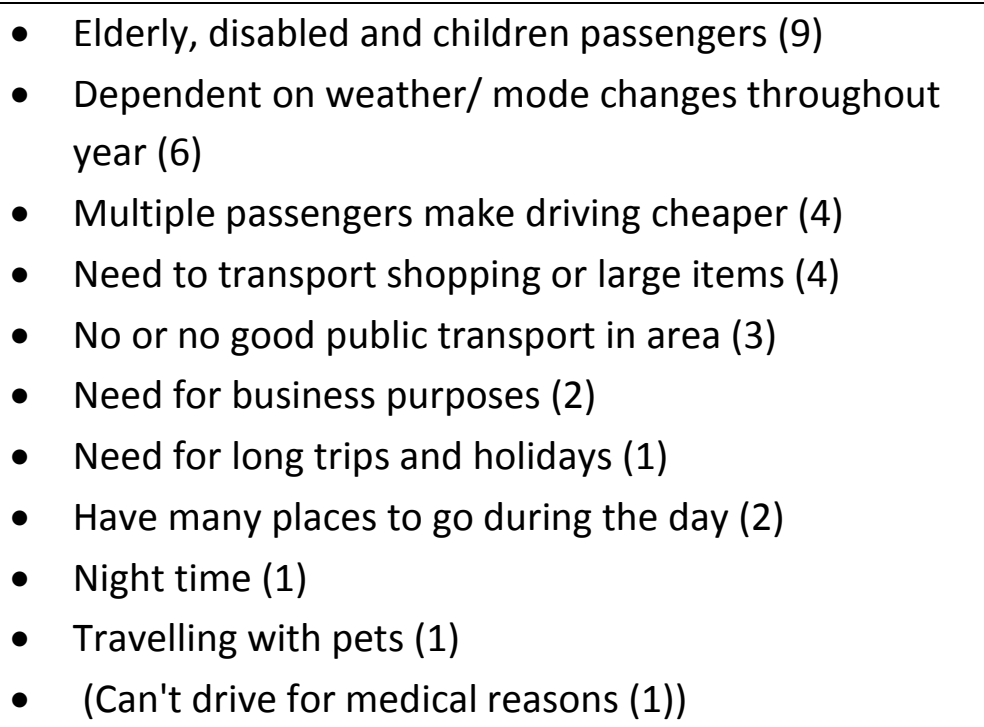 \\
\hline $\begin{array}{l}\text { Public } \\
\text { transport }\end{array}$ & $\begin{array}{l}\text { - } \text { Cost issues (18) } \\
\text { - } \text { Need to be more frequent and reliable (15) } \\
\text { - Time and convenience issues (12) } \\
\text { - More focus on PT needed (12) } \\
\text { - } \text { Route issues (5) } \\
\text { - } \text { More focus on trains (2) } \\
\text { - Good at present with many positives (2) } \\
\text { - Subsidize hybrid taxis as public transportation (1) }\end{array}$ \\
\hline $\begin{array}{l}\text { Active } \\
\text { transport }\end{array}$ & $\begin{array}{l}\text { - } \text { More cycleways and walkways (27) } \\
\text { - Need more focus on AT (10) } \\
\text { - } \text { Need more bike and scooter parking (6) } \\
\text { - } \text { Many benefits that need to be highlighted (2) } \\
\text { - } \quad \text { Subsidise AT as much as PT (2) } \\
\text { - } \text { Bike tunnel needed (Mt Victoria) (1) } \\
\text { - } \text { Age concern (1) } \\
\text { - } \quad \text { Bike share programme needed (1) } \\
\text { - } \quad \text { Easy access around the CBD (1) } \\
\text { - } \quad \text { No priority should be given to cycling (re rates) (1) }\end{array}$ \\
\hline Cars & $\begin{array}{l}\text { - Large number of cars per household (4) } \\
\text { - Issues of large SUVS/ give small car or electric vehicle } \\
\text { priority (3) } \\
\text { - Use more scooters or motorcycles (3) } \\
\text { - Increase fuel costs (3) } \\
\text { - Car sharing (1) } \\
\text { - } \\
\text { Need 'Google' cars/ self-driving taxis (1) }\end{array}$ \\
\hline
\end{tabular}




\begin{tabular}{|c|c|}
\hline & $\begin{array}{l}\text { - } \text { Easiest to use in Wellington (1) } \\
\text { - } \quad \text { Driving to work the problem (1) }\end{array}$ \\
\hline Roading & $\begin{array}{l}\text { - No cars in CBD or need certain number of passengers } \\
\text { - } \text { or certain times ( } 8 \text { ) } \\
\text { - } \text { More roads and bypasses needed (1) } \\
\text { - } \text { Loading zones are an issue (1) } \\
\text { - } \text { Bus stops are an issue (1) } \\
\text { - Stop building roads and overpasses (1) } \\
\text { - Some wide one-way streets becoming parking (1) } \\
\text { - } \text { Decrease footpaths and remove median strips (1) } \\
\text { - Use space for storm water treatment (1) }\end{array}$ \\
\hline Parking & 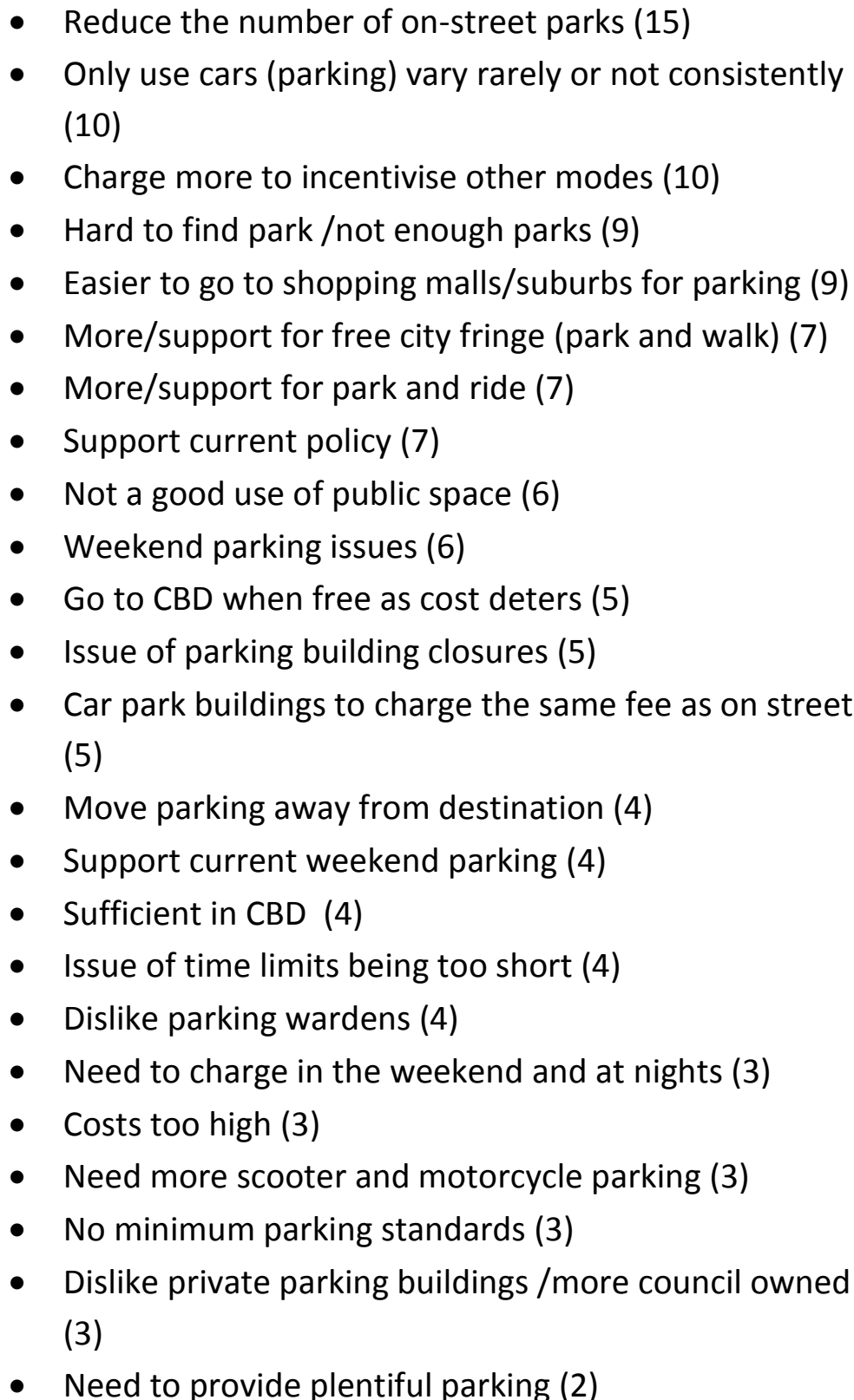 \\
\hline
\end{tabular}




\begin{tabular}{|c|c|}
\hline & $\begin{array}{l}\text { - } \text { More short-term (2) } \\
\text { - More resident parks/right to park outside house (2) } \\
\text { - } \text { Levy private parks / retailers fund parking (2) } \\
\text { - } \text { Early-bird parking options (2) } \\
\text { - } \text { Need to be priced at market price to reflect vacancy } \\
\text { - } \text { rate (2) } \\
\text { - } \text { Poorly run (1) } \\
\text { - } \text { Only park in shop car parks (1) } \\
\text { - More in suburbs to support elderly and young children } \\
\text { - } \text { (1) } \\
\text { - Ungle parking issue for wheelchairs (1) } \\
\text { - } \text { Fines (1) } \\
\text { - Fees need to be in line with other cities (1) }\end{array}$ \\
\hline Other & 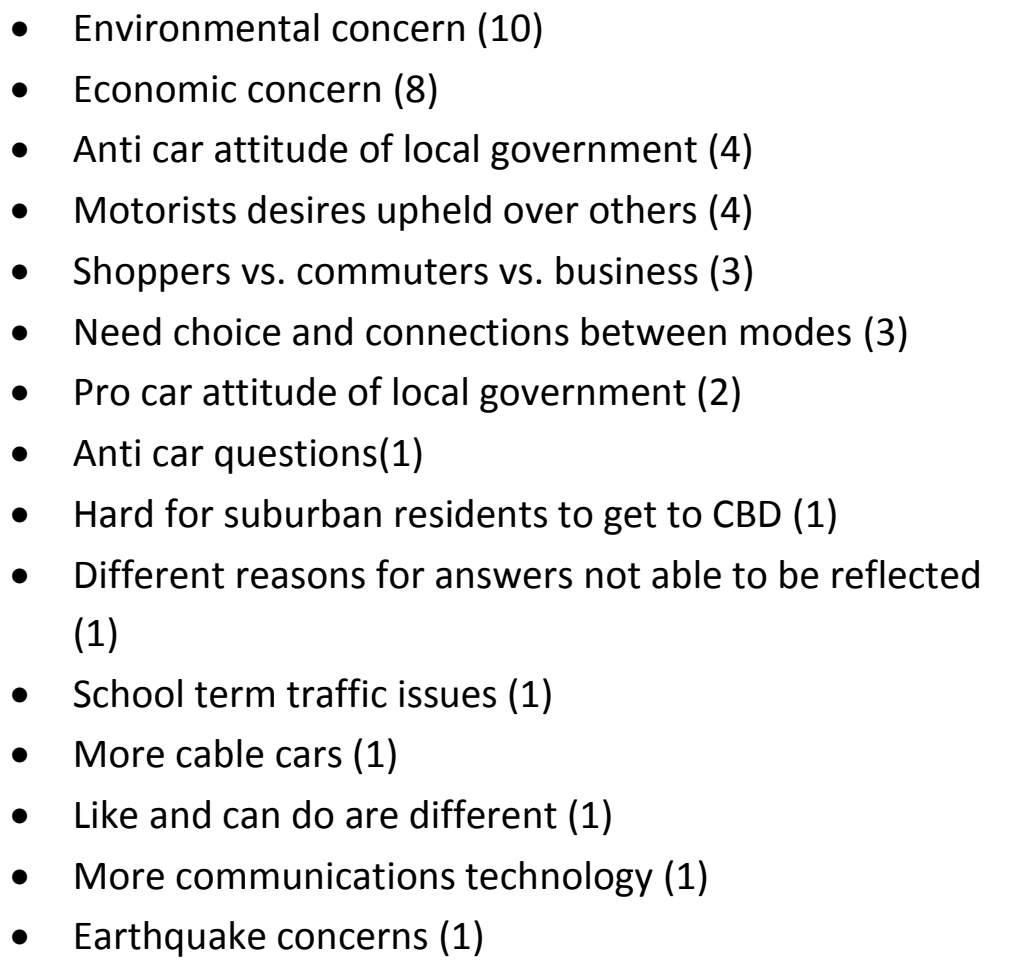 \\
\hline
\end{tabular}

